San Jose State University

SJSU ScholarWorks

Master's Theses

Master's Theses and Graduate Research

1989

\title{
Comparison of micropacks to thermocouples in heat penetration applications in thermally processed canned foods
}

Kristina Johnson-Hollinger

San Jose State University

Follow this and additional works at: https://scholarworks.sjsu.edu/etd_theses

\section{Recommended Citation}

Johnson-Hollinger, Kristina, "Comparison of micropacks to thermocouples in heat penetration applications in thermally processed canned foods" (1989). Master's Theses. 3078.

DOI: https://doi.org/10.31979/etd.zp8d-5bp3

https://scholarworks.sjsu.edu/etd_theses/3078

This Thesis is brought to you for free and open access by the Master's Theses and Graduate Research at SJSU ScholarWorks. It has been accepted for inclusion in Master's Theses by an authorized administrator of SJSU ScholarWorks. For more information, please contact scholarworks@sjsu.edu. 


\section{INFORMATION TO USERS}

The most advanced technology has been used to photograph and reproduce this manuscript from the microfilm master. UMI films the text directly from the original or copy submitted. Thus, some thesis and dissertation copies are in typewriter face, while others may be from any type of computer printer.

The quality of this reproduction is depencient upon the quality of the copy submitted. Broken or indistinct print, colored or poor quality illustrations and photographs, print bleedthrough, substandard margins, and improper alignment can adversely affect reproduction.

In the unlikely event that the author did not send UMI a complete manuscript and there are missing pages, these will be noted. Also, if unauthorized copyright material had to be removed, a note will indicate the deletion.

Oversize materials (e.g., maps, drawings, charts) are reproduced by sectioning the original, beginning at the upper left-hand corner and continuing from left to right in equal sections with small overlaps. Each original is also photographed in one exposure and is included in reduced form at the back of the book. These are also available as one exposure on a standard $35 \mathrm{~mm}$ slide or as a $17^{\prime \prime} \times 23^{\prime \prime}$ black and white photographic print for an additional charge.

Photographs included in the original manuscript have been reproduced xerographically in this copy. Higher quality $6^{\prime \prime} \times 9^{\prime \prime}$ black and white photographic prints are available for any photographs or illustrations appearing in this copy for an additional charge. Contact UMI directly to order.

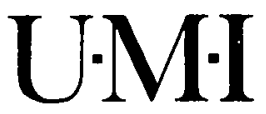

University Microfilms International

A Bell \& Howell Information Company 

Order Number 1337812

Comparison of Micropacks to thermocouples in heat penetration applications in thermally-processed canned foods

Johnson-Hollinger, Kristina, M.S.

San Jose State University, 1989

Copyright (C)1990 by Johnson-Hollinger, Kristina. All rights reserved. 


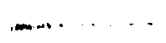




\title{
COMPARISON OF MICROPACKS TO THERMOCOUPLES \\ IN HEAT PENETRATION APPLICATIONS IN \\ THERMALLY PROCESSED CANNED FOODS
}

\author{
A Thesis \\ Presented to \\ The Faculty of the Department of \\ Nutrition and Food Science \\ San Jose State University \\ In Partial Fulfillment \\ of the Requirements for the Degree \\ Master of Science
}

By

Kristina Johnson-Hollinger

May, 1989 


\section{APPROVED FOR THE DEPARTMENT OF}

\section{NUTRITION AND FOOD SCIENCE}

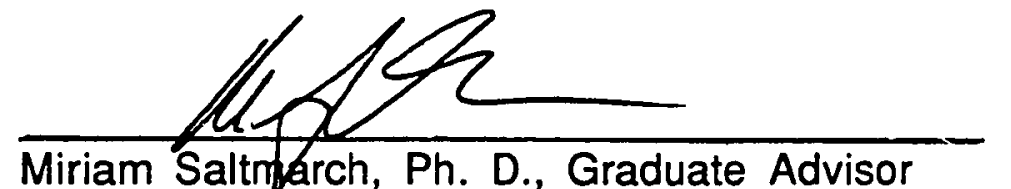
Miriam Saltmarch, Ph. D., Graduate Advisor Department of Nutrition and Food Science

Teffy Heyliger, Sr. Research Engineer

FMC Corporation

$$
\text { A. TW.Cccoms PoD. }
$$

Dr. H. W. Adams, Vice President

Pharmaceutical \& Food Specialists

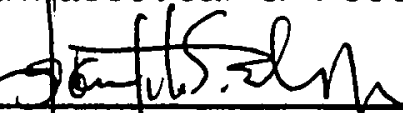

Dr. Pan Belo, Ph. D. Associate Professor

Department of Nutrition and Food Science

APPROVED FOR THE UNIVERSITY

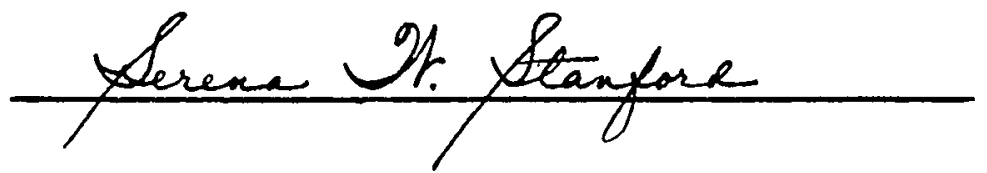




\section{Acknowledgements}

Funding for this study was provided by FMC, Santa Clara, CA. The author gratefully acknowledges Dr. Miriam Saltmarch, Terry Heyliger, Dr. H. W. Adams, and Dr. Pan Belo for their contributions of time and overall assistance. The author acknowledges Dr. Ray Elizondo and Dr. James Wang for providing statistical and organizational assistance in the evaluation of the data. The author thanks Bruce Hollinger for his patience and understanding throughout the research and especially the writing of this thesis. 


\section{Table of Contents}

\section{CHAPTER}

1 Introduction......................................................................................................................1

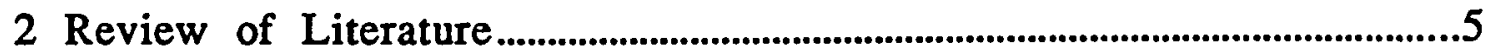

Methods to Evaluate Thermal Processing.................................................5

Plotting Heat Penetration Data ..................................................................8

Convective and Conductive Properties of Canned Foods..............13

Stationary Retort Conditions.............................................................................15

Axial Rotational Conditions .......................................................................16

Heat Penetration Measurement Devices................................................1 7

Thermometer .......................................................................................1 17

Thermocouples............................................................................................18

BESD Datatrace TempTM Temperature Environment

Measurement System.......................................................................19

Studies Evaluating Micropacks....................................................20

3 Materials and Methods .......................................................................................25

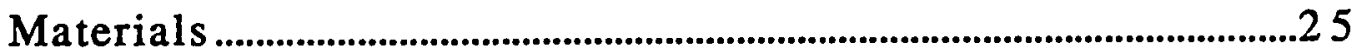

Method s..........................................................................................................................2

Analysis of Data ............................................................................................3

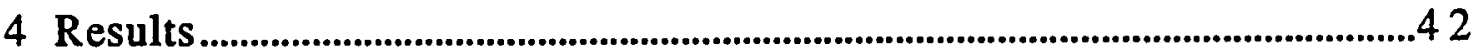

Viscon Stationary ..................................................................................................4 4

Viscon Separate Can Data....................................................................4 2

Viscon Paired Can Data ...........................................................................4 7

Viscon Comparison of Paired and Separate Can

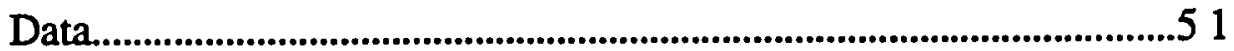


CHAPTER

PAGE

Viscon Axial Rotational...........................................................................5

Viscon Separate Can Data..............................................................57

Viscon Paired Can Data ......................................................................5

Viscon Comparison of Paired and Separate Data..................65

Whole Kernel Corn ................................................................................................68

Whole Kernel Corn (300 X 407) ...................................................68

Whole Kernel Corn (401 X 411) ......................................................72

Whole Kernel Corn (603 X 700) ...................................................76

Evaporated Milk.................................................................................................79

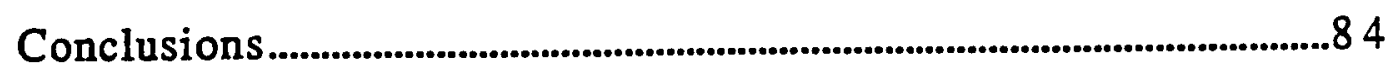

Implications for Further Research............................................................85

5 References

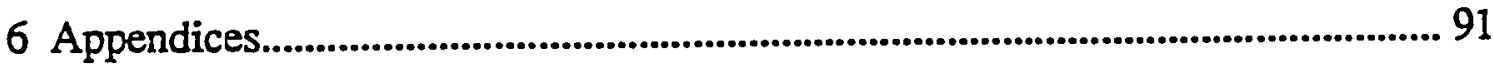

Appendix A: Example Computer Plot of Data..................................91

Appendix B: Viscon Original Data for Stationary.............................97

Appendix C: Viscon Original Data for Axial Rotational...............103

Appendix D: Whole Kemel Com (300 X 407).................................109

Appendix E: Whole Kemel Corn (401 X 411)................................115

Appendix F: Whole Kernel Com (603 X 700)................................120

Appendix G: Evaporated Milk..................................................................124 


\section{List of Tables}

\section{TABLES}

1. Mean Heating Parameter Values for Viscon

Under Stationary Conditions with Micropacks

and Thermocouples in Separate Cans

2. Mean Heating Parameter Values for Viscon

Under Stationary Conditions with Micropacks and

Thermocouples in Separate Cans.

3. Mean Lethality Values and Overall Process

Times of Viscon Under Stationary Conditions

with Micropacks and Thermocouples in

Separate Cans.

4. Slowest $\mathrm{Bb}$ of Micropacks and Thermocouples

for Viscon Stationary Conditions/Separate Cans.

5. Mean Heating Parameter Values for Viscon

Under Stationary Conditions with Micropacks

and Thermocouples in the Same Cans

6. Mean Heating Parameter Values for Viscon

Under Stationary Conditions with Micropacks

and Thermocouples in the Same Cans.

7. Mean Lethality Values and Overall Process

Times of Viscon Under Stationary Conditions

with Micropacks and Thermocouples in

the Same Cans.

8. Slowest $\mathrm{Bb}$ of Micropacks and Thermocouples

for Viscon Stationary Conditions/Paired Together 
TABLES

PAGE

9. Range and Standard Deviations of Heating

Parameter Values for Viscon Under

Stationary Conditions with Micropacks and

Thermocouples in Separate Cans and Paired

Together in the Same Cans.

10. Range and Standard Deviations of Heating

Parameter Values for Viscon Under

Stationary Conditions with Micropacks and

Thermocouples in Separate Cans and Paired

Together in the Same Cans

11. Range and Standard Deviation of Heating Parameter

Values for Viscon Under Stationary Conditions with

Micropacks and Thermocouples in Separate Cans and

Paired Together in the Same Cans.

12. Mean Heating Parameter Values for Viscon Under

Axial Rotational Conditions with Micropacks and

Thermocouples in Separate Cans

13. Mean Lethality Values and Overall Process Times

of Viscon Under Axial Rotational Conditions with

Micropacks and Thermocouples in Separate Cans.

14. Slowest $\mathrm{Bb}$ of Micropacks and Thermocouples for

Viscon Axial Rotational Conditions/Separate Cans.

15. Mean Heating Parameter Values for Viscon Under

Axial Rotational Conditions with Micropacks and

Thermocouples in the Same Cans. 
TABLE

PAGE

16. Mean Lethality Values and Overall Process Times of Viscon Under Axial Rotational Conditions with Micropacks and Thermocouples in the Same Can

17. Slowest $\mathrm{Bb}$ of Micropacks and Thermocouples for Viscon Axial Rotational Conditions/Paired Together.

18. Range and Standard Deviation of Heating Parameter Values for Viscon Under Axial Rotational Conditions with Micropacks and Thermocouples in Separate Cans and Paired Together in the Same Cans. .66

19. Range and Standard Deviation Mean Heating Parameter Values for Viscon Under Axial Rotational Conditions with Micropacks and Thermocouples in Separate Cans and Paired Together in the Same Cans.

20. Mean Heating Parameter Values for Whole Kernel Corn (300 X 407)

21. Mean Lethality Values and Overall Process Times for Whole Kernel Corn (300 X 407).

22. Slowest $\mathrm{Bb}$ of Micropacks and Thermocouples for Whole Kernel Corn (300 X 407)

23. Mean Heating Parameter Values for Whole Kernel Corn $(401 \mathrm{X} 411)$ 
24. Mean Lethality Values and Overall Process

Times for Whole Kernel Corn (401 X 411)............................................74

25. Slowest $\mathrm{Bb}$ of Micropacks and Thermocouples

for Whole Kernel Corn (401 X 411)................................................................75

26. Mean Heating Parameter Values for Whole

Kernel Corn (603 X 700).....................................................................................77

27. Mean Lethality Values and Overall Process

Times for Whole Kernel Corn (603 X 700)..............................................78

28. Slowest $\mathrm{Bb}$ of Micropacks and Thermocouples

for Whole Kernel Corn (603 X 700).........................................................80

29. Mean Heating Parameter Values for

Evaporated Milk

30. Mean Lethality Values and Overall Process

Times for Evaporated Milk

31. Slowest $\mathrm{Bb}$ of Micropacks and Thermocouples for Evaporated Milk. 
1. Typical Heating Curve............................................................................................9

2. Broken Heating Curve........................................................................................10

3. Cooling Curve...............................................................................................................11

4. Micropack and Thermocouple Position in Cans for Paired Can Runs.........................................................................................29

5. "Extender" Position in 603 X 700 Cans.......................................................36 


\section{ABSTRACT \\ COMPARISON OF MICROPACKS TO THERMOCOUPLES \\ IN HEAT PENETRATION APPLICATIONS \\ IN THERMALLY PROCESSED CANNED FOODS}

by Kristina Johnson-Hollinger

Heat penetration tests were conducted under axial rotational and stationary retort conditions to compare Micropack Tracers to Type-T thermocouples using viscon model system, whole kernel corn, and evaporated milk. Mean values and standard deviations were determined for heating parameters, accumulative lethality values, and process times. Micropack $\mathrm{jh}$ and fh values were larger for evaporated milk and viscon under axial rotational conditions. Micropack $x b h$ values were larger and $f 2$ values smaller for viscon under stationary conditions. No significant differences were found at the $\mathrm{p}<0.05$ level for whole kernel corn $(300 \times 407)$ can size. Micropack $\mathrm{jh}$ and Fo values were larger and $\mathrm{Bb}$ values smaller in whole kernel corn $(401 \times 411)$ can size while just the opposite was found in whole kernel corn $(603 \times 700)$ can size. Neither Micropacks nor thermocouples consistently reported longer $\mathrm{Bb}$ except in whole kernel corn (603 X 700) can size where Micropacks Bb were larger. 


\section{Chapter 1}

\section{Introduction}

Food container materials and food processing systems have advanced and changed considerably over the past three and one-half decades. The techniques used to gather heat penetration data have changed to accommodate the different packaging materials being used for retorted food products. The apparatus used in recording heat-penetration data has moved from the single-point, portable potentiometer (Wheatstone bridge) to state-of-the-art electronic process monitors that can gather several data points per time interval, print the data, and interface with desktop computers. However, until now, the basic equipment used to acquire heatpenetration data has not advanced to the same degree (Cross \& Lesley, 1985).

The copper-constantan thermocouple (Ecklund Custom Thermocouples, Cape Coral, FL) has merely become more streamlined with the advent of stainless-steel-needle type and flexible-wire thermocouples. Thermocouple leads must be used and connections made to join the data recorder to the thermocouple inside the food container located within a retort (Ecklund, 1949). There is a need in the food and pharmaceutical industry for a small portable instrument capable of collecting time and temperature (heat penetration) data. Recently Ball Corporation Electronic Division 
Industrial Instruments (Westminster, CO), developed the Micropack tracer tm (Micropacks), a completely self-contained miniature computer/temperature sensor to fill this need.

Micropacks make it possible to acquire heat penetration data without the use of connectors and lead wires. The system consists of miniaturized microcomputer sensors and a PC Interface System used for connecting the Micropacks to personal computers. The Micropacks are hermetically sealed, self-contained instruments. They are designed to store up to 1,000 temperature readings, and can be programmed for start time, data collection interval, and run identification. They make it possible to run heat penetration tests in all types of sterilizers (at present heat penetration data can only be collected in non-continuous production retorts in plants) rather than simulating plant operations in pilot plants (Cross \& Lesley, 1985).

Work thus far has focused on Micropacks in the 300 X 407 can size under stationary rotational conditions. As yet only one study has compared Micropacks to thermocouples under axial retort conditions. That study compared the two instruments in a homogeneous product (Underferth, 1987). No one as yet has investigated the effect various food systems have on Micropacks under axial rotational conditions in different can sizes and compared the data to that acquired from thermocouples under the same conditions. The purpose of this study was to make those comparisons. 
Initially an easily controlled homogeneous model system was used because it lacked intrinsic variability that food systems might have. Viscon was the synthetic material used, rather than a Bentonite solution, because Bentonite tends to break down and lose viscosity from repeated use under axial rotational conditions while Viscon does not. Secondly food systems of varying rheological and heat transfer behaviors were studied. Specifically the objectives for this study were:

1. To obtain baseline data for Micropacks and thermocouples using Viscon.

A. Viscon has reproducible heating characteristics and is a viscous homogeneous synthetic model system similar in viscosity and heating parameters to that of cream style corn. Viscon remains stable and viscous when heated to $1210 \mathrm{C}\left(250^{\circ} \mathrm{F}\right)$ for at least ten consecutive times (Hardt, Adams, \& Henderson, 1980). Under stationary retort conditions both convective and conductive heating exists while under axial rotational conditions forced convective heating exists.

B. Micropacks and thermocouples were secured at opposite ends of the same cans and heat penetration tests were conducted in both the stationary and axial rotational mode.

C. The tests were repeated with the Micropacks and thermocouples in separate cans. 
2. To compare Micropacks and thermocouples in food systems with varied heat transfer behavior. Several food systems were selected to represent typical heat transfer behavior encountered in canned foods.

A. Whole Kernel Corn is representative of particulates in brine. The brine in the can is non-viscous and heats by convection while the Kernels in the can are medium sized particulates and heat by conduction. Under stationary conditions this product yields a broken heating curve; however, under axial rotational conditions forced convective heating exists.

B. Evaporated Milk is a homogeneous low viscosity food system which heats by natural convection under stationary conditions, as well as under axial rotational conditions.

3. To compare Micropacks to thermocouples under axial rotational retort conditions. Thus the three food systems selected were all run under axial rotational retert conditions.

4. To compare Micropacks to thermocouples in different can sizes. Comparative heat penetration tests were conducted using whole Kernel corn in $300 \times 407,401 \times 411$, and $603 \times 700$ can sizes. 


\section{Chapter 2}

Review of Literature

\section{Methods to Evaluate Thermal Processing}

The methods for evaluating heat penetration data have evolved and changed much over the past forty years. The first systematic approach to thermal process evaluation was that of Bigelow, Bohart, Richardson, and Ball (1920). Their method combined bacteriological data with heat penetration data and is usually referred to as the "General Method." The method was essentially a graphical one. From values obtained by thermocouple measurements, heating and cooling curves were constructed to represent temperatures existent during the thermal process. Each temperature represented by a point on the curve was considered to have a sterilizing or lethal rate value. The lethal rate value assigned to each temperature was numerically equal to the reciprocal number of minutes required to destroy some given percentage of spores at a particular temperature. The percentage of destruction was represented by thermal death time curves. These curves were obtained by plotting the time required to destroy a high percentage of microbiological spores in a given microbial population against temperature of heating. For example, if the thermal death time curve indicated that ten minutes were required at $115^{\circ} \mathrm{C}(2390 \mathrm{~F})$, 
the lethal rate value assigned to this temperature would be 2.45 at a $z$ value of $10^{\circ} \mathrm{C}(180 \mathrm{~F})($ Stumbo,1973).

Ball (1923) derived a mathematical or "Formula Method" for evaluating processes, which was an equation of the straight-line semilog heating curve. Ball (1928) followed up his original work with procedures for employing either the "Formula" or "General Method." This work included the construction of a hypothetical thermal death curve passing through 1 minute at $121^{\circ} \mathrm{C}\left(250^{\circ} \mathrm{F}\right)$. This permitted a direct comparison of relative sterilizing capabilities of different heat processes. For example, a process equivalent to 4 minutes at $1210 \mathrm{C}\left(250^{\circ} \mathrm{F}\right)$ was considered to have twice the sterilizing capacity as one equivalent to 2 minutes at $121^{\circ} \mathrm{C}\left(250^{\circ} \mathrm{F}\right)$. It was later shown (Stumbo, 1948, 1949, 1953) that was only the case for convection heating products (Stumbo, 1973). Ball (1928) also contributed an equation for calculating lethal rate. The "Nomographic Method" was developed by Olson and Stevens (1939) in an attempt to simplify Ball's "Formula Method." It is applicable to canned foods exhibiting straight-line semilogarithmic heating curves. Schultz and Olson (1938) improved the graphing method of the "General Method" by the use of special coordinate paper. This paper simplified calculations and reduced the chance of misplotting points, but required a different specially printed coordinate paper for each new thermal-death-time slope of $z$ value used in calculations. They also introduced formulae that apply to conduction and convection 
heating. These formulas were simple to use and therefore increased the applicability of the "General Method." Resende, Stumbo, and Francis (1969) further improved upon Schultz and Olson's work. Patashnik (1953) simplified the procedure for thermal process evaluation by taking container temperature readings at equal time intervals. These values corresponded to lethal ratio $(\mathrm{F} / \mathrm{t})$ values which were tabulated and totaled. The product of this sum and the equal-time-interval used gave the process value directly without plotting a curve. Stumbo (1949) developed the graphical integration method which made possible a determination of the number of bacteria or spores of known heat resistance which would survive in a given container of food during any designated thermal process. Hicks (1951) presented a procedure for evaluating thermal processes which was based on essentially the same principles regarding bacterial destruction and mechanism of heat transfer as was the procedure developed by Stumbo (1949). Gillespy (1951) also presented a procedure for evaluating processes for conductionheating foods, also based on the same principles. Stumbo (1953) developed convenient procedures for evaluating thermal processes for foods in cylindrical containers. The procedures integrated heat effects throughout the container and translated the sum into its equivalent, in minutes at $121^{\circ} \mathrm{C}\left(250^{\circ} \mathrm{F}\right)$, with respect to its capacity to reduce the number of viable bacteria in the container. 


\section{Plotting Heat Penetration Data}

Time-temperature data are plotted directly on lethal-rate paper to obtain a lethality curve, when using the improved general method. The area beneath the curve is proportional to the lethality of the process.

When mathematical methods are employed, the timetemperature data are most conveniently plotted on semilogarithmic paper. To obtain the heating curve, the difference between retort temperature and internal can temperature is plotted on the log scale against time on the linear scale. This is accomplished by turning the paper upside down (see figures 1 and 2) and labeling the top line one degree below retort temperature, then plotting temperatures directly. To obtain the cooling curve, the difference between internal can temperature and cooling-water temperature is plotted on the log scale against time on the linear scale. In this case the semilog paper is kept in its normal position (see figure 3), the bottom line is labeled one degree above cooling water temperature, and the temperatures are plotted directly. The following are definitions of process calculations from the National Canners Association Research Labs (1968):

RT The retort temperature in of.

CT The temperature of the can contents at the slowest heating point 
Figure 1

Typical Heating Curve

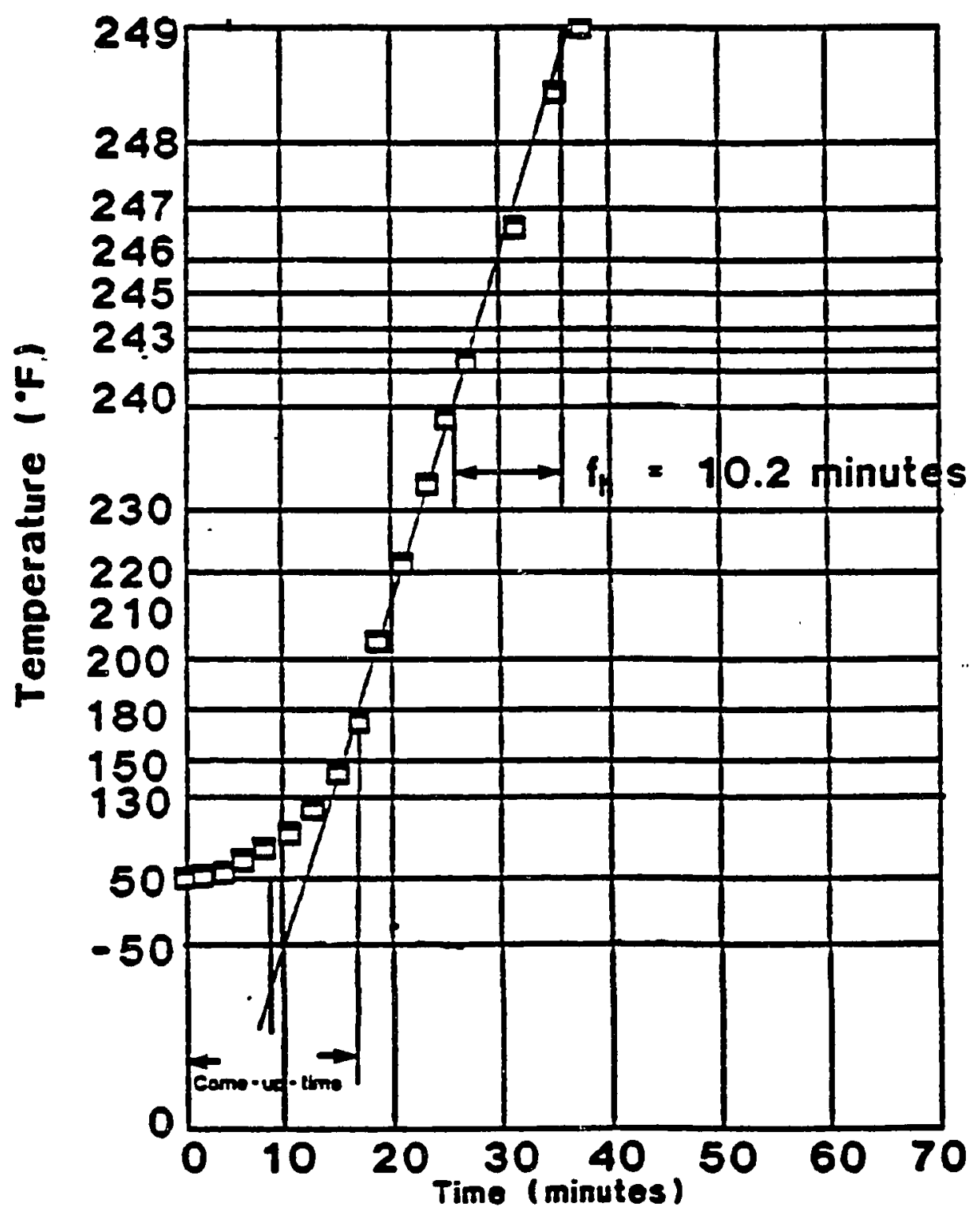


Figure 2

Broken Heating Curve

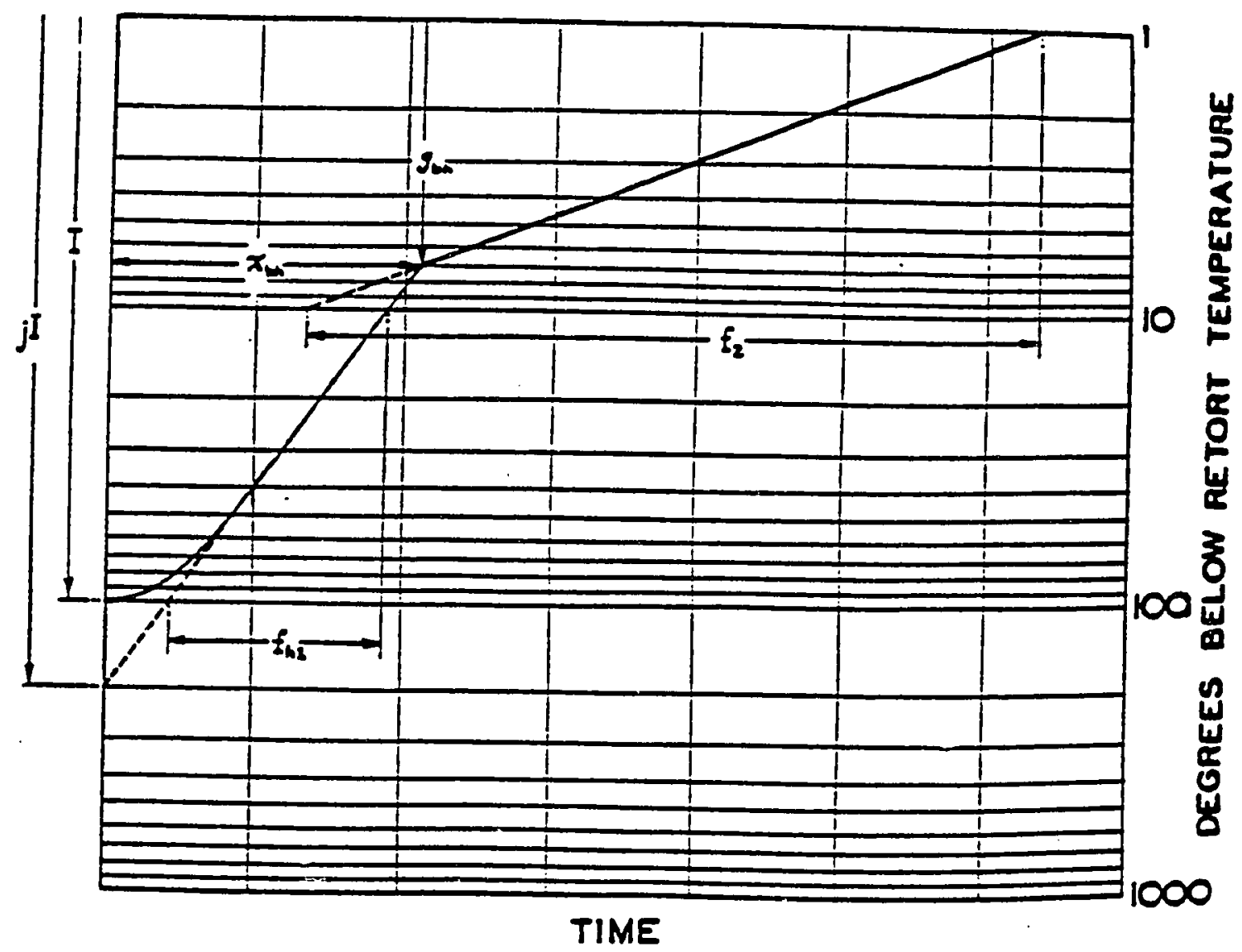


Figure 3

Cooling Curve

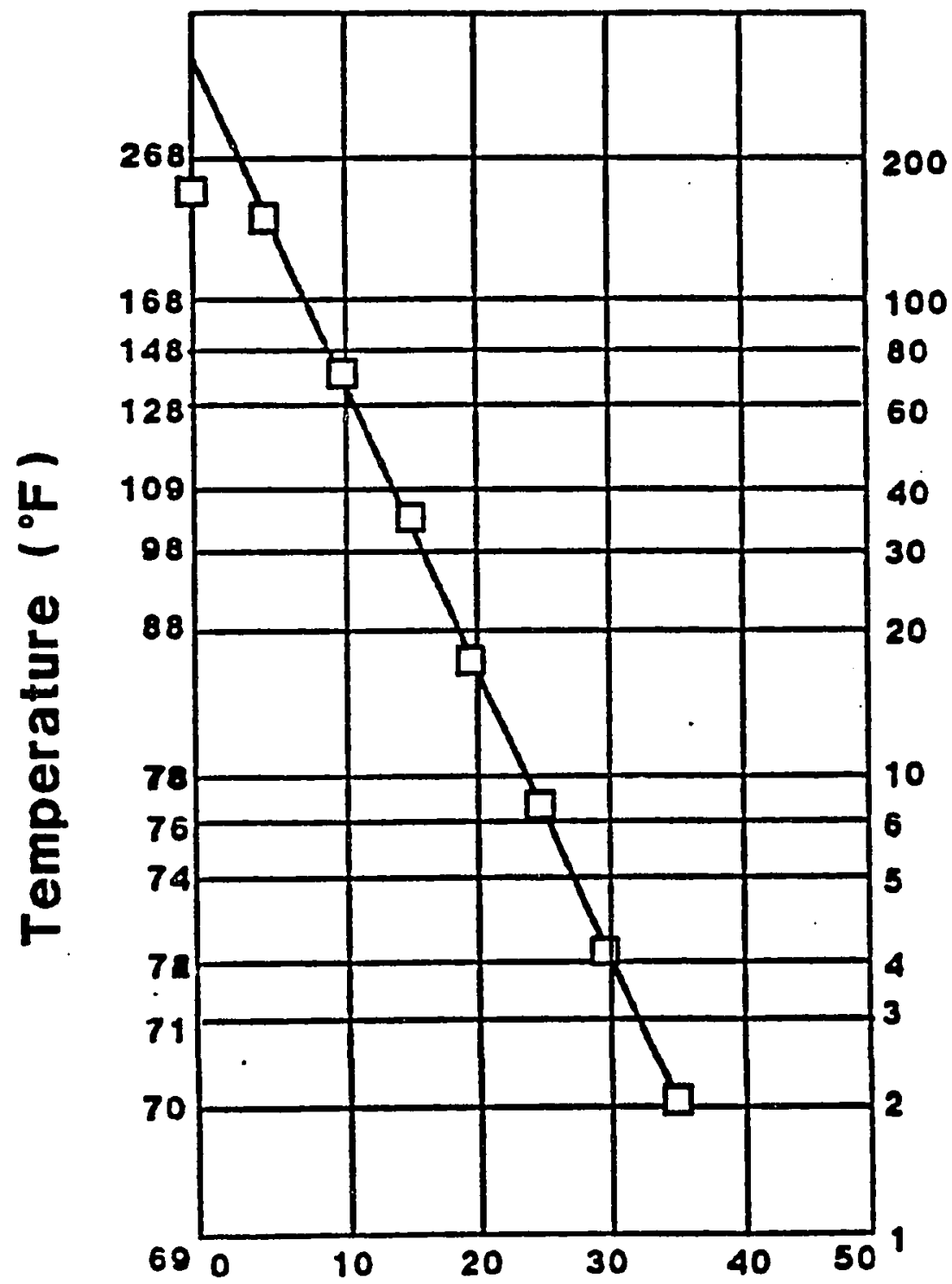


IT This is the temperature of the product at zero time of heating and cooling.

I The difference, RT-IT

jI The number of degrees below RT where the extended straight line of the heating curve crosses the corrected zero time of the process.

jh The ratio of $\mathrm{jI} / \mathrm{I}$. A number representing the time lag before RT-CT assumes straight line characteristics on semi-log paper with time.

fh The number of minutes required for the straight line portion of the heating curve to pass through one log cycle.

$\mathrm{xbh}$ The number of minutes from the start of the heating period to the break in the heating curve.

f 2 When the heating curve is expressed as a broken curve (two straight lines of different slope) this term represents the number of minutes required for the second heating curve to traverse one logarithmic cycle on the temperature scale. The form and position of a simple heating curve are determined by RT, IT, $j$ and fh. The additional terms $x b h$ and $\mathrm{f} 2$ are required to determine a broken heating curve.

jc Lag time before cooling curve assumes a straight line.

fc The number of minutes required for the straight line portion of the cooling curve to pass through one log cycle. 
Fo The number of minutes required to destroy a specified number of spores at $121^{\circ} \mathrm{C}\left(250^{\circ} \mathrm{F}\right)$ when $\mathrm{z}=10^{\circ} \mathrm{C}$ $\left(18^{\circ} \mathrm{F}\right)$. A z value of $10^{\circ} \mathrm{C}\left(18^{\circ} \mathrm{F}\right)$ is usually assumed for Clostriduim botulinum when thermal death time determinations have not been made on the product under consideration.

$z$ The negative reciprocal of the slope of the thermal death time curve or "phantom" thermal death time curve. The $z$ value represents the number of degrees $F$ required for the curve to traverse one logarithmic cycle, and measures the change in thermal death time or death rate with changing temperature.

$\mathrm{Bb}$ The process time in minutes.

Convective and Conductive Properties of Canned Foods

Convection is the transfer of heat by movements or currents within a volume of gas or liquid. It is caused by the expansion produced by heating a portion of the liquid or gas, thus making it rise and mix with the cooler portions. Relatively few papers have been published dealing specifically with convection heating in cans. Conduction is the transfer of heat between adjacent molecules. (Bigelow et al., 1920). Fagerson and Esselen (1950), McConnell (1952), and Fagerson, Esselen, and Licciardello (1951), presented results of studies of temperature distribution during heating. A paper by Okada (1940) combined the dimensional theory with 
hydrodynamics to correlate the physical factors influencing the heating rates. Another paper by Shultz and Olson (1938) developed a theory of convection on the temperature distribution in the can. In the heat processing of canned foods, heat transmission by convection occurs in foods that are composed either wholly or in part of liquid of low enough viscosity to permit it to respond to the force of gravity when non-uniform density is produced in it through heating. It can also occur in foods that contain voids of sufficient size to accommodate a flow of liquid or of vapor (Ball \& Olson, 1957). The ratio between convection and conduction heating also depends on the physical dimension of solid pieces in the container, the manner of filling the product, and the viscosity of the liquid portion of the product. A longer time is required for heat to be transmitted to the center of a large solid piece than for a small solid piece, because the heat transfer in the solids is by conduction. A product having large pieces requires a longer process than a product having small pieces of similar shape, even though the liquid in the interstices of the two products is the same and the rates of heating by convection currents in this liquid is essentially the same in the two products (Ball \& Olson, 1957).

During conduction heating, transfer of heat into the can takes place without actual transfer of heated material and during most or all of the sterilization process there is a difference in temperature between the center of the can and a point near the outside. The 
center temperature increases only as long as this difference exists, since heat flows only from a place of higher temperature to one of a lower temperature. On the other hand, when heating is by convection, the rise in temperature at the center of the can is due principally to the actual transfer of heated material from the hotter portions of the can. Most liquid foods such as tomato juice and thicker fruit juices heat by a combination of conduction and convection. If the food is of heavy consistency, conduction is the most important factor and large temperature differences are present within the can (Shultz \& Olson, 1938).

\section{Stationary Retort Conditions}

Many foods which heat by conduction exhibit simple heating curves; for example, cream-style corn, pumpkin, potted meats, thick soups, and tomato juices of heavy consistency. Other foods, such as dilute broths, thin fruit juices, brine-packed peas, syrup-packed fruits, and evaporated milk, heat mainly be convection currents but also exhibit simple heating curves. However, a third group of foods, including the thicker soups, brine-packed whole-grain corn, certain tomato juices and a number of specialty or formulated products can exhibit the so-called broken heating curve. These products heat for some time by convection, then, because of starch or some other thickening agent, they thicken and continue to heat by conduction. Generally these products cool by conduction alone. Less common are products that for some time heat by conduction, then for the 
remainder of the period heat by convection. These are generally products with both liquid and solid phases. The solid phase settles to the lower section of the container, however, after a time the convective forces become strong enough to disperse the pieces and start moving with the liquid phase causing convective heating. These products generally cool by convection (Stumbo, 1973). The intersection of the two heating curves is called the "break" (Jackson \& Olson, 1940). Considerably more information is needed regarding the factors which might affect broken heating curve.

\section{Axial Rotational Conditions}

Many products that heat by conduction in a still cook heat by forced convection during axial rotational cook. This is not true convection, but rather rapid heating due to mechanical agitation causing product movement. The semilogarithmic heating and cooling curves are generally straight lines with slope values comparable to those for curves exhibited by convection-heating products (Stumbo, 1973).

Axial and end-over-end are two general types of in-can agitation. An important factor in causing product movement is movement of the head-space "bubble" through the product as the cans turn over and over. The "bubble" is actually the head-space in the can. For this reason head-space control or specification for minimum headspace is vital to the success of the axial rotational cook process (Shultz \& Olson, 1938). 


\section{Heat Penetration Measurement Devices}

\section{Thermometer}

An early measurement device was the mercury thermometer which was placed in a metal frame that adapted to the screw top of a test can. This thermometer contained an obstruction in its interior wall to prevent the return of mercury to the well. Unfortunately the instrument had several disadvantages. It recorded only the maximum temperature attained, and had no means of indicating the time necessary to reach that or any other point on the scale. Also, the metal casing and the glass tube of the thermometer itself were objectionable because they conducted heat from the top of the can to the center. Therefore, the recorded increase in temperature was more rapid than what actually occurred, and was not a typical record of the heating of a can (Bigelow et al., 1920).

Bitting (1912) described a mercury thermometer which was sealed into an ordinary can by means of a stuffing box soldered to the top. The outside of the stuffing box was threaded in such a way that it screwed into an opening in the top of a retort, with the thermometer protection on the outside. This allowed the temperature of a product to be observed while the can heated by steam.

The recording thermometer was adapted for use in heat penetration studies in canned foods. A mercury bulb passed through a screw cap in a can and was connected to the recording instrument 
by means of a flexible tube. A niche was cut in the rubber gasket at the top of the retort to permit the insertion of the tube. This allowed the apparatus to be used in a canner's retort rather than in a research facility. However, the device did not record the temperature at the center of the can (Bigelow et al., 1920).

\section{Thermocouples}

At first thermocouples were made with lead wires attached so that thermocouples were inserted into the cans through stuffing boxes. Unfortunately closing the test cans with a closing machine was difficult because the lead wires attached to the cans impeded necessary can rotation for closure. Eventually connector type thermocouples were developed, which allowed the lead wire to disconnect from the thermocouple. This permitted joining several lead wires into cable and sealing the cable through the retort body with a packing gland. Closing was still difficult on a closing machine because the thermocouple projected from the test can.

The newest type of thermocouple is detached from the lead wire, and is also designed so that the thermocouple and the receptacle which holds the thermocouple in place do not project from the side of the can. This feature allows closure of the can on a closing machine (Ecklund, 1949). Thermocouples used in the food industry for heat penetration tests are of copper and constantan wires, and are referred to as T-type thermocouples. The wires are soldered at the hot junction end and attached to drilled copper and constantan 
inserts at the threaded end of the thermocouple. Thermocouples are made in various lengths to fit various can diameters or lengths (Ecklund, 1949). Thermocouples are available in molded plastic, stainless-steel needle, plastic tube and rod, and flexible. Although the style of the thermocouple is different, they provide almost identical results (Anonymous, 1978).

BESD Datatrace Temp ${ }^{\mathbb{M}}$ Temperature Environment Measurement

\section{System}

The Datatrace Temp ${ }^{\mathrm{TM}}$ System is comprised of miniaturized time and temperature recording devices, called Micropacks and the PC Interface System for programming and reading the Micropacks (Ball Corporation Electronic Systems Division Industrial Instruments, 1987). Micropacks are wireless, non-transmitting temperature sensing devices that allow unrestricted temperature monitoring of food products and retort processes in a wide variety of systems (Lesley, 1987). Micropacks consist of a stainless steel shell with a sensor at one end and recorder at the other end. The sensor is a thermister which gives the Micropack high sensitivity and low thermal mass at the sensing element. The recording end is larger and contains a lithium battery as the power supply, microprocessor for sensor readings, and a low power clock which restarts the microprocessor. The power supply also contains a small amount of air which can act as an insulator (Cross \& Lesley, 1985). The recording end of the Micropack tracer measures $29 \mathrm{~mm}$ by $35 \mathrm{~mm}$ 
(11 $7 / 16$ in by $141 / 2$ in) and is designed to record and store up to 1,000 temperatures. It is a hermetically sealed, self-contained instrument, programmable for start time, sample interval, run identification, and security passwords. It operates from $10-150^{\circ} \mathrm{C}\left(50-302^{\circ} \mathrm{F}\right)$ and is completely submersible in a conductive fluid (Cross \& Lesley, 1985). The Micropacks are programmed within the PC Interface System, which has userfriendly, step-by-step, menu-driven instructions (Cross \& Lesley, 1985).

Micropacks can be either internally or externally mounted. An Internal Retainer Assembly is used to mount the Micropacks to the inside of containers. First a gasket is placed over a threaded stud. Next the threaded stud is slipped through a hole which has been punched in the bottom or lid of a container. Then the two tracer spring mounts are placed on the inside of the can or lid over the threaded stud at $90^{\circ}$ angles from each other. Finally a hex nut from an Ecklund No. C-5 thermocouple receptacle is tightened over the spring mounts until the assembly is secure (Ball Corporation Electronic Systems Division Industrial Instruments, 1987). Studies Evaluating Micropacks

Lesley (1986) studied the effects various viscosities had on data acquired from Micropacks paired together in the same cans and in separate cans with thermocouples. Bentonite solutions of $1 \%$, $31 / 4 \%$, and $5 \%(w t: w t)$ in deionized water were used to simulate 
convection, broken, and conduction heating curve food products, respectively. The results of tests on convection (1\%) and broken curve $(31 / 4 \%)$ bentonite solutions show the largest difference in heat penetration parameters generated from Micropack and thermocouple acquired data. Lesley (1986) attributed the differences to three conditions caused by the tracer placed inside the container: (1) displacement of fill volume; (2) a difference in the heating characteristics of the Micropack material compared to the faster heating solutions; and (3) disturbance by the Micropack of natural thermal currents found in the less viscous solutions. Lesley's (1986) results for the $1 \%$ and $31 / 4 \%$ bentonite solutions showed slower fh values and longer $\mathrm{Bb}$ values for Micropacks in both paired and separate can data. The heat penetration parameters generated from test data from the conduction $5 \%$ bentonite solution showed good agreement between the Micropack and thermocouple acquisition methods. Heat penetration parameters were similar for data from both external and internal tracer placement in the conduction solution. Lesley (1986) concluded the more viscous five percent bentonite solution heats much like the tracer material and therefore was not effected as much as the other two test solutions.

In another study conducted by Lesley (1987a), single strength chicken broth, reprocessed whole Kernel corn in brine, and reprocessed pumpkin were used to compare Micropacks to thermocouples in $300 \times 407$ can size under stationary retort 
conditions. The Ball Method was used to calculate the accumulated lethality and minimum process time from heat penetration data. The test time was considered as the time it took the sensing devices to reach within $0.90 \mathrm{C}(10 \mathrm{~F})$ of retort temperature and was used to calculate accumulated lethality. Cans were either secured with Micropacks and thermocouples together in the same cans, or separately in cans. Micropacks were either internally or externally mounted. All junctures were located at the geometric center of the cans. Larger $\mathrm{fh}, \mathrm{f} 2$, test time, and accumulated Fo values were calculated for the Micropack data in the three products tested; however, when set to constant Fo values, initial temperature, and retort temperature, the Micropack data resulted in minimum process time $(\mathrm{Bb})$ similar to those from thermocouple data.

Lesley (1987) further compared Micropacks to thermocouples using single strength chicken broth, single strength tomato soup, whole Kernel corn in brine, cut green beans in brine, pumpkin, and pork and beans in $300 \times 407$ cans under stationary retort conditions. The Micropacks were either internally or externally mounted, and the two instruments measured either the cold-spot of the can or the geometric center. The time required for the respective monitoring device to reach within $0.90 \mathrm{C}(10 \mathrm{~F}$ )of retort temperature (test time) was used in the calculation of Fo. Minimum process time ( $\mathrm{Bb}$ ) was determined using the calculated heat penetration parameters holding the initial temperature, retort temperature, and respective product 
lethality value constant, as calculated by the Ball Method. Micropack data from both the internal and external placement resulted in heat penetration values (fh, $f 2$, test time, Fo) that were larger than comparable thermocouple data values for the products tested. Calculated process times (Bb) from Micropack and thermocouple heat penetration values were similar except for internal mounted tracers in tomato soup and with green beans in brine. In both cases the process time was shorter.

NFPA (National Food Processors Association) has begun collecting data for process establishment for continuous-rotary cookers (Underferth, 1987). The food product studied was a homogeneous liquid without discrete particles. The studies were conducted in an FMC Steritort located at NFPA-Dublin California Research Lab. The following variables were studied:

1. Micropack mounted externally

2. Micropack mounted internally

3. Conditions 1 and 2 paired with a thermocouple

4. Thermocouple-only data.

All heat penetration tests were conducted on $300 \times 407$ containers filled with a product made to a standardized solids level that exhibited a j-value of approximately 1.7 and an $f_{h}$ value of 44.0 minutes when heated statically and when measured with thermocouples. Headspace in all containers was adjusted to $1.96 \mathrm{~mm}$ $(8 / 32$ in). All heat penetration tests were run in the Steritort with a 
reel speed equivalent to a typical production rate of 300 cans per minute $(6.38 \mathrm{rpm})$. Results showed the $\mathrm{j}$-values for Micropack runs were always greater than for thermocouple runs, indicating perhaps that there would be no need for a $j$-correction factor such as is currently applied to thermocouple data. There was no difference between Micropacks, both externally and internally mounted, and thermocouples in overall lethality and process times. 


\section{Chapter 3 \\ Materials and Methods}

\section{Materials}

1. Type-T stainless steel needle thermocouples $6.25 \mathrm{~mm}$ (2 $5 / 32 \mathrm{in}$ ) in length were used for tests conducted in $300 \times 407$ and $401 \times$ 411 can sizes, and $9.36 \mathrm{~mm}$ ( $39 / 16$ in) long thermocouples were used for tests conducted in $603 \times 700$ can size.

2. Micropacks, $5.52 \mathrm{~mm}$ ( $23 / 16 \mathrm{in}$ ) length, were obtained from Ball Corporation. Since no other length of Micropacks was available at the time this research was conducted, the same eight Micropacks were used for all three can sizes (see section: Whole Kernel Corn (603 X 700) for details as to how the Micropacks were extended so that their junctures measured the geometric center of the cans). Micropacks with serial numbers MTS02839, MTS02842, MTSO1783, MTS01737, MTS02786, MTS01851, MTS01741, and MTS02826 were used.

3. Viscon is a synthetic product consisting of $.03 \% \mathrm{NaCl}$ (Morton salt), 5\% Avicel RC 591, and 2\% Viscarin GP 209 (Hardt et al., 1980). The small amount of $\mathrm{NaCl}$ was used to stabilize the viscon mixture. Avicel RC 591 is a co-dried blend of $89 \%$ microcrystalline cellulose and $11 \%$ sodium carboxymethylcellulose (CMC). Avicel RC 591 is produced by FMC, Inc. (Anonymous, 1972). Viscarin GP 209 is made from kappa carrageenan and is produced by Marine Colloids/FMC, Inc. (Anonymous, 1977). 


\section{Whole Kernel Corn}

Golden jubilee sweet corn harvested between July and September of 1987 from Oregon and Washington was shipped to a plant in Watsonville, CA where it was bulk cut and boxed in twenty pound boxes and held in frozen storage at $-17.7^{\circ} \mathrm{C}\left(0^{\circ} \mathrm{F}\right)$. Eventually this corn was shipped to various wholesalers in California. FMC (Santa Clara, CA) purchased thirty boxes of Lot No. N1307A1 from ISIS Food Co. (Santa Clara, CA) in March of 1988. It was stored at $-17.7^{\circ} \mathrm{C}\left(0^{\circ} \mathrm{F}\right)$ in a freezer at FMC until used in March and April of 1988.

5. Evaporated Milk Thirty cans of Carnation brand evaporated milk were purchased from a supermarket in May of 1988 and stored at room temperature in the Food Laboratory at FMC in Santa Clara.

6. FMC Steritort

The FMC Steritort is used in pilot plants to simulate the FMC Rotary Pressure Sterilizer and Still Batch Retort. The unit consists of a shallow pressure shell capable of holding one ring of cans, with a motor and drive chain to rotate the reel holding the cans or jars, steam and air fittings, and instruments to monitor internal temperature and pressure. The control panel provides the necessary switches to regulate temperature, pressure and rotation speed, together with recording readouts of temperature and pressure. 


\section{Methods}

1. Calibration of Micropacks and Thermocouples

The temperature sensing devices were collectively fitted into a wire basket with their tips placed as closely together as possible so that each device would sense the same location in the steritort (FMC, Santa Clara, CA). The steritort was heated and maintained at $121^{\circ} \mathrm{C}\left(250^{\circ} \mathrm{F}\right)$. The time and temperature of the steritort and devices was carefully monitored. Calibration factors were determined by comparing the time and temperature of the devices with the time and temperature of the steritort. For instance, at $2: 00 \mathrm{pm}$ the retort was at $121^{\circ} \mathrm{C}\left(250^{\circ} \mathrm{F}\right)$ and thermocouple number 1 was reading $121.6^{\circ} \mathrm{C}\left(250.8^{\circ} \mathrm{F}\right)$; therefore, thermocouple number 1 had a correction factor of $0.4^{\circ} \mathrm{C}\left(-0.8^{\circ} \mathrm{F}\right)$.

2. Viscon Preparation and Heat Penetration Tests

A. Preparation of Viscon

a. The dry ingredients were measured by weight and blended together.

b. One third of the blended dry ingredients along with three liters of dionized water were mixed at high speed for five minutes in a Waring blender.

c. This procedure was repeated until twenty liters total were prepared.

d. The Viscon was sealed and stored in $603 \times 700$ size cans. 
e. The cans were labeled and dated and heated in an FMC Steritort for 60 minutes at $121^{\circ} \mathrm{C}\left(250^{\circ} \mathrm{F}\right)$ to stabilize the mixture.

f. The Viscon was stored at $1.66^{\circ} \mathrm{C}\left(35^{\circ} \mathrm{F}\right)$. Viscosity of the viscon was tested using a Brookfield LVT Viscometer with the guard leg attached, at $12 \mathrm{rpm}$ using spindle number 4 . A viscosity measurement was taken following 12 rotations of the spindle in the Viscon. The viscometer was calibrated using an NBS traceable standard. The viscosity was tested before any of the heat penetration tests were run and again after all the tests using viscon were completed to determine if the viscon had become less viscous. The first viscosity reading was 1705 centipoises and the final viscosity reading was 1695 centipoises indicating the viscon had not decreased in viscosity.

B. Viscon Heat Penetration Tests

a. Tests using Viscon were conducted in $300 \times 407$ cans in an FMC Steritort under axial rotational and stationary conditions.

b. The cans were instrumented with either copper-constantan type-T thermocouples or Micropacks.

c. Cans contained either thermocouples and Micropacks in the ends of separate cans or paired together at opposite ends of the same can. See Figure 4. The Micropacks were internally 
Figure 4

Micropack and Thermocouple Position in Cans

for Paired Can Runs.

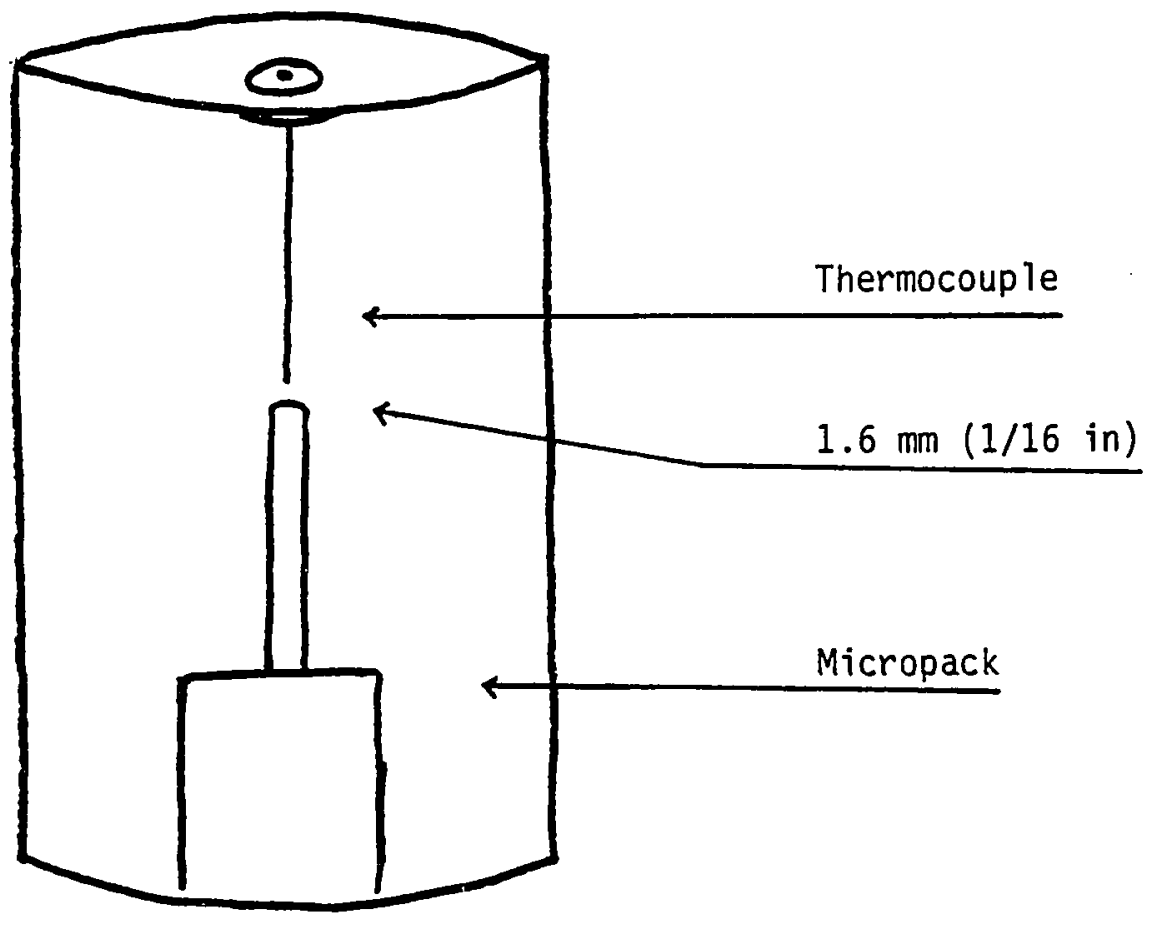


mounted using the Internal Retainer Assembly while thermocouples were secured using Ecklund No. C-5 thermocouple receptacle and hex nut.

d. Three runs each, with between $4-6$ thermocouples and Micropacks per run, were conducted with Micropacks and thermocouples paired together or separately in both the axial rotational and stationary mode, resulting in twelve total runs using viscon.

e. The geometric center of the cans was determined and Micropacks and thermocouples were selected so that both measured the geometric center of the cans for both the stationary and axial rotational tests.

f. Cans used in the axial rotational runs were filled to a $1.96 \mathrm{~mm}(8 / 32 \mathrm{in})$ headspace, while cans used in the stationary runs were filled to zero headspace.

g. The Micropacks were first programmed using the PC Interface System and then placed into cans.

h. Water heated in a steam jacketed kettle to between $60-71^{\circ} \mathrm{C}\left(140-160^{\circ} \mathrm{F}\right)$ was poured into the cans containing the Micropacks to preheat them.

i. Micropacks tend to cause a heat sink and drop the initial temperature of the product by at least ten degrees if they are not preheated $(\mathrm{H}$. W. Adams, personal conversation April, 1988). 
j. The Viscon was also heated to between $60-710 \mathrm{C}$ $(140-1600 \mathrm{~F})$ in another steam jacketed kettle.

k. The water was emptied from the cans secured with Micropacks and all cans were then filled at the same time with viscon.

1. To prevent the temperature of the viscon from dropping, the cans were kept in a closed styrofoam container during filling, weighing, and sealing.

m. Weight and headspace of all the cans were recorded.

n. The cans were sealed with a Rooney Semi-Automatic Closing Machine (Bellingham, Washington).

o. Prior to each run the FMC Steritort was preheated to $1270 \mathrm{C}$ $(2600 \mathrm{~F})$.

p. At the end of the preheat the steam was turned off, pressure released and the door opened.

q. The cans with thermocouples were immediately attached to the appropriate leads and either placed in the reel for axial rotational tests or on a rack equidistant from each other in a vertical position for stationary tests.

r. Cans containing Micropacks were positioned with the instrumented end of the cans facing the door of the Steritort.

s. For runs in the axial rotational mode, the reel was started and the containers checked for free rotation and proper 
thermocouple function before the door of the Steritiort was closed.

t. The reel was operated at 6.38 revolutions per minute (rpm), simulating 300 cans per minute (cpm).

u. For all runs, the Steritort was vented with both the drain and vent open. At $990 \mathrm{C}\left(210^{\circ} \mathrm{F}\right)$ the drain was closed. At $104^{\circ} \mathrm{C}\left(220^{\circ} \mathrm{F}\right)$ the vent was closed and the time noted.

$v$. The run ended when the product temperature reached $121^{\circ} \mathrm{C}\left(250^{\circ} \mathrm{F}\right)$ in the axial rotational runs and $118^{\circ} \mathrm{C}$ $\left(245^{\circ} \mathrm{F}\right)$ in the stationary runs.

w. At the end of the process, cans were cooled by filling. the retort half-way with city water and then spraying the cans with water until the product temperature fell to $490 \mathrm{C}$ $\left(120^{\circ} \mathrm{F}\right)$.

$x$. Over-riding air pressure was used during the first five minutes of the cool to prevent the cans from buckling.

$y$. At the end of the run the water was turned off and the drain and vent opened.

3. Whole Kernel Corn Heat Penetration Tests (300 X 407, 401 X 411)

A. Micropacks and thermocouples were secured in the ends of separate cans with their junctures located $0.74 \mathrm{~mm}$ (3/32 in) from the geometric center.

B. Cans secured with Micropacks were filled with $38^{\circ} \mathrm{C}$ 
$\left(1000^{\circ} \mathrm{F}\right)$ water to prevent a loss of product initial temperature after filling.

C The Steritort was pre-heated at $127^{\circ} \mathrm{C}\left(260^{\circ} \mathrm{F}\right)$ for ten minutes prior to each test.

D. Frozen whole Kernel corn was held in a straining basket and blanched in boiling water for two minutes.

E The blanched corn was thoroughly drained.

F. Fill weights for $300 \times 407$ and $401 \times 411$ cans secured with thermocouples were $311 \mathrm{gm}(11 \mathrm{oz})$ and $609.5 \mathrm{gm}$ $(21.5 \mathrm{oz})$, respectively.

G Fill weights for $300 \times 407$ and $401 \times 411$ cans secured with Micropacks were $284 \mathrm{gm}(10 \mathrm{oz})$ and $582.5 \mathrm{gm}(20.6 \mathrm{oz})$ respectively.

H. Fill weights for Micropacks were determined by the amount of water displaced by a $5.52 \mathrm{~mm}$ ( $23 / 16$ in) Micropack and securing clip, which equalled $27 \mathrm{gm}(0.95 \mathrm{oz})$. Therefore, the two can sizes secured with Micropacks were filled with $27 \mathrm{gm}(0.95 \mathrm{oz})$ less of whole Kernel corn than the cans secured with thermocouples. Although specific gravities are different for water and corn, water was used because variabilities exist with corn, but not with water.

I. All cans were overfilled with $\left(38^{\circ} \mathrm{C}\right) 100^{\circ} \mathrm{F}$ tap water used as brine. 
J. Cans were closed on a Rooney semiautomatic closing machine.

$\mathrm{K}$ All tests were run in the axial rotational mode at a reel speed of $6.38 \mathrm{rpm}$ (300 cpm).

L. Cans secured with Micropacks were positioned in the reel with the instrumented end of the cans facing the door of the Steritort.

M. Prior to closing the Steritort door the reel was started and cans viewed rotating to assure all cans were rotating properly.

$\mathrm{N}$. The test started when the steam was turned on.

O. The drain was closed when the temperature of the Steritort reached $93^{\circ} \mathrm{C}\left(200^{\circ} \mathrm{F}\right)$.

P. The vent was closed when the Steritort reached $1040 \mathrm{C}$ $(2200 \mathrm{~F})$ and the time was noted.

Q. The come-up-time (CUT) was also noted when process temperature of $121^{\circ} \mathrm{C}\left(250^{\circ} \mathrm{F}\right)$ was reached.

$\mathrm{R}$. The steam was turned off when all cans reached $120^{\circ} \mathrm{C}$ (2480 F).

S. Cans were cooled by filling the retort halfway full with city water, and then letting spray water fall over the cans until product fell below $540 \mathrm{C}\left(130^{\circ} \mathrm{F}\right)$.

T. Average cooling water temperature was $380 \mathrm{C}\left(100^{\circ} \mathrm{F}\right)$. 
4. Whole Kernel Corn Heat Penetration Tests (603 X 700)

A. Micropacks and thermocouples were secured in the ends of separate cans with their junctures located at the geometric center.

B. Two inch long and $2.1 \mathrm{~mm}(7 / 8 \mathrm{in})$ wide hollow stainless steel "extenders" (see Figure 5) were used in the cans containing Micropacks so that the Micropacks juncture would be located at the geometric center of the cans.

C. The Steritort was pre-heated to $127^{\circ} \mathrm{C}\left(260^{\circ} \mathrm{F}\right)$ for ten minutes prior to each test.

D. Frozen whole kernel corn was held in a straining basket and blanched in boiling water for three minutes.

E The blanched corn was thoroughly drained.

F. Fill weights were $2126 \mathrm{gm}(74.8 \mathrm{oz})$ for the thermocouples and $2091 \mathrm{gm}(63.6 \mathrm{oz})$ for the Micropacks.

G. The fill weight for the Micropacks was determined by the amount of water a $5.5 \mathrm{~mm}$ (2 $3 / 16 \mathrm{in}$ ) Micropack, $6.7 \mathrm{~mm}$ (2 7/8 in) "extender," and securing clip displaced, which equalled $35 \mathrm{gm}(1.2 \mathrm{oz})$. Therefore, the cans containing Micropacks were filled with $35 \mathrm{gm}(1.2 \mathrm{oz})$ less of whole kernel corn than the cans containing thermocouples.

$\mathrm{H}$. All cans were filled with $82^{\circ} \mathrm{C}\left(180^{\circ} \mathrm{F}\right)$ water and filled to a headspace of $1.96 \mathrm{~mm}(3 / 8 \mathrm{in})$. 
Figure 5

"Extender" Position in $603 \times 700$ Cans.

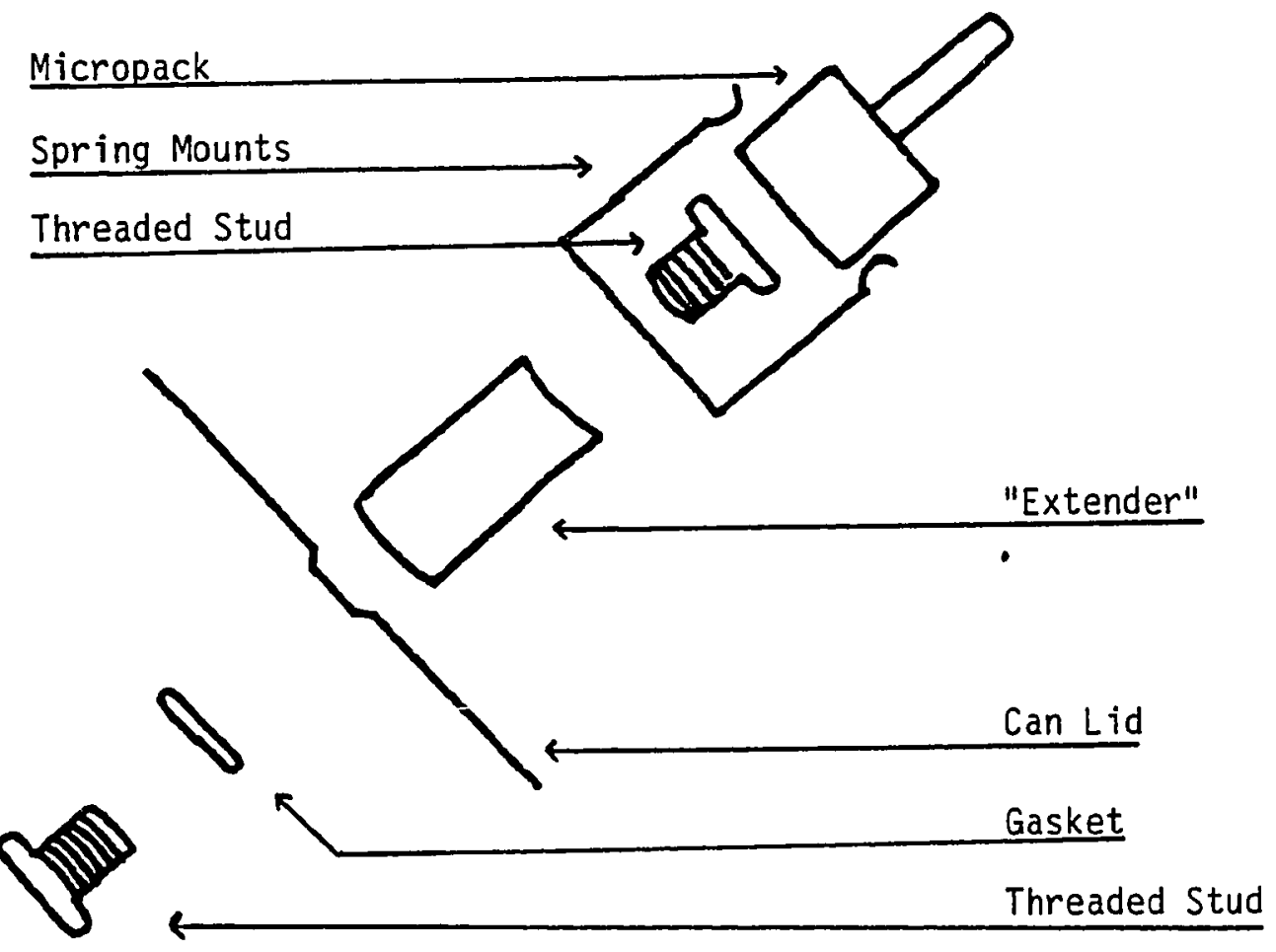


I. Cans were closed on a Rooney semiautomatic closing machine.

J. All tests were conducted in the axial rotational mode at a reel speed of $3.33 \mathrm{rpm}(80 \mathrm{cpm})$.

$\mathrm{K}$. Cans secured with Micropacks were positioned in the reel in the same manner as the thermocouples.

L. Prior to closing the Steritort door the reel was started and the cans viewed to assure all cans were rotating properly.

M. The test started when the steam was turned on.

$\mathrm{N}$. The drain was closed when the temperature of the Steritiort reached $930 \mathrm{C}\left(200^{\circ} \mathrm{F}\right)$, and the vent was closed when the temperature of the Steritort reached $104^{\circ} \mathrm{C}\left(220^{\circ} \mathrm{F}\right)$.

O. The CUT was noted when $121^{\circ} \mathrm{C}\left(250^{\circ} \mathrm{F}\right)$ was reached.

P. Steam was turned off and cooling started when all cans reached within one degree of the retort temperature.

Q. Cans were cooled to $490 \mathrm{C}\left(120^{\circ} \mathrm{F}\right)$, and average cooling water was $36^{\circ} \mathrm{C}\left(97^{\circ} \mathrm{F}\right)$.

5. Evaporated Milk Heat Penetration Tests

A. Cans (300 X 407) were filled to a headspace of $1.96 \mathrm{~mm}$ $98 / 32$ in) with room temperature processed evaporated milk.

B. Thermocouples and Micropacks were secured in the ends of cans with the juncture located at the geometric center of the container. 
C Cans were placed in the reel and checked for free rotation and proper thermocouple function before the door of the Steritiort was closed:

D. Cans were pre-heated in the Steritort to simulate preheating in an actual plant.

E Cans were heated to $44^{\circ} \mathrm{C}\left(110^{\circ} \mathrm{F}\right)$ for 2.5 minutes, $66^{\circ} \mathrm{C}$ $\left(150^{\circ} \mathrm{F}\right)$ for 2.5 minutes, and $82^{\circ} \mathrm{C}\left(180^{\circ} \mathrm{F}\right)$ for 2.5 minutes. At this time the vent and drain of the Steritort were closed. Heating continued at $93^{\circ} \mathrm{C}\left(200^{\circ} \mathrm{F}\right)$ for 2.5 minutes; the temperature was then increased to $121^{\circ} \mathrm{C}\left(250^{\circ} \mathrm{F}\right)$.

F. When the Steritort reached $121^{\circ} \mathrm{C}\left(250^{\circ} \mathrm{F}\right)$, the heat penetration tests began.

G. Steam was turned off when the $F_{0}$ value of each can secured with a thermocouple reached at least 7.0.

H. Cans were cooled by filling the retort half-way full with water and then spraying the cans with water until product temperature fell below $380 \mathrm{C}\left(100^{\circ} \mathrm{F}\right)$.

Analysis of Data

All heat penetration studies were conducted in an FMC Steritort (Santa Clara, CA) in either the stationary or axial rotational mode. Time/temperature heat penetration data for the thermocouples were collected on a Kaye Digistrip II datalogger, Model DR-1A electronic potentiometer (Kaye Instruments Co., Bedford, MA) as well as on an IBM PC using Calsoft (Technical, Inc., Metairie, Louisiana) software. 
Micropacks time/temperature data were collected on an IBM PC using a PC interface system and later transferred into Calsoft for data evaluation. Calsoft software program stores raw data received from the Kaye Digistrip II datalogger or from the PC interface system and can then automatically plot the heating and cooling curves as well as determine the process time $(\mathrm{Bb})$ and Fo (lethality) based on the Ball Method or the General Method.

Using the Calsoft software program the following heating and cooling curve parameters were plotted and the process times and lethality values were calculated. Below are the definitions of process calculations from the National Canners Association Research Labs (1968):

RT The retort temperature in $\mathrm{OF}$.

CT The temperature of the can contents at the slowest heating point.

IT This is the temperature of the product at zero time of heating and cooling.

I The difference, RT-IT.

jI The number of degrees below RT where the extended straight line of the heating curve crosses the corrected 0 of the process.

$\mathrm{j}_{\mathrm{h}}$ The ratio of $\mathrm{jI} / \mathrm{I}$. A number representing the time lag before RT-CT assumes straight line characteristics on semi-log paper with time. 
$f_{h}$ The number of minutes required for the straight line portion of the heating curve to pass through one log cycle.

$\mathrm{x}_{\mathrm{bh}}$ The number of minutes from the start of the heating period to the break in the heating curve.

$\mathrm{f}_{2}$ When the heating curve is expressed as a broken curve (two straight lines of different slope) this term represents the number of minutes required for the second heating curve to traverse one logarithmic cycle on the temperature scale. The form and position of a simple heating curve are determined by RT, IT, $j$ and fh. The additional terms $x b h$ and $f 2$ are required to determine a broken heating curve.

$\mathrm{j}_{\mathrm{c}} \quad$ Lag time before cooling curve assumes a straight line.

$f_{c}$ The number of minutes required for the straight line portion of the cooling curve to pass through one log cycle.

$F_{0}$ The number of minutes required to destroy a specified number of spores at $121^{\circ} \mathrm{C}\left(250^{\circ} \mathrm{F}\right)$ when $\mathrm{z}=10^{\circ} \mathrm{C}$ $\left(18^{\circ} \mathrm{F}\right)$. A $\mathrm{z}$ value of $10^{\circ} \mathrm{C}\left(18^{\circ} \mathrm{F}\right)$ is usually assumed for Clostriduim botulinum when thermal death time determinations have not been made on the product under consideration.

$z$ The negative reciprocal of the slope of the thermal death time curve or "phantom" thermal death time curve. The $z$ value represents the number of degrees $F$ required for 
the curve to traverse one logarithmic cycle, and measures the change in thermal death time or death rate with changing temperature.

$\mathrm{Bb}$ The process time in minutes.

Calsoft performs a linear regression on the actual heat penetration data ( $\mathrm{jh}, \mathrm{fh}, \mathrm{jc}$, and $\mathrm{fc}$ ). In Appendix $\mathrm{A}$ the ' $\mathrm{X}$ ' marks show the actual heat penetration data generated by either a Micropack or thermccouple. The solid lines were manipulated by the author to best fit the heat penetration data. The Fo used in the analysis of these data was the general method rather than than the Ball method because the general method gives the actual Fo based on the data generated by the sensing device while the ball method derives the Fo based on the manipulated lines. This means the ball method is dependent on how the computer operator manipulates the line while the general method is not.

Means and standard deviations were determined for all heating and cooling curve parameters as well as process times and lethality values obtained using both the Micropacks and thermocouples. The mean heat penetration values of the two heat sensing devices were compared statistically using the students $\underline{t}$-test. The students $\underline{t}$-test for paired data was used to analyze viscon data where the two instruments were secured in the same cans (Oyster, Hanten, \& Llorens, 1987). Significant differences were determined at the p $<.05$ level. 


\section{Chapter 4}

Results

\section{Viscon Stationary}

\section{Viscon Separate Can Data}

Results from the three tests (Tables 1 and 2) show there was a significant difference between $\mathrm{jh}$, fh, and $\mathrm{f} 2$ values for the Micropacks and thermocouples (refer to Appendix B for original data tables and $\mathrm{n}$ values). The Micropacks exhibited larger $\mathrm{jh}$ values (in two of the three runs), larger fh values and smaller $f 2$ values than the thermocouples for all three runs. It was hypothesized that during the heating portion of the heat penetration tests, from which $\mathrm{jh}$ and fh values were calculated, the Micropacks acted as heat sinks where heat was rapidly absorbed by Micropacks by removing the heat from the viscon during the early portion of the heating process. The air inside the Micropacks' stainless steel shell could have acted as an insulating layer which caused a lag in the heat penetration into the product. This lag resulted in larger $\mathrm{jh}$ and $\mathrm{fh}$ values. As the Micropacks approached the retort temperature, they in effect came to temperature equilibrium and began to effectively transfer heat energy through the Micropacks' stainless steel shell, due to its high thermal conductivity. At this point the recording end of the Micropacks transferred heat energy to the viscon and possibly to the probe sensor itself, resulting in smaller f2 values. Based on this it 


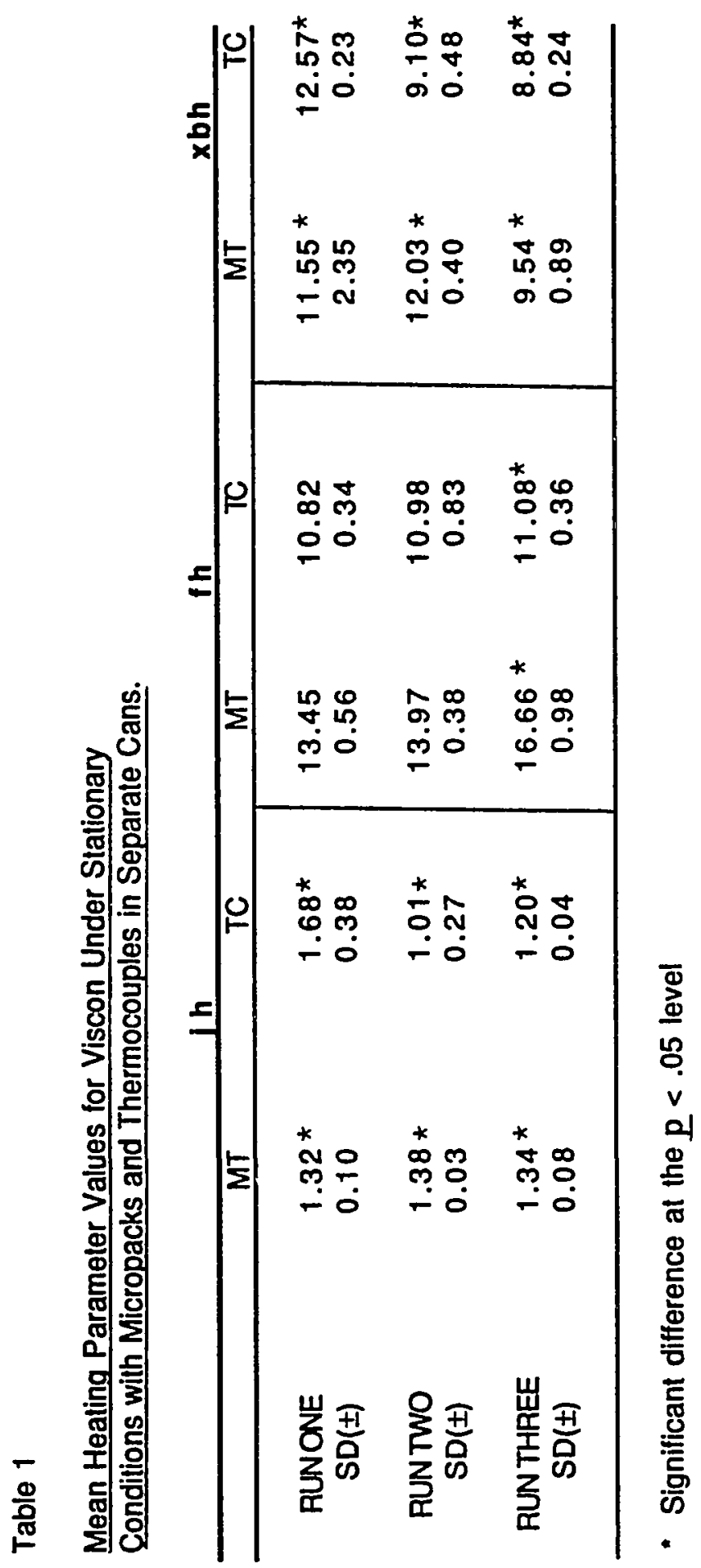




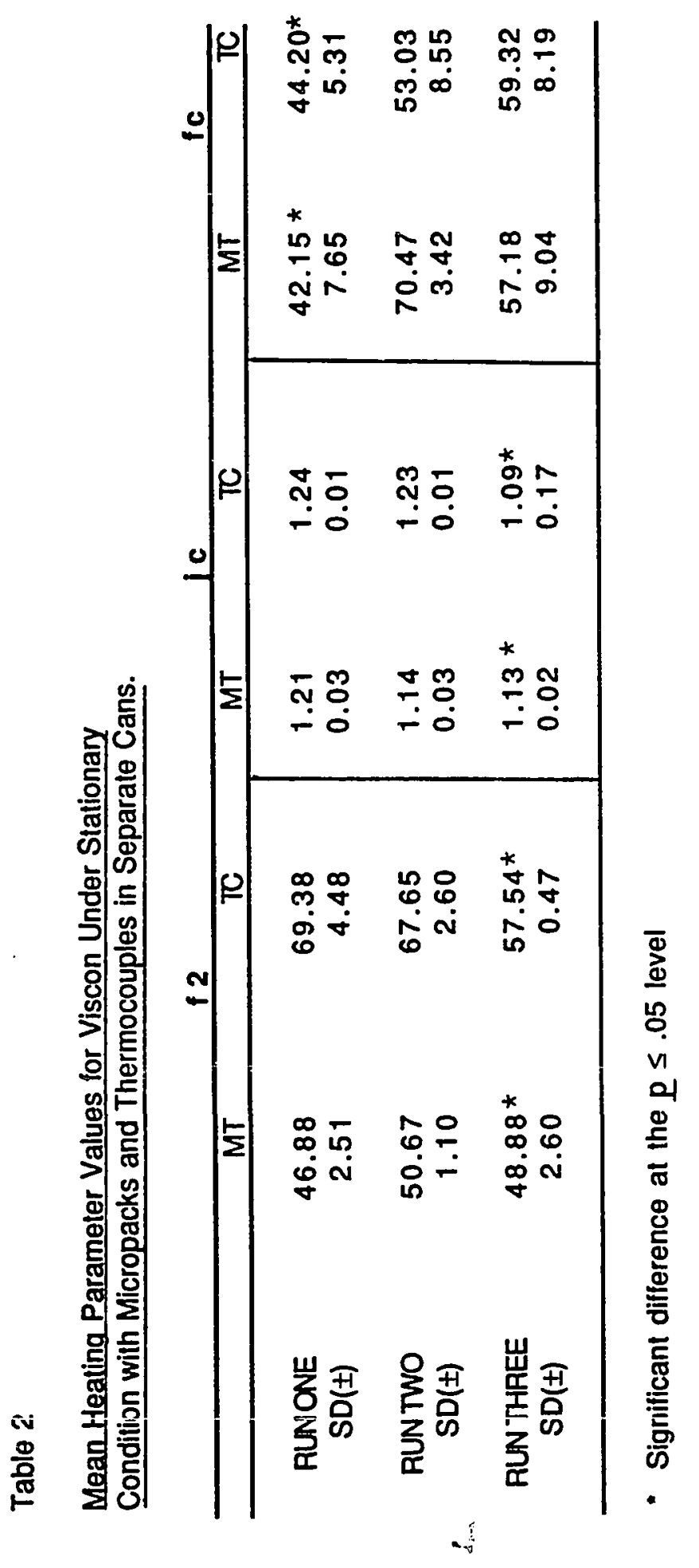


appeared that Micropacks and thermocouples behave differently in viscon under stationary conditions when Micropacks and thermocouples are secured in separate cans.

All three of the viscon runs showed significant differences in xbh values at the $p<.05$ level (Table 1 ), where two of the three values for Micropacks were higher. The break in the curve for both Micropacks and thermocouples occurred between $109.4-112.20 \mathrm{C}$ $\left(229-234^{\circ} \mathrm{F}\right)$ for all three runs. It took the Micropacks a few minutes longer than the thermocouples to reach the temperature where the break occurred. This could again be due to the insulating air in the recording end of the Micropacks which caused $\mathrm{jh}$ and fh values for the Micropacks to be longer than the thermocouple's jh and $\mathrm{fh}$ values. Based on this it appeared that Micropacks and thermocouples behave differently in viscon under stationary conditions when Micropacks and thermocouples are secured in separate cans. The viscon appeared to behave similarly based on the similar temperatures at which the break in the curve occurred.

The jc and fc values (Table 2) for both the Micropacks and thermocouples showed no consistent pattern. In addition no significant differences existed at the $\underline{p}<.05$ level between Micropacks and thermocouples in viscon under stationary conditions when Micropacks and thermocouples were secured in separate cans.

The Bb was larger for the Micropacks (Table 3) in all three tests, but only significantly larger at the $p<.05$ level in runs two and 


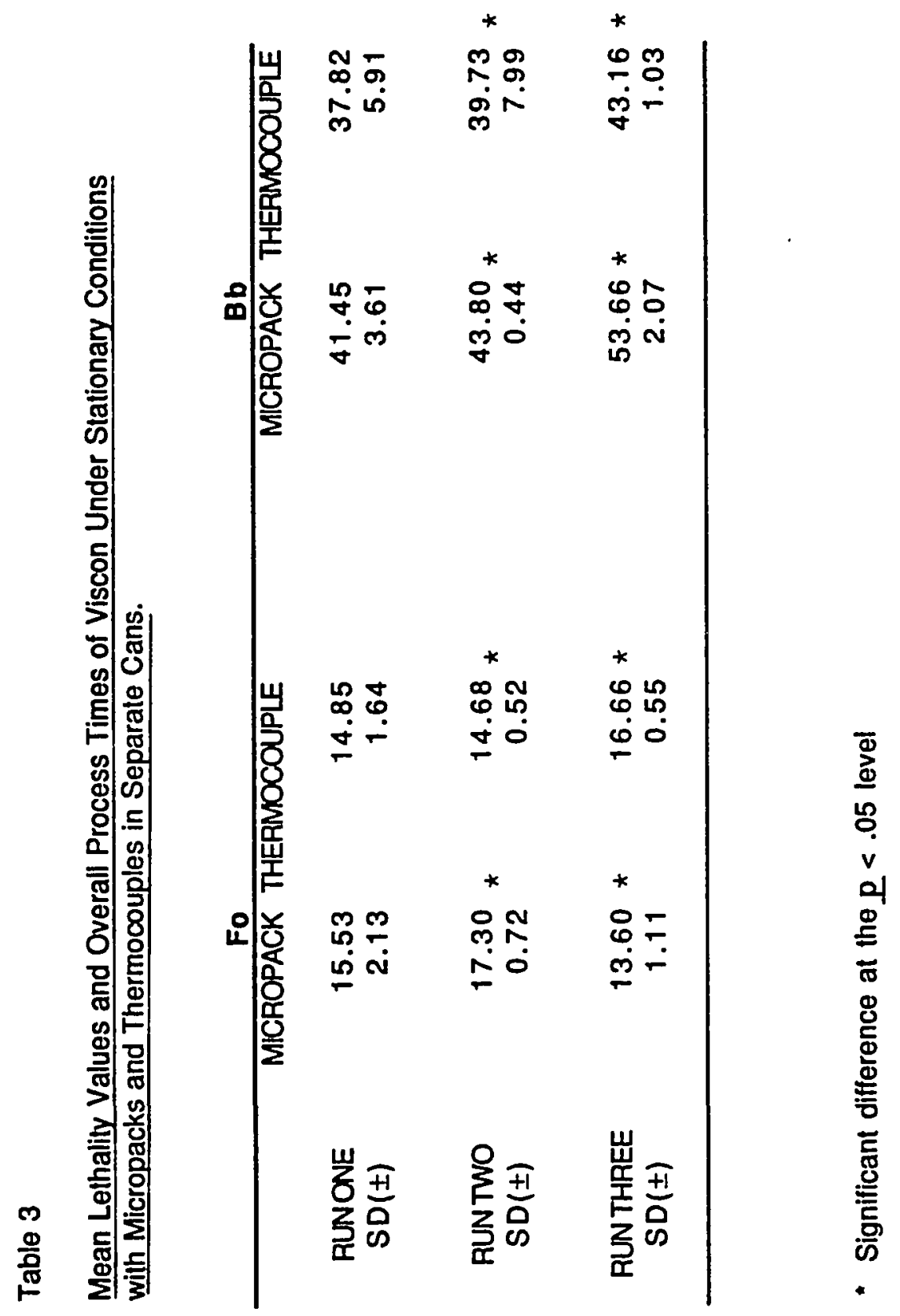


three. However, Table 4 compares the slowest $\mathrm{Bb}$ of the Micropacks and thermocouples for each run and shows that neither the Micropacks nor thermocouples consistently reported the slowest process times; therefore, neither heat sensing device was consistently more conservative than the other one. This is important information since in actual situations heat penetration data used to set $\mathrm{Bb}$ for food products is based on the slowest heating data which correspond to the longer $\mathrm{Bb}$.

\section{Viscon Paired Can Data}

The results from these tests for Micropacks and thermocouples in the same can were similar to the results of the stationary viscon tests for the Micropacks and thermocouples in separate cans (refer to Appendix $\mathrm{B}$ for original tables and $\mathrm{n}$ values). Tables 5 and 6 show larger $\mathrm{jh}$ values, larger fh values and shorter f2 values for the Micropacks.

The xbh values (Table 5) were significantly higher for the Micropacks as compared to the thermocouples in all three runs at the $\underline{p}<.05$ level. The jc values (Table 6) shows no consistent pattern between the Micropacks and thermocouples and the fc values for both were very similar to each other. The $\mathrm{Bb}$ values were significantly larger for the Micropacks in two of the three runs (Table 7). Table 8 compares the slowest $\mathrm{Bb}$ in each run for both the Micropacks and thermocouples. Neither the Micropacks nor the thermocouples consistently reported longer process times. 
Table 4

Slowest Bb of Micropacks and Thermocouples for Viscon Stationany Conditions/Separate Cans.

RUNONE

42.1

44.6

44.1

52.8

$\begin{array}{llll}\text { MICROPACK } & 44.6 & 44.1 & 52.8\end{array}$




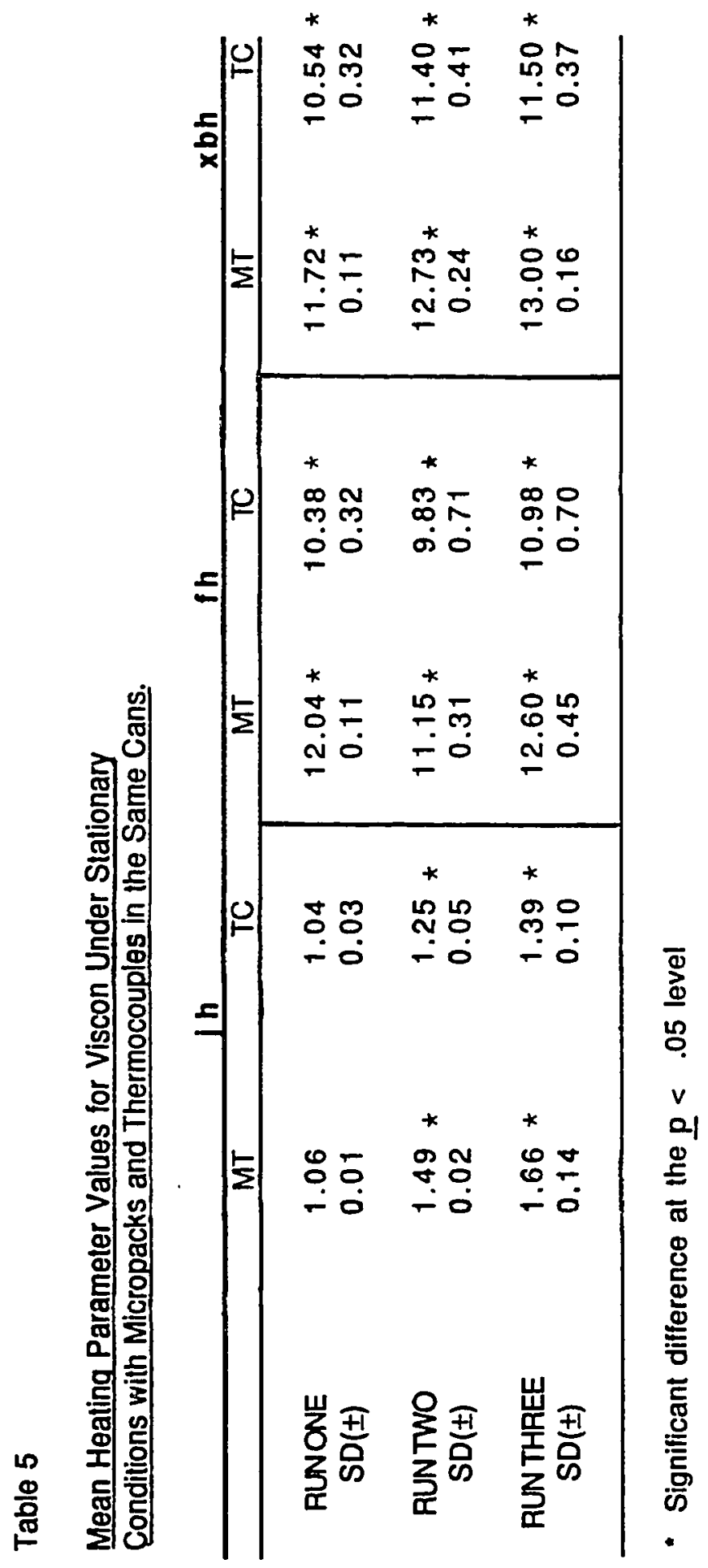




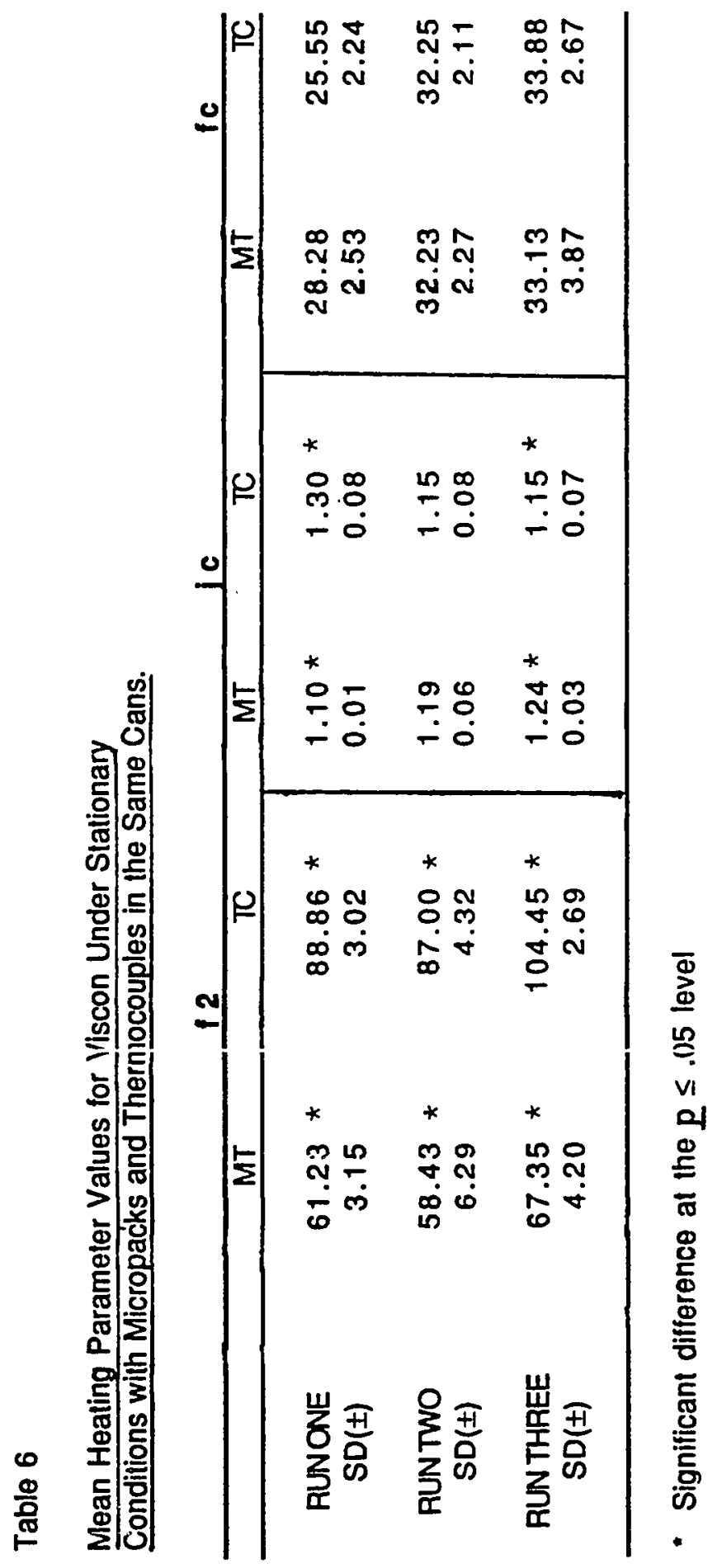


Lesley (1986) reported larger fh values and longer $\mathrm{Bb}$ values for Micropacks in tests using $31 / 4 \%$ wt:wt bentonite solution which exhibits a broken heating curve under stationary conditions as does viscon. These findings were similar to the viscon results. Unfortunately Lesley (1986) did not report $\mathrm{f} 2, \mathrm{jc}, \mathrm{fc}$, or xbh data so no comparison of these variables could be made. Viscon Comparison of Paired and Separate Can Data

Tables 9, 10, and 11 show the difference in ranges between the separate and paired can data (refer to Appendix B for original tables and $\mathbf{n}$ values). The range of fc values for the Micropacks separate can data (Table 10) shows a very large range in values as noted by the high standard deviation. Experimental variation may account for the large range.

Table 11 shows that the range of $\mathrm{Bbs}$ for the average of all the runs was actually longer and therefore more conservative for the Micropacks for both the paired and separate can data. Although neither the thermocouples nor Micropacks consistently reported longer Bbs, the overall average Bbs were longer for the Micropacks. The paired can runs were run two to three weeks prior to the separate can runs which could account for the overall differences in heat parameter values between the separate can and paired can data. Although the actual data for the two were different, the table of the ranges shows that the Micropacks and thermocouples generated similar ranges and in most of the variables the standard 


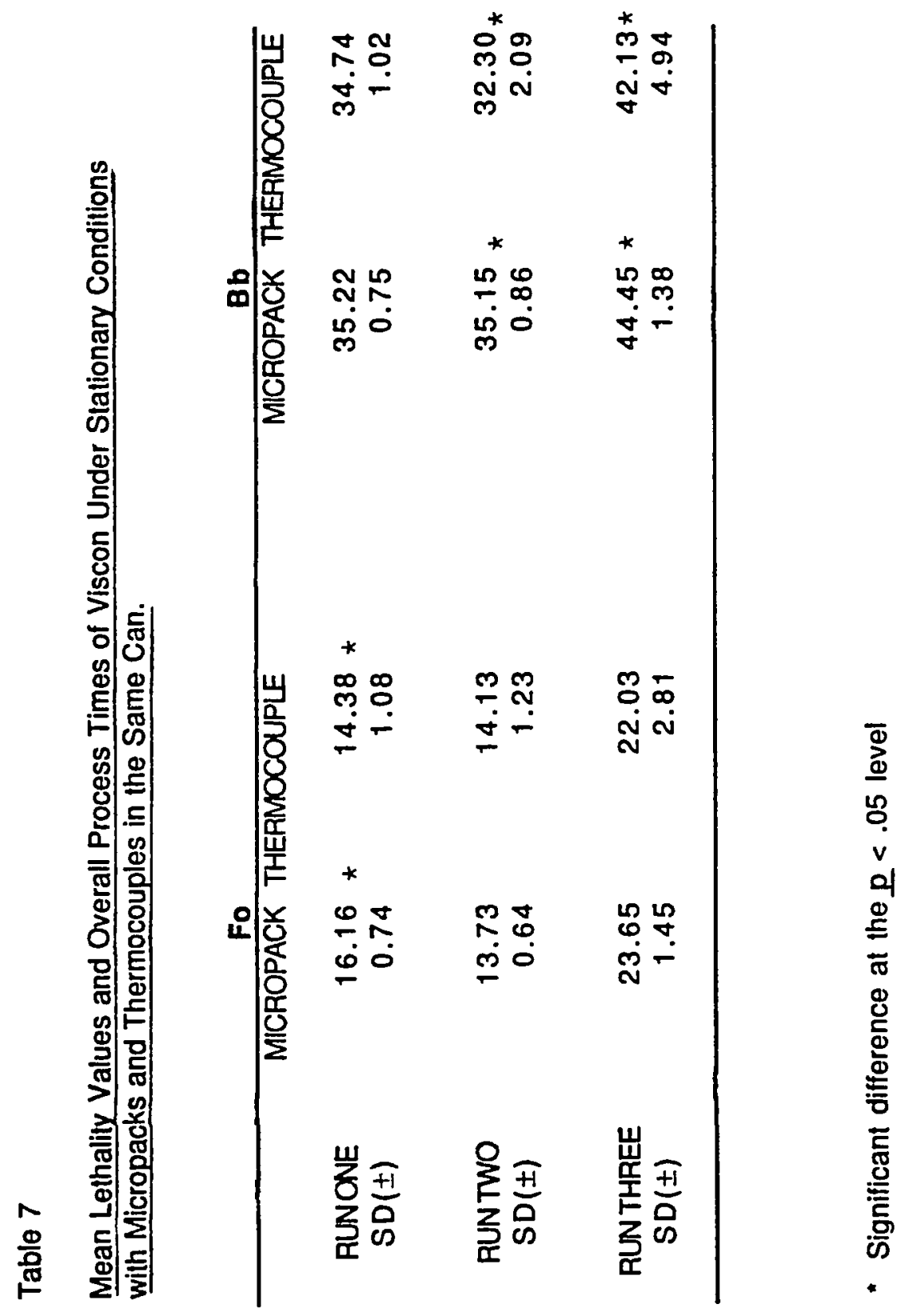


Table 8

Slowest Bb of Micropacks and Thermocouples for Viscon Stationary Conditions/Paired Together.

RUNONE RUNTWO RUNTHREE

THERMOCOUPLE

35.5

34.5

49.1

MICROPACK

36.1

36.1

44.9 


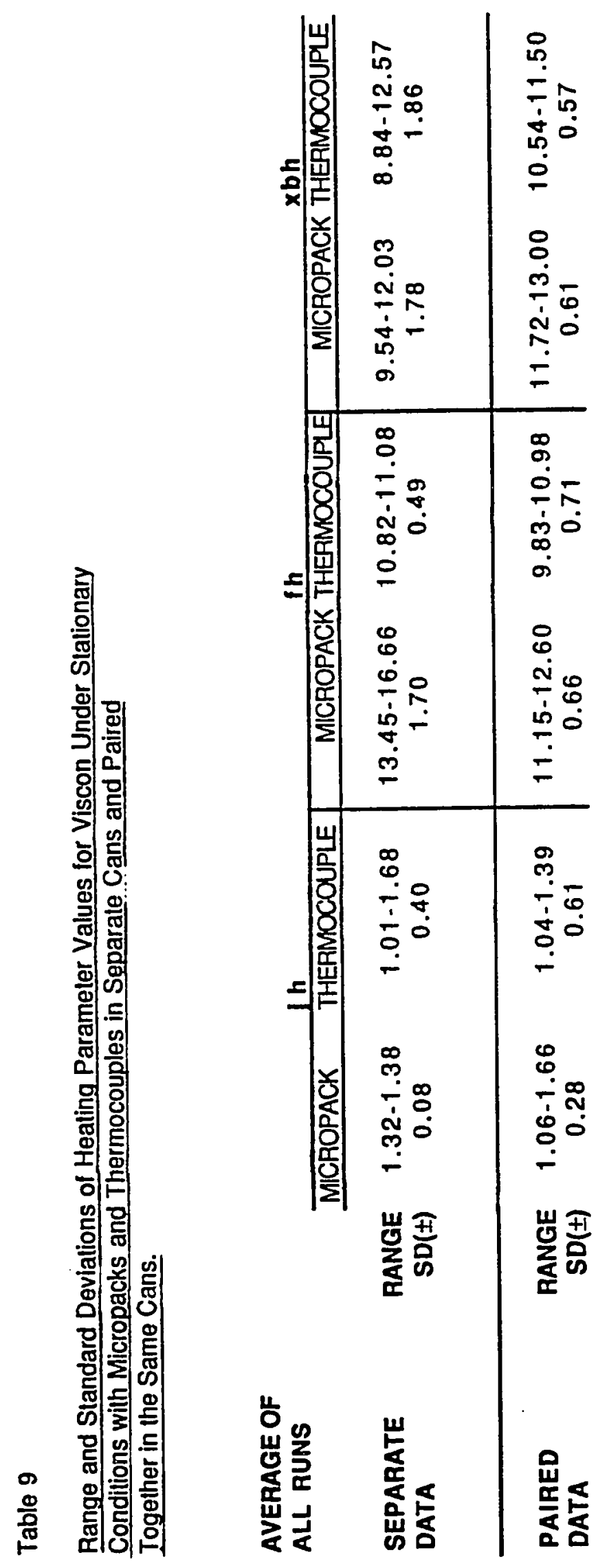



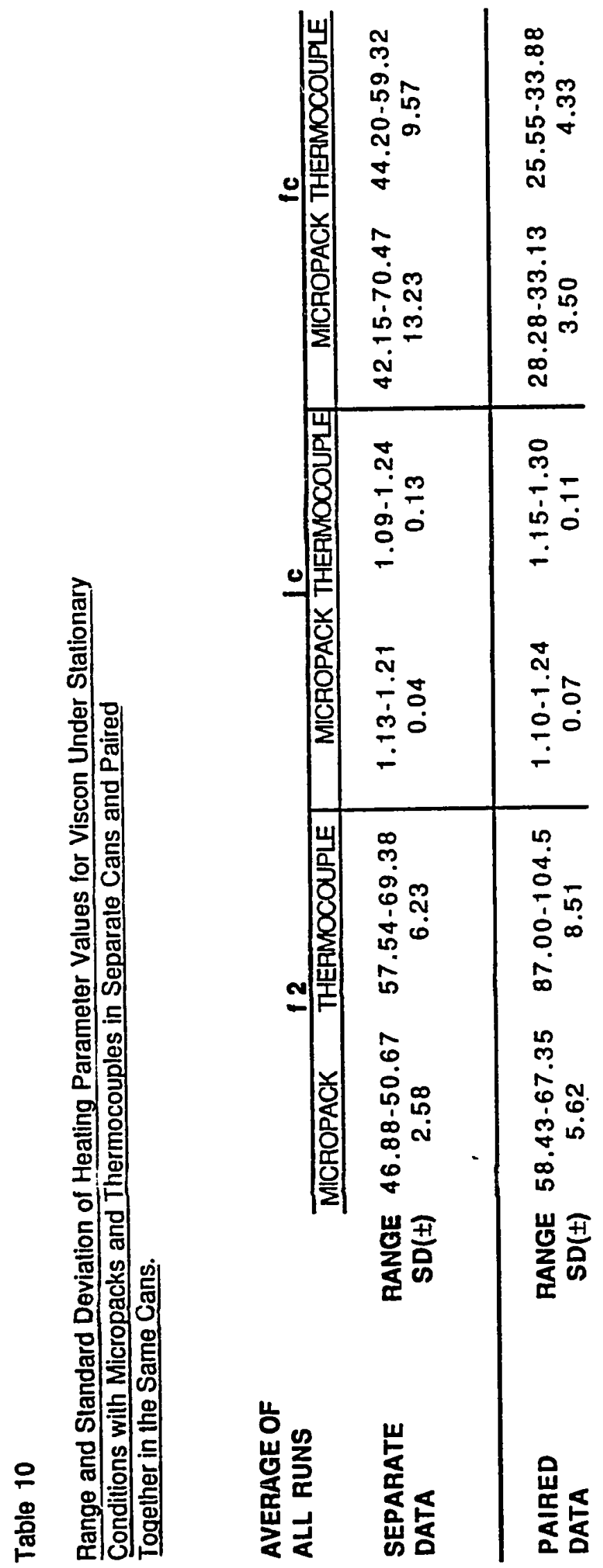


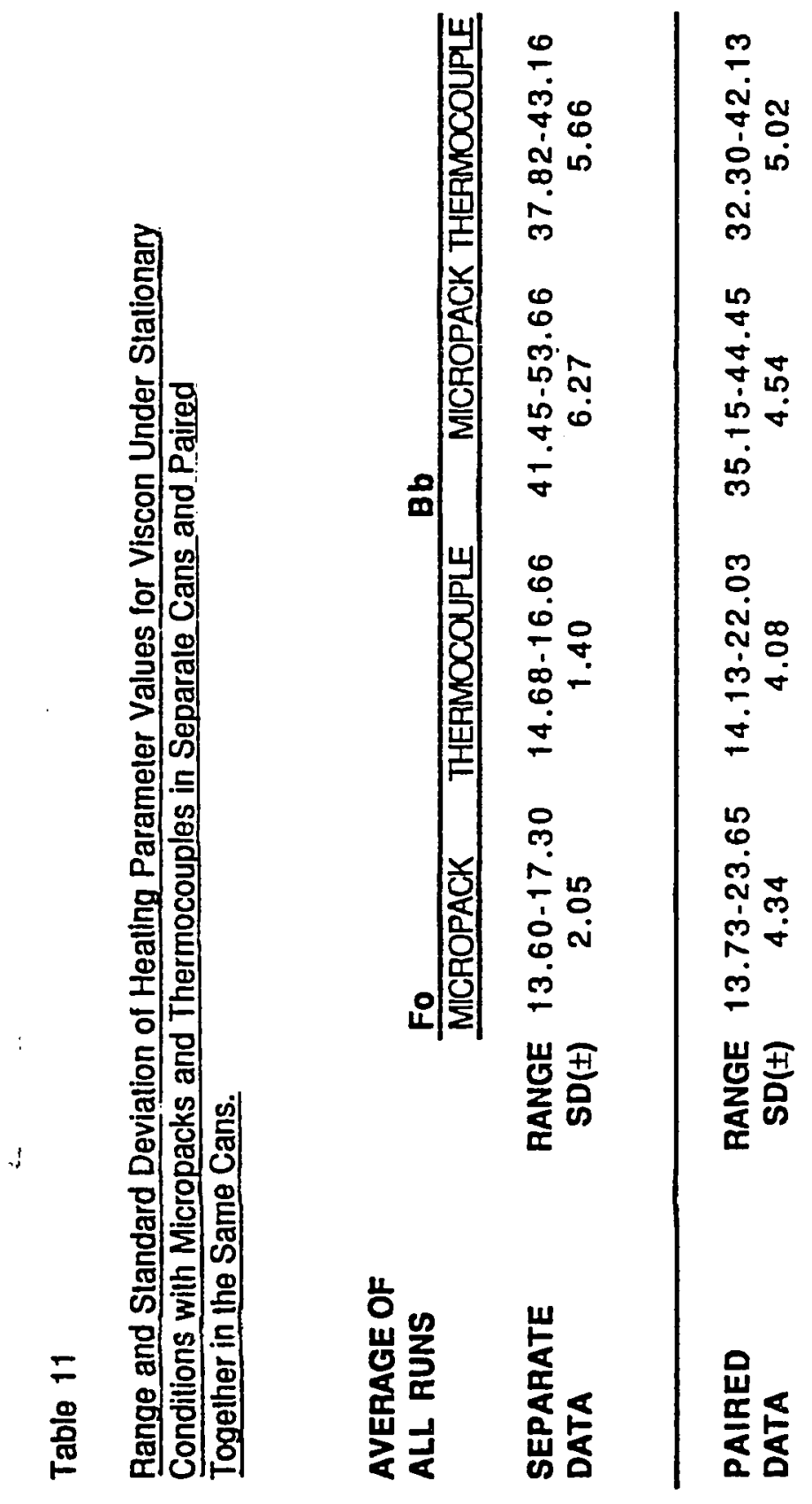


deviations for the two were similar. These findings support the apparent precision and reproducibility of both Micropacks and thermocouples.

\section{Viscon Axial Rotational}

\section{Viscon Separate Can Data}

In all three runs (Table 12) the jh values for the Micropacks were larger and fh values smaller than the thermocouples (refer to Appendix $\mathrm{C}$ for original tables and $\mathrm{n}$ values). It is hypothesized that during the first part of the heat penetration test from which jh values were calculated the air space in the Micropacks' recording end acted as an insulation barrier which caused a lag in the heat penetration into the product. This lag resulted in larger $\mathrm{jh}$ values. As the Micropacks approached the retort temperature they in effect came to temperature equilibrium and began to effectively transfer heat energy into the viscon which in turn more rapidly heated up the viscon. This resulted in shorter fh values for the Micropacks.

In all three runs the jc values were higher for the thermocouples, but not significantly at the $\mathrm{p}<.05$ level (Table 12). Table 12 also shows there were no consistent patterns in fc values and no significant differences. There were no significant differences between the Fo and $\mathrm{Bb}$ (Table 13), and neither the Micropacks nor the thermocouples reported consistently longer $\mathrm{Bb}$ values (Table 14). 


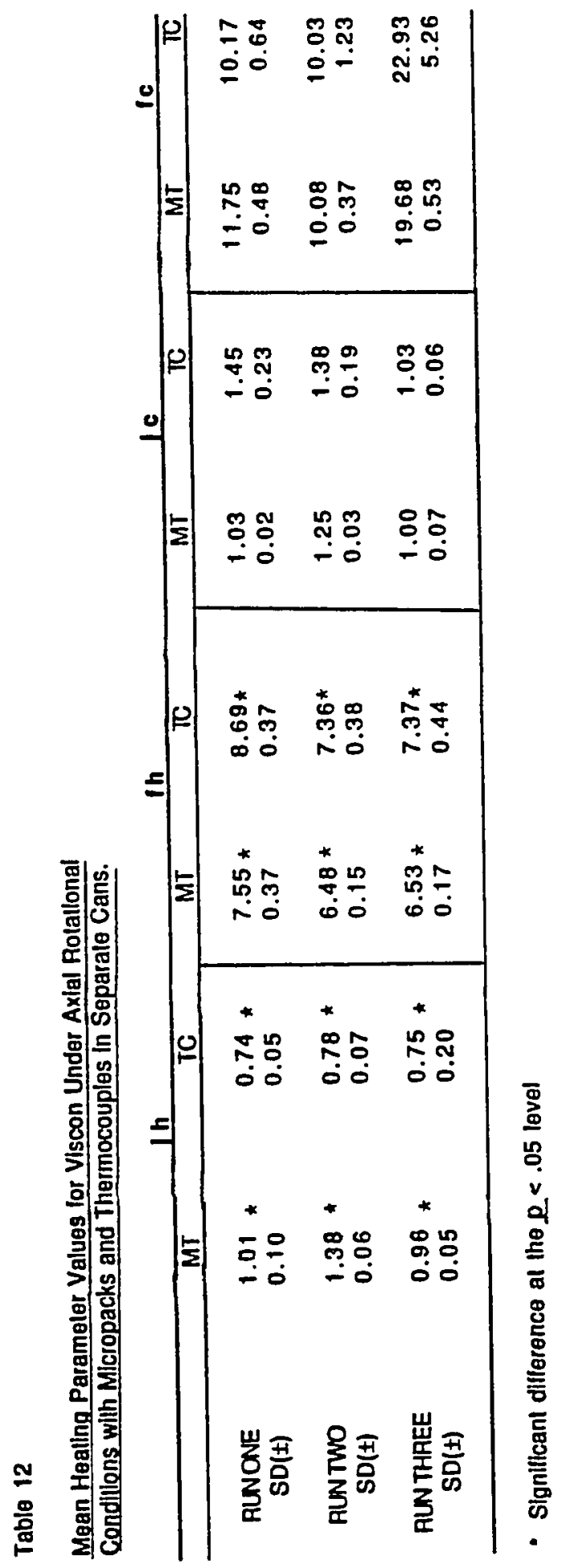




\section{Viscon Paired Can Data}

These results concurred with the results from the viscon separate can data (refer to Appendix $\mathbf{C}$ for original tables and $\mathbf{n}$ values). In all three runs (Table 15 ) the $\mathrm{jh}$ values were larger and $\mathrm{fh}$ values smaller than the thermocouples. There were significant differences between jc and fc values for the Micropacks and thermocouples in run three, but no consistent pattern was apparent (Table 15).

In all three runs the Fo values were greater for the Micropacks and significantly different in run three (Table 16). Table 16 also shows that none of the $\mathrm{Bb}$ values for Micropacks and thermocouples were significantly different at the $p<.05$ level. Table 17 compares the slowest $\mathrm{Bb}$ for Micropacks and thermocouples for the three runs. Runs one and two show good correlation between Micropacks and thermocouples; however, run three shows the Micropacks' $\mathrm{Bb}$ to be five minutes longer than the thermocouples. There may have been some experimental variation or error that occurred to account for the variations in run three. Although there were variations in run three the $\mathrm{Fo}$ and $\mathrm{Bb}$ were more conservative for the Micropack as compared to the thermocouple.

Underferth (1987) studied a homogeneous liquid with no discrete particles and found that the Micropacks generated larger jh values, but similar fh values as that of the thermocouples. The liquid Underferth (1987) used in his study was less viscous than the viscon 


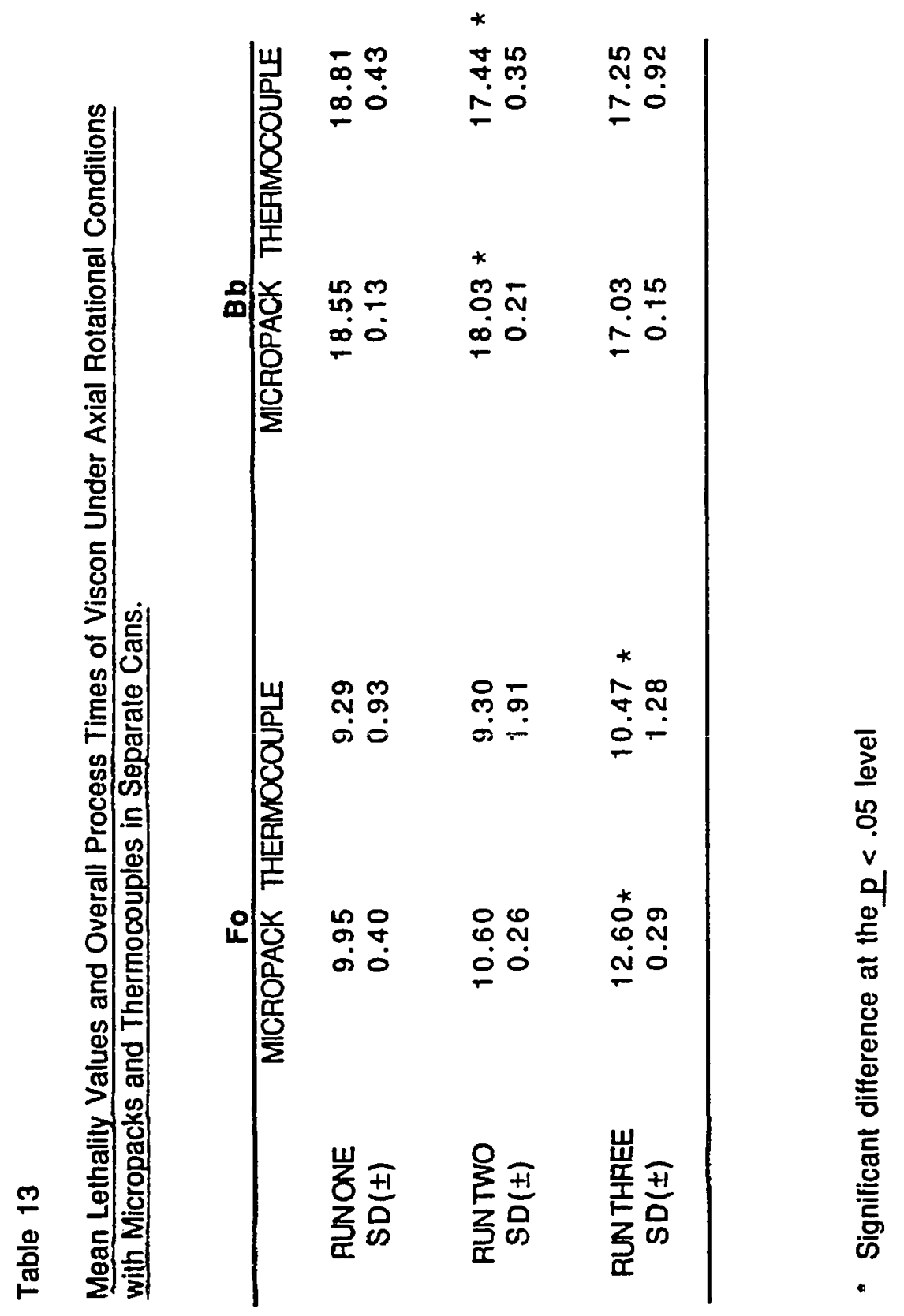


Table 14

Slowest Bb of Micropacks and Thermecouples for Viscon_Axial_Botational Conditions/Separate Cans.

RUNONE RUNTWO RUNTHREE

THERMOCOUPLE

MICROPACK
19.7

18.7

18.2

17.2 


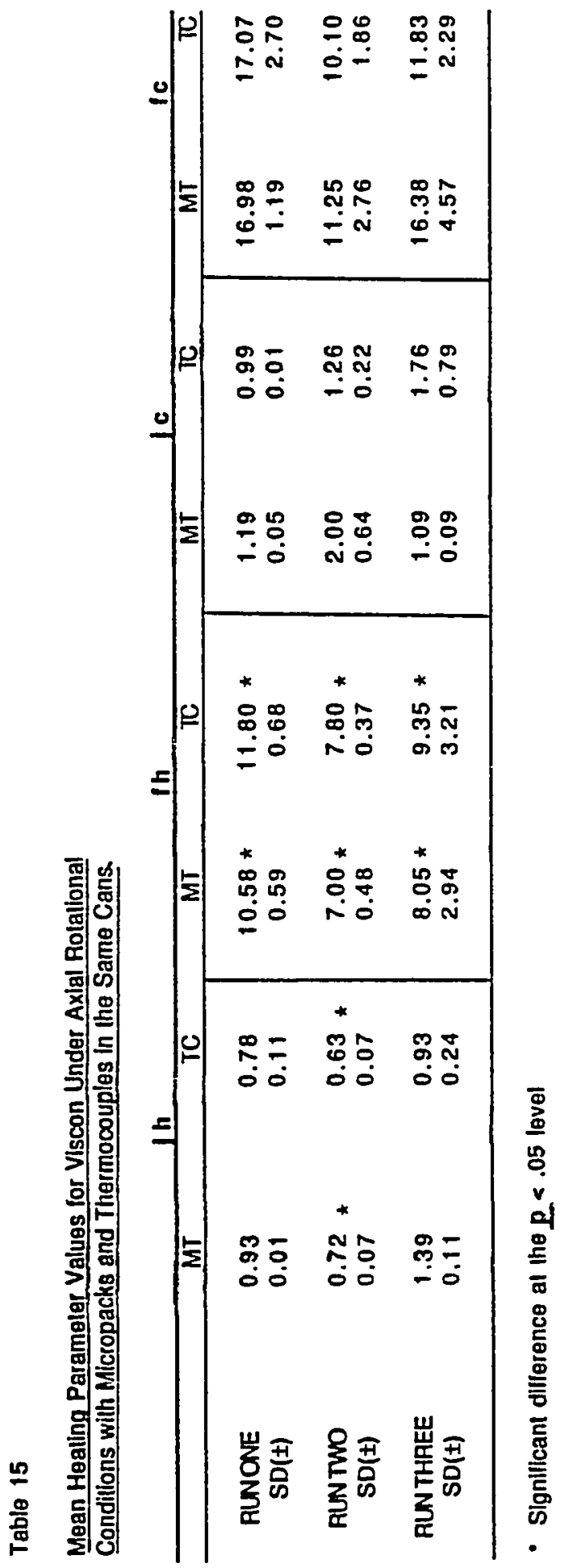




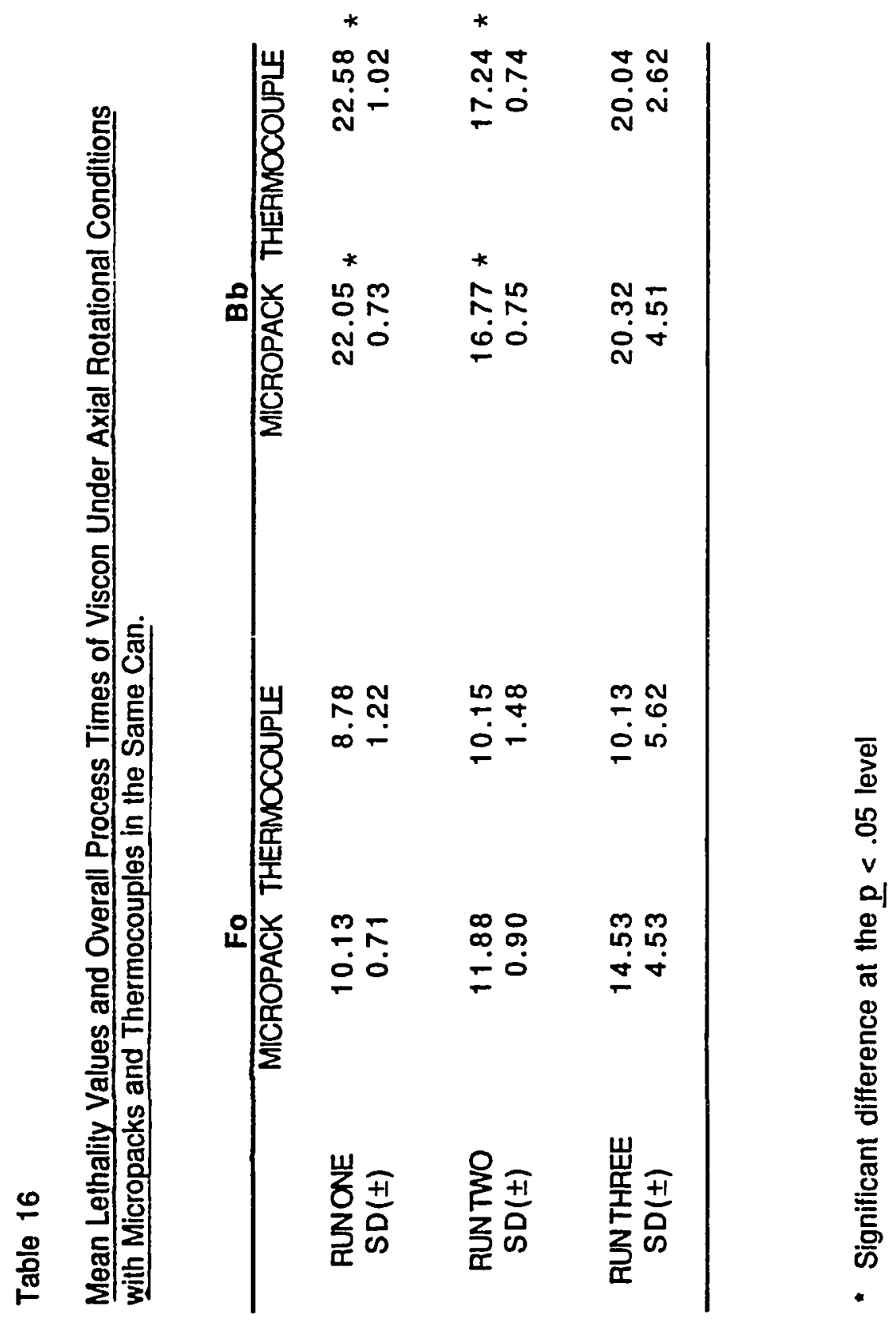


Table 17

Slowest Bb of Micropacks and Thermocouples for Viscon Axial Rotational Conditions/Paired Together.

RUNONE RUNTWO RUNTHREE

$\begin{array}{llll}\text { THERMOCOUPLE } & 23.8 & 17.9 & 23.0\end{array}$

$\begin{array}{llll}\text { MICROPACK } & 22.8 & 17.2 & 27.0\end{array}$


the Fo and $\mathrm{Bb}$ were more conservative for the Micropack as compared to the thermocouple.

Underferth (1987) studied a homogeneous liquid with no discrete particles and found that the Micropacks generated larger $\mathrm{jh}$ values, but similar fh values as that of the thermocouples. The liquid Underferth (1987) used in his study was less viscous than the viscon used in this study and may account for the different fh results of the two studies. The lower viscosity of Underferth's liquid material may not have taken up heat from the stainless steel mass the way the more viscous viscon did.

Viscon Comparison of Paired and Separate Data

Tables 18 and 19 show the difference in ranges between the separate and paired can data (refer to Appendix $C$ for original tables and $n$ values). Tabie 19 shows that the range of $B b$ for the average of all the runs was actually longer and therefore more conservative for the thermocouple for both the paired and separate can data. Although neither the thermocouples nor Micropacks consistently reported longer $\mathrm{Bbs}$, the overall average $\mathrm{Bbs}$ were longer for the thermocouples. The paired can runs were conducted two to three weeks prior to the separate can runs and could account for the differences between the heating parameter values for paired and separate can data. Although the actual data for Micropacks and thermocouples were different the table of the ranges show that the two heat sensing devices had similar size of ranges and in most of 

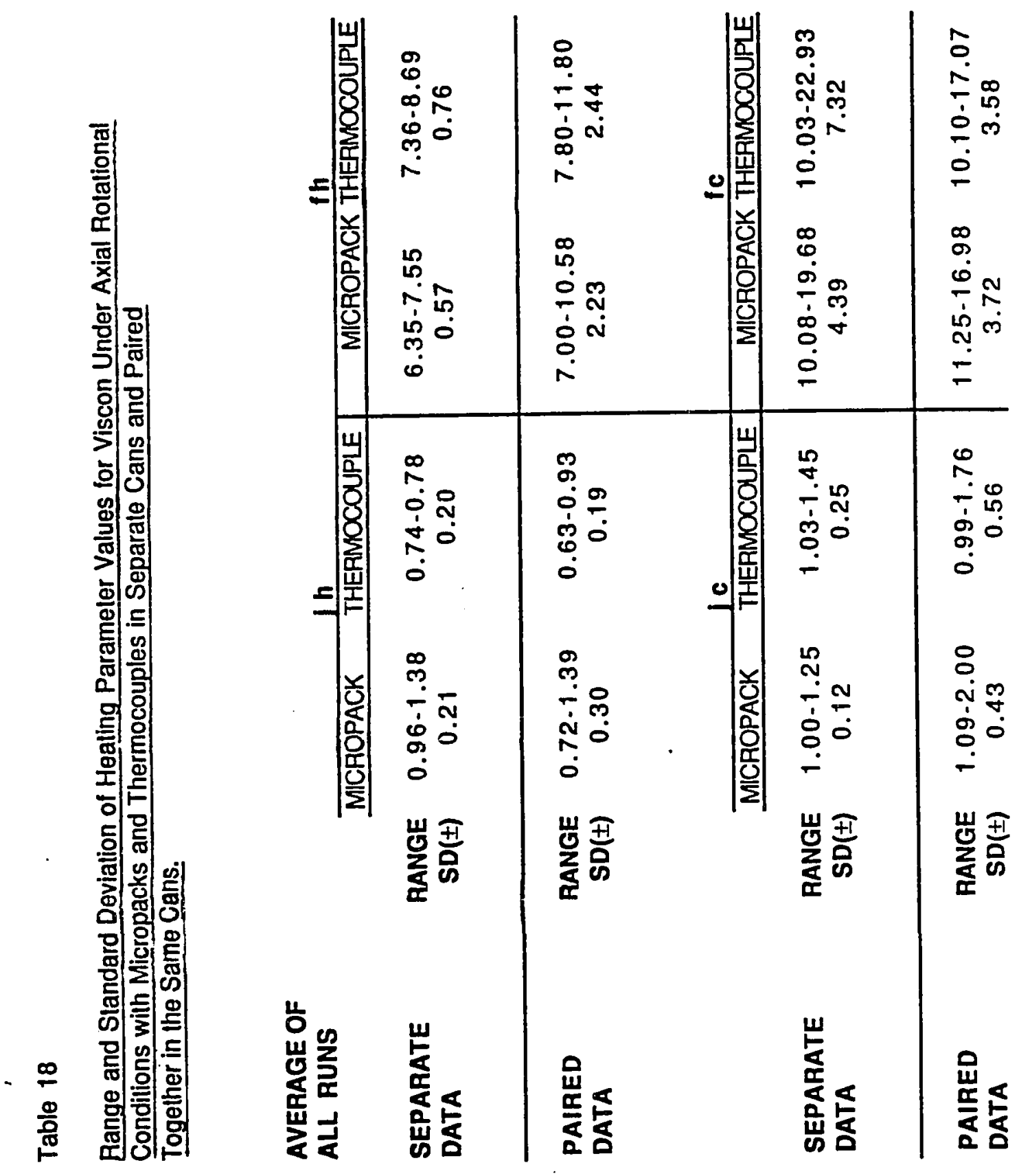

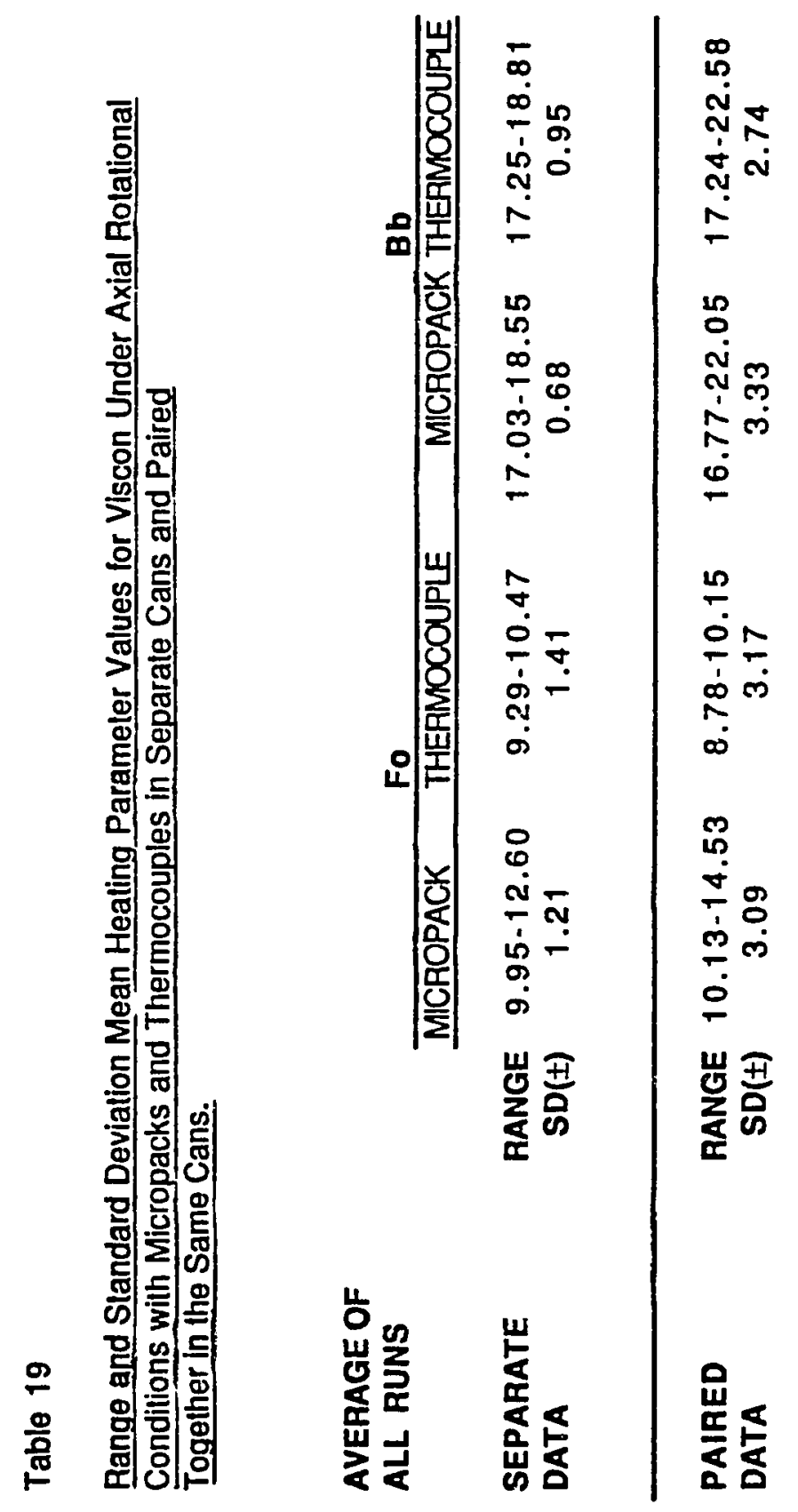


\section{Whole Kernel Corn}

Whole Kernel Corn $(300 \times 407)$

Tables 20 and 21 show that $\mathrm{jh}$ values were significantly different at the $p<.05$ level for runs four, five, and six, fh values were significantly different at the $\mathrm{p}<.05$ level for runs three and five, $\mathrm{jc}$ values were significantly different at the $\mathfrak{p}<.05$ level for runs one and four, fc values were not significantly different at the $\mathrm{p}<.05$ level for any of the runs, Fo values were significantly different at the $\mathrm{p}<.05$ level for runs three, four, and six, and $\mathrm{Bb}$ were significantly different at the $\mathrm{p}<.05$ level for runs three and four (refer to Appendix $D$ for original tables and $n$ values). There was no consistent pattern in the variations between runs. The differences in these runs could be due to experimental variation.

The results from run five were somewhat out of line with the rest of the data. For instance the $\mathrm{jh}$ values for the thermocouples were very low as compared to the Micropacks' jh values (Table 20) and none of the thermocouples recorded any jc or fc values. These differences could have been due to experimental error associated with the thermocouples. Table 22 compares the slowest $\mathrm{Bb}$ of the Micropacks and thermocouples for each run and shows that neither the Micropacks nor thermocouples consistently reported the slowest process times.

Lesley (1987 a,b) reported larger fh and Fo values for Micropacks in his tests using whole kernel corn in brine under 


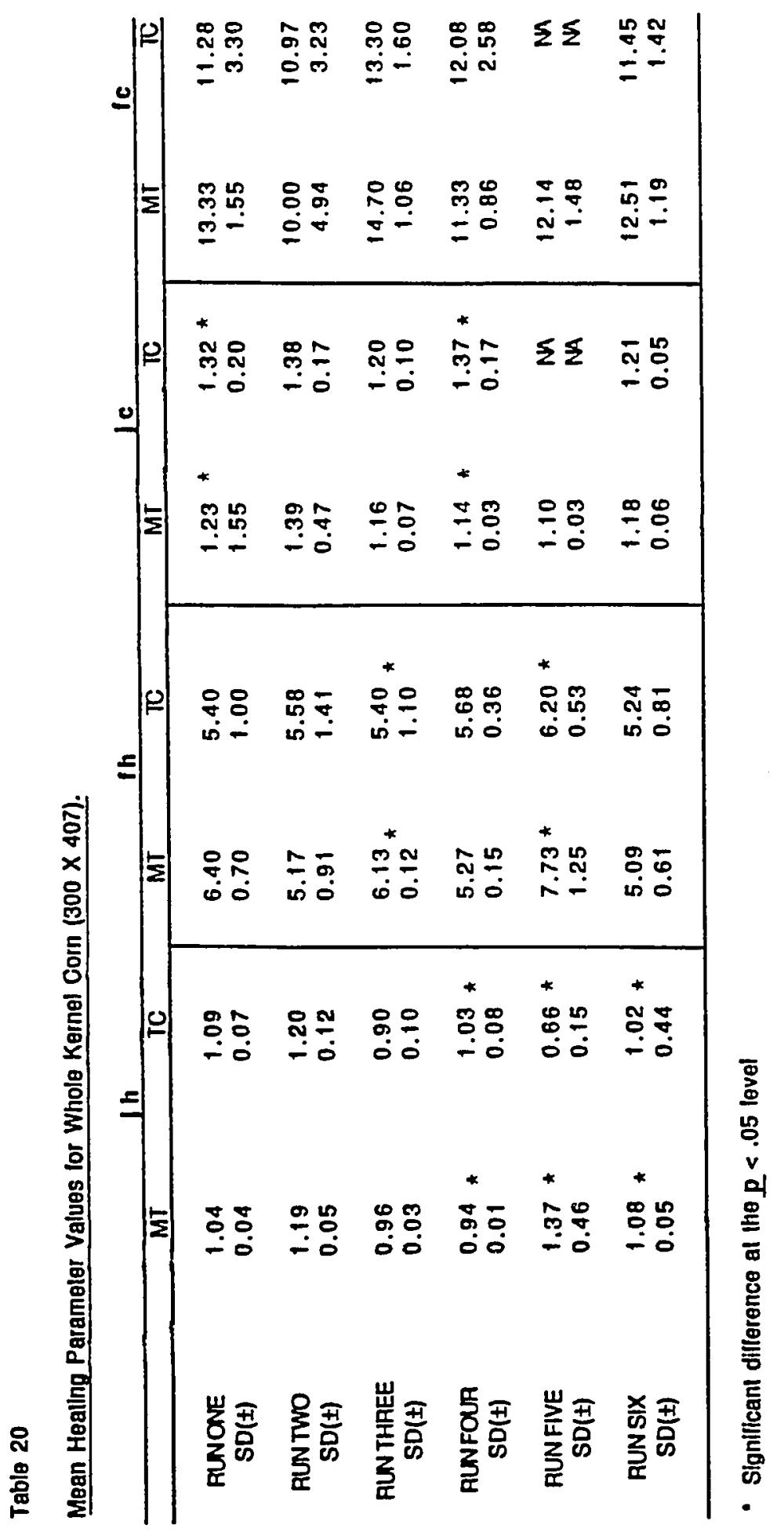




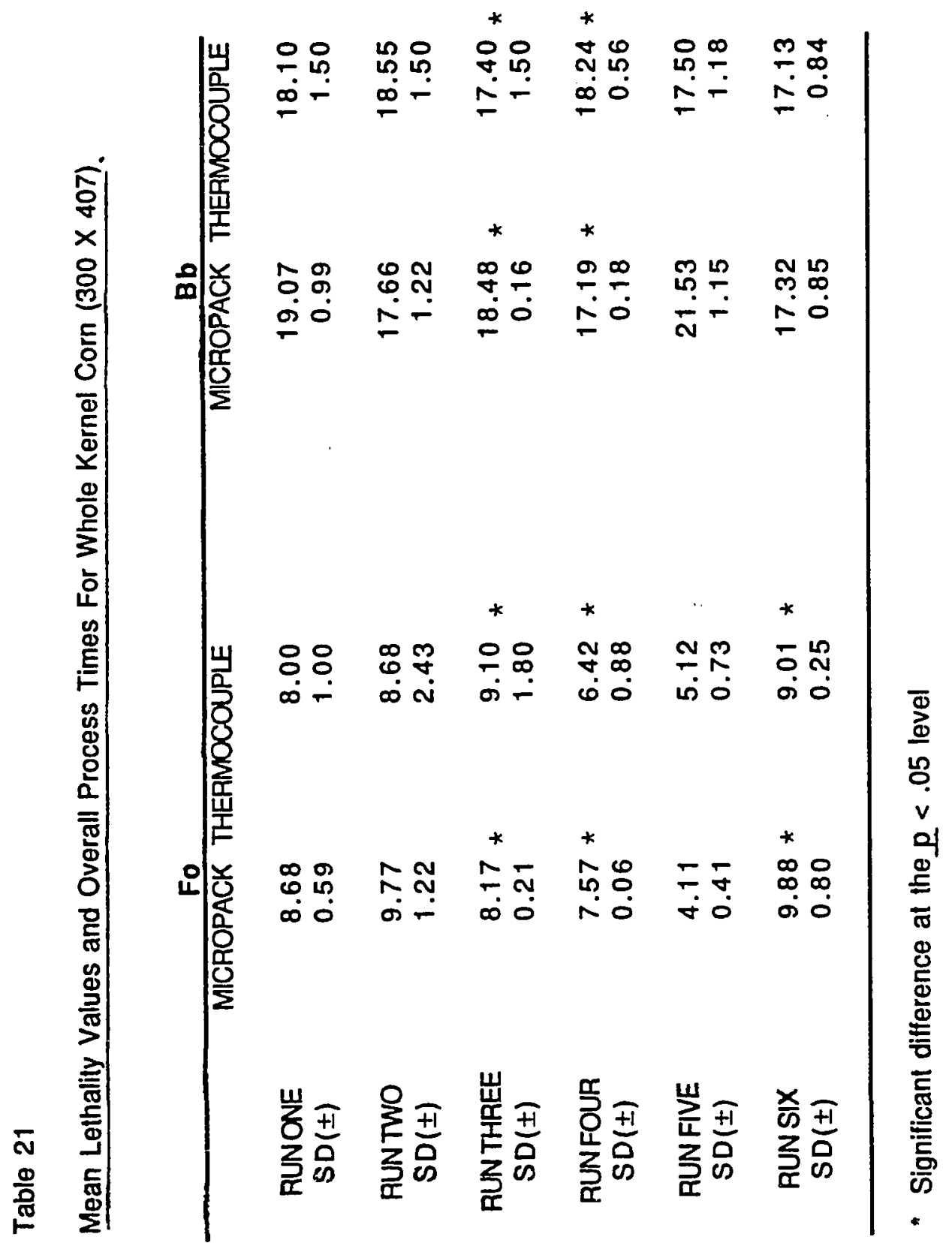




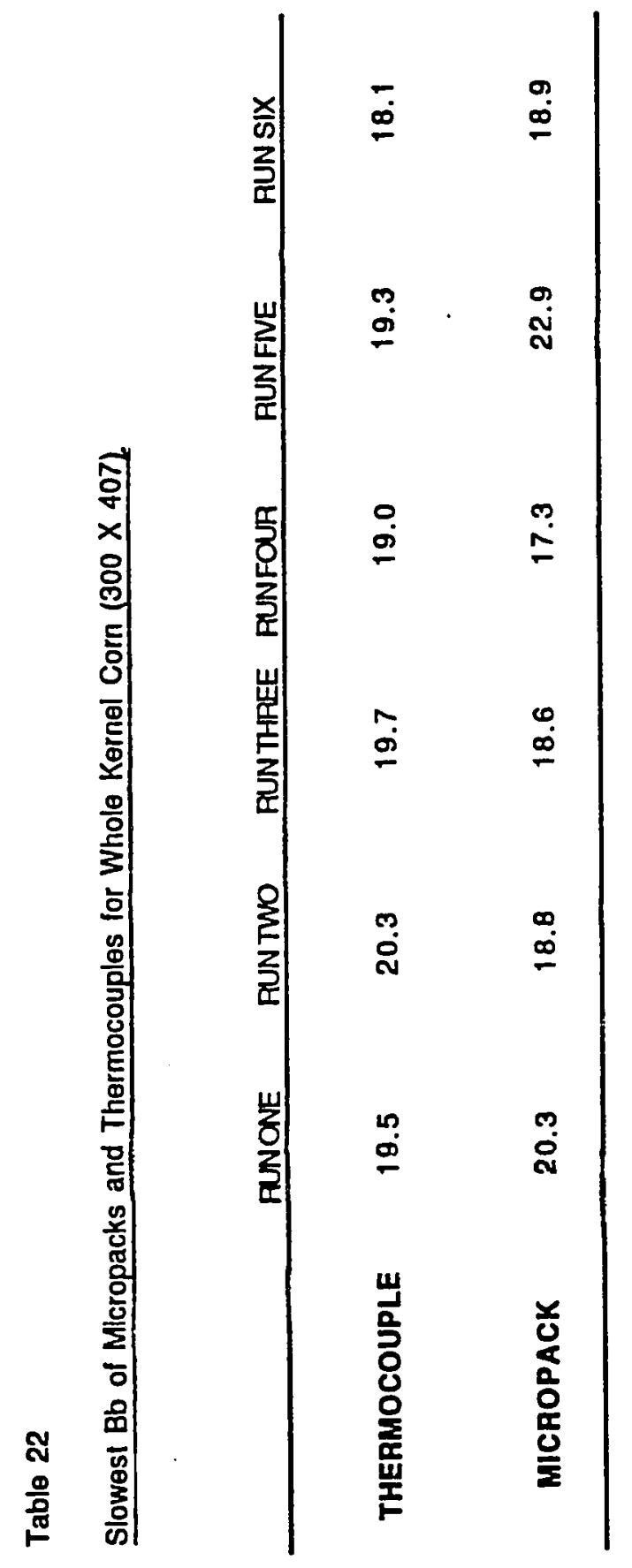


stationary conditions in $300 \times 407$ cans. It appeared that Micropacks behave similarly to thermocouples when run under axial rotational conditions and differently when run under stationary conditions. Whole Kernel Corn $(401 \times 411)$

Tables 23 and 24 show jh values were higher for the Micropacks in four of the five runs and significantly higher at the $p<.05$ level in run one. The air space in the Micropacks' recording end acted as an insulation barrier which caused a lag in the heat penetration into the product. This lag resulted in larger $\mathrm{jh}$ values. The $f h$ and $j c$ values were not significantly different at the $p<.05$ level in any of the runs. The fc values were significantly different at the $\underline{p}<.05$ level in runs one, two, and four but no consistent pattern was found. The Fo values were significantly different at the $p<.05$ level in runs two and four, and in four of the five runs the Micropack values were higher. The $\mathrm{Bb}$ values were significantly different at the $p<.05$ level in run four, and in four of the five runs the thermocouple's values were longer (refer to Appendix E for original tables and $\mathrm{n}$ values). Table 25 compares the slowest $\mathrm{Bb}$ of the Micropacks and thermocouples for each run and shows that neither the Micropacks nor the thermocouples consistently reported the slowest $\mathrm{Bb}$. The overall results from these runs showed larger $\mathrm{jh}$ values, larger Fo values, and shorter $\mathrm{Bb}$ values for the Micropacks. Furthermore, whole kernel corn with Micropacks took less process 


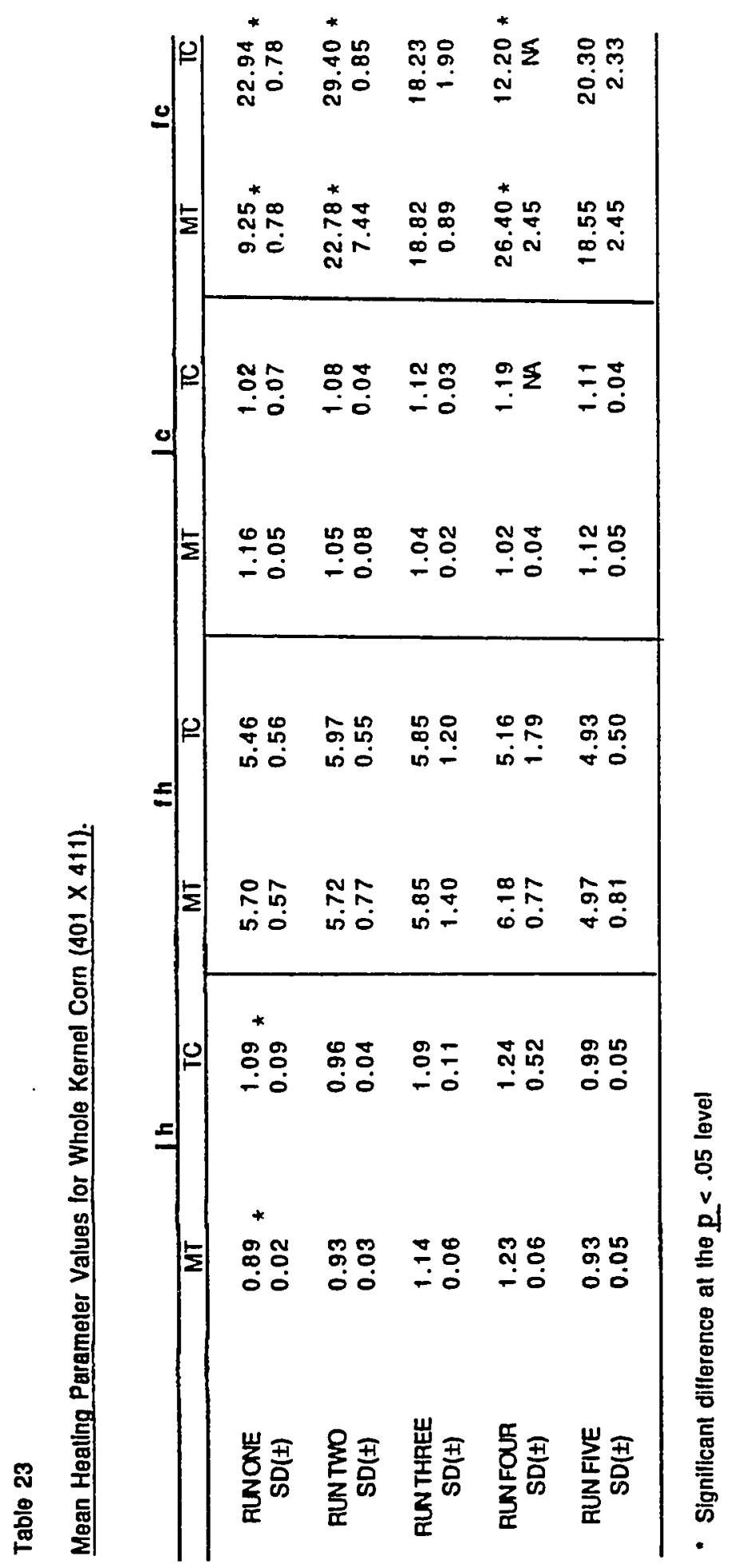




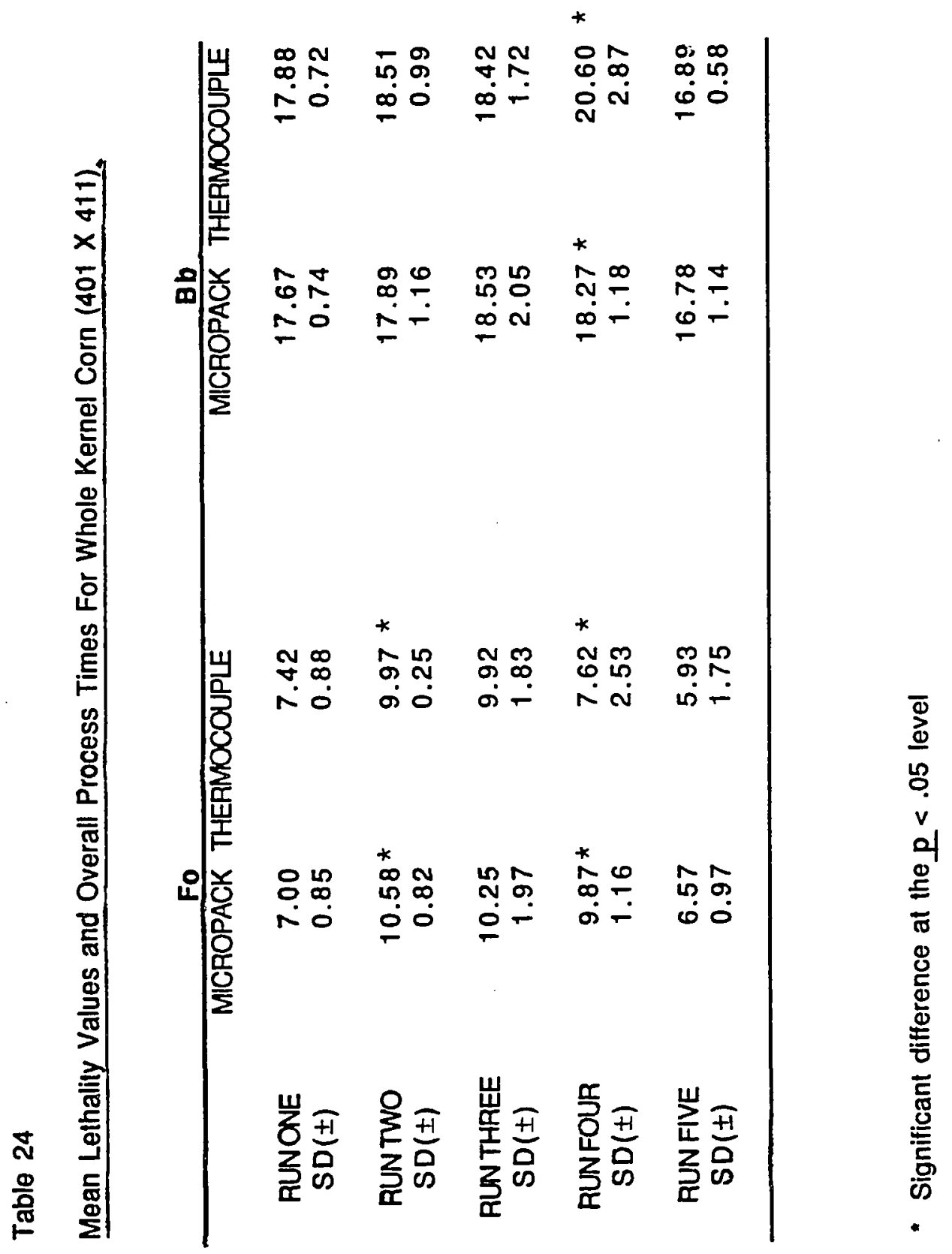




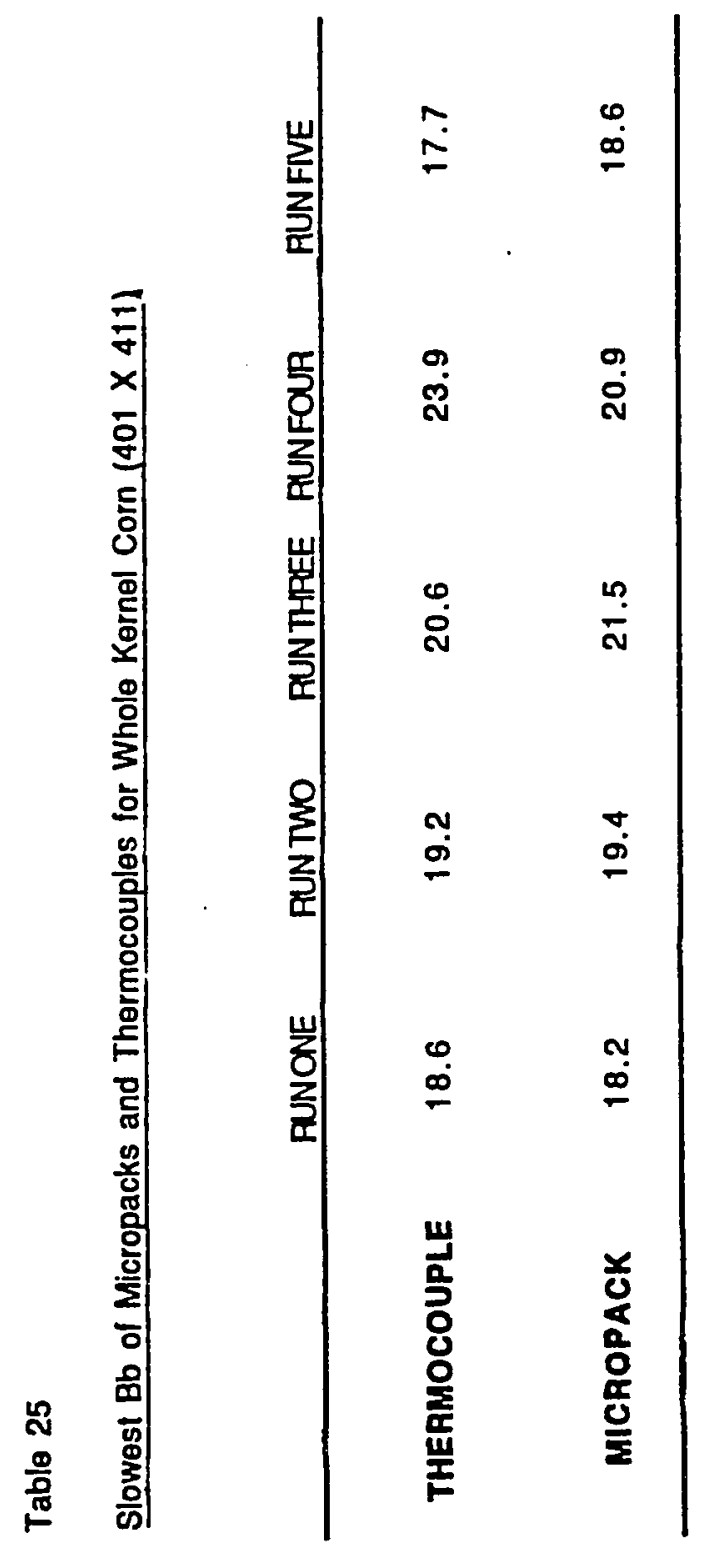


time than thermocouples but achieved more lethality than the thermocouples.

Whole Kernel Corn $(603 \times 700)$

Tables 26 and 27 show $\mathrm{jh}$ values were significantly different at the $p<.05$ level in all four runs, and in three of the four runs the thermocouple $\mathrm{jh}$ values were larger. It was hypothesized that the smaller jh values associated with the Micropacks could be due to the "extenders." The stainless steel mass of the "extenders" may have heated up the whole kernel corn more quickly than the whole kernel corn with thermocouples, which would shorten the jh values. The fh values were not significantly different at the $p<.05$ level in any of the runs. The jc values were significantly larger in runs two and three, and in three of the four runs the Micropack values were larger. The fc values were significantly different at the $p<.05$ level in runs two and three, and in all four runs the thermocouple values were larger (refer to Appendix $\mathrm{F}$ for original tables and $\mathrm{n}$ values). The Fo values were significantly different in runs three and four, and in all four runs the Fo values were larger for the thermocouple data. There were no significant differences in $\mathrm{Bb}$; however, in three of the four runs the $\mathrm{Bb}$ were longer for the Micropacks.

Table 28 compares the slowest $\mathrm{Bb}$ of the Micropacks and thermocouples for each run and shows that in all four runs the Micropacks reported the slowest $\mathrm{Bb}$, but not significantly at the 


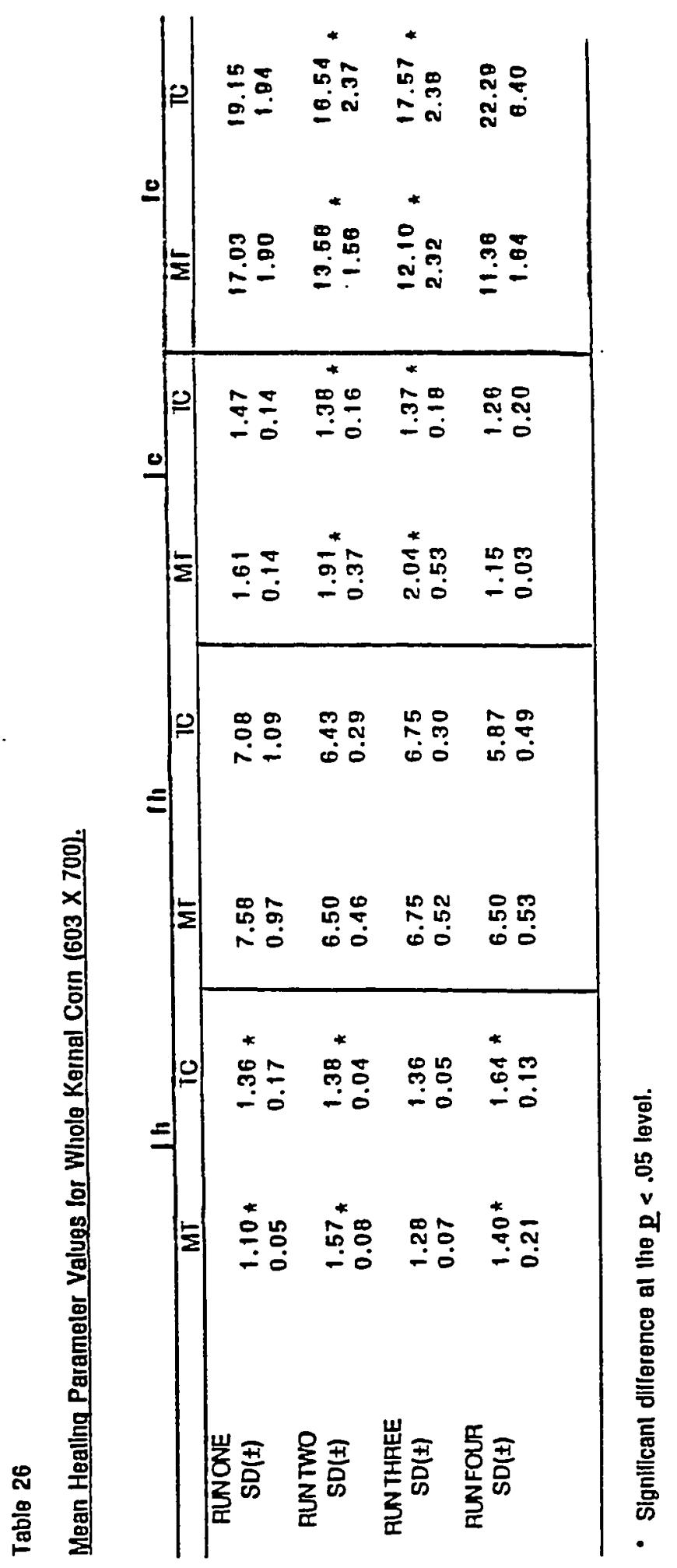




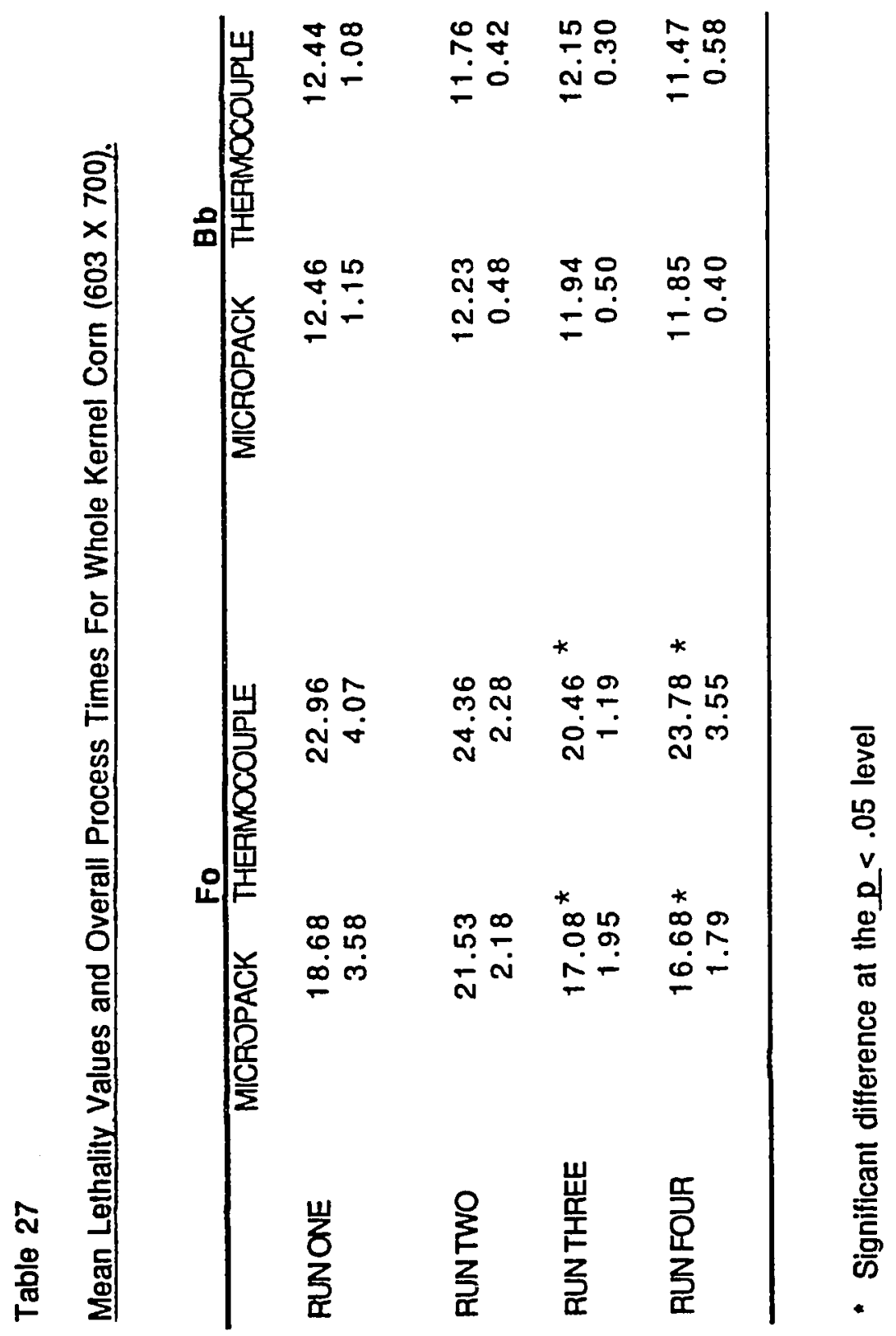


$p<.05$ level in any of the four runs. These were the only set of runs where the Micropacks were more conservative in all four runs. The overall results from these tests show the Micropacks to have shorter jh values, larger jc values, shorter fc values, lower Fo values, and longer $\mathrm{Bb}$ values. The Micropacks do not appear to act as heat sinks in $603 \times 700$ can size. Based on the results of these runs it appears Micropacks and thermocouples behave significantly different from each other at the $\mathrm{p}<.05$ level. The difference may be due to the "extenders" which were only used in 603 X 700 can size.

\section{Evaporated Milk}

Tables 29 and 30 showed no significant differences in $\mathrm{jh}$, fh, or jc values; however, in all three runs the fh values were shorter in the Micropack which was also reported for viscon (Underferth, 1987; Lesley, 1986) (refer to Appendix $G$ for original tables and $n$ values). The jc values were larger for the Micropacks in all three runs. The fc values were significantly different in run two, and no significant differences were found for $\mathrm{Fo}$ and $\mathrm{Bb}$ values;however, in all three runs the $\mathrm{Bb}$ values were slightly shorter in the Micropack data. Table 31 compares the slowest $\mathrm{Bb}$ of the Micropacks and thermocouples for each run and shows that neither the Micropacks nor thermocouples consistently reported the slowest $\mathrm{Bb}$. The Micropack recording ends appeared to act as insulating barriers in evaporated milk in $300 \times 407$ can size based on the larger jh values. The lower fh values could be a result of the effective heat conduction 
Table 28

Slowest Bb of Micropacks and Thermocouples for Whole Kemel Corn $(603 \times 700)$.

RUNONE RUNTWO RUNTHPEE RUNFOUR

$\begin{array}{lllll}\text { THERMOCOUPLE } & 14.0 & 12.1 & 12.6 & 12.2\end{array}$

$\begin{array}{lllll}\text { MICROPACK } & 14.1 & 13.0 & 12.6 & 12.3\end{array}$




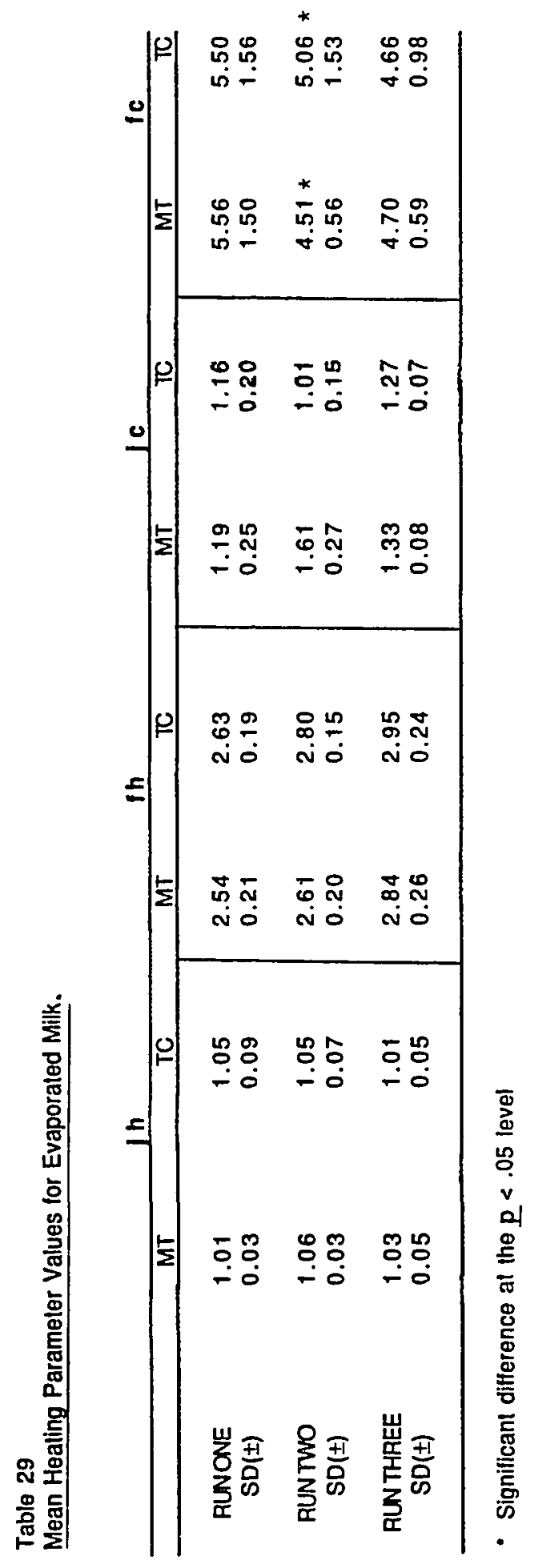




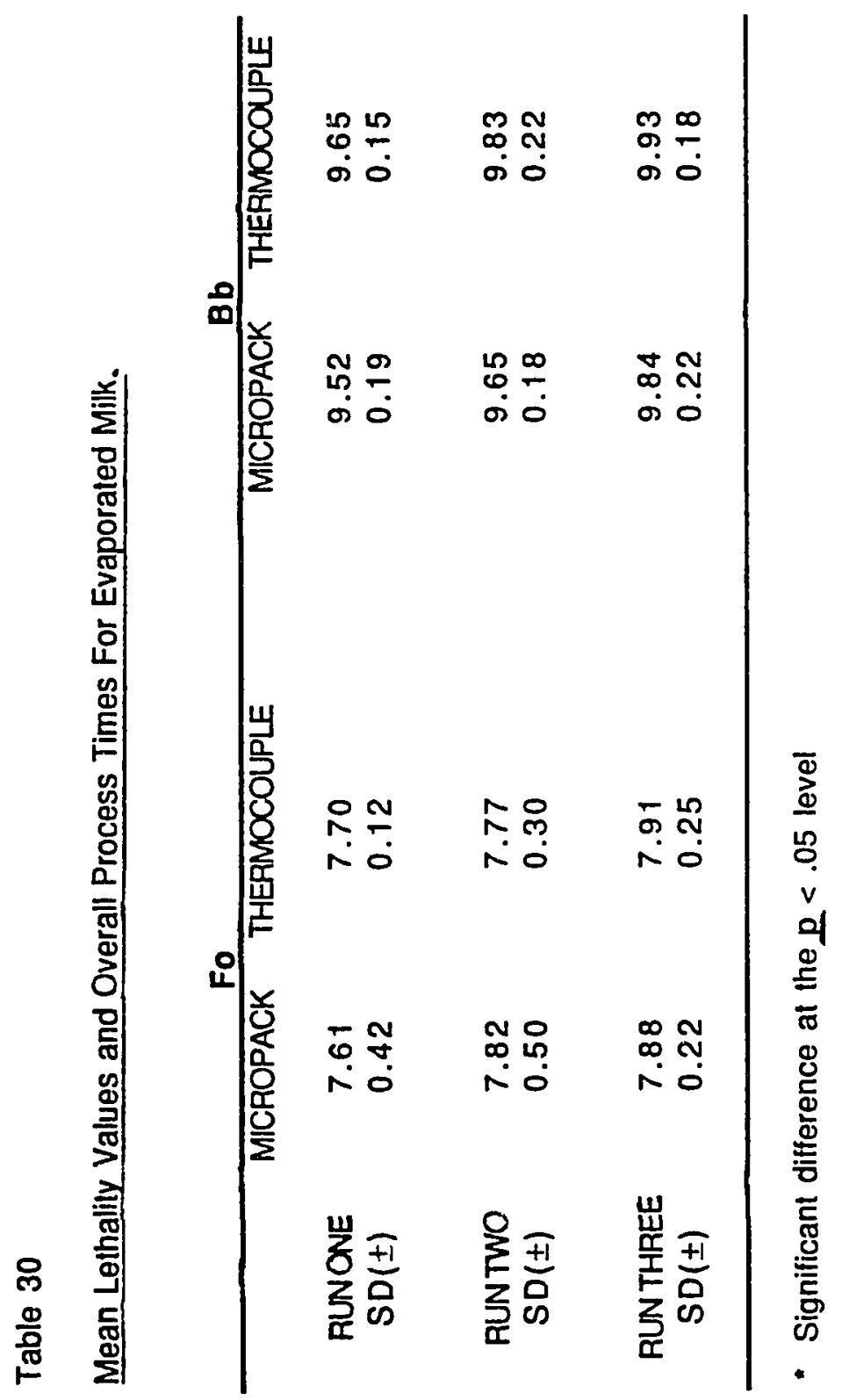


Table 31

Slowest Bb of Micropacks and Thermocouples for Evaporated Milk.

RUNONE RUNTWO RUNTHREE

$\begin{array}{llll}\text { THERMOCOUPLE } & 9.8 & 10.1 & 10.1\end{array}$

$\begin{array}{llll}\text { MICROPACK } & 9.9 & 10.0 & 10.1\end{array}$


of the stainless steel shell of the Micropacks. Based on these findings Micropacks and thermocouples behaved significantly different from each other at the $\mathrm{p}<.05$ level.

Conclusions

The results from the heat penetration tests showed that the recording end of the Micropacks acted as insulating barriers during the early stages of the heat penetration tests in homogeneous liquids with non discrete particles. The stainless steel shell of the Micropacks caused a lag in the heat penetration into the product. This lag resulted in larger $\mathrm{jh}$ values in both viscon and evaporated milk. As the Micropacks approached retort temperature they in effect came to temperature equilibrium and began to transfer heat into the viscon and evaporated milk. This resulted in smaller $\mathrm{f} 2$ values for viscon run under stationary conditions and smaller fh values in evaporated milk and viscon run under axial rotational conditions.

The $x b h$ values were significantly larger at the $p<.05$ level in Micropacks. It appeared to take the Micropacks longer to reach the same temperature that thermocouples were at when the break in the heating curve occurred.

The jc and fc values showed no consistent pattern in any of the runs except the whole kernel corn in $603 \times 700$ can size. In those runs the jc were larger and fc smaller for the Micropacks. In addition the Micropacks exhibited smaller $\mathrm{jh}$ values in the $603 \mathrm{X} 700$ 
can size. These differences may have been due to the heat transfer properties of the Micropacks and "extenders" themselves.

The whole kernel corn tests showed no significant differences at the $\mathfrak{p}<.05$ level for runs in the $300 \times 407$ can size. The data for 401 $\mathrm{X} 411$ can size was just the opposite of those run in $603 \times 700$ can size. The $\mathrm{jh}$ values were larger, Fo values were larger, and $\mathrm{Bb}$ values shorter for the Micropacks in tests run in 401 X 411 can size; however, jh values were smaller, Fo values smaller, and $\mathrm{Bb}$ values larger for Micropacks in tests run in 603 X 700 can size.

The ranges of the heat penetration parameters for both Micropacks and thermocouples were not significantly different in most runs, "which" supports apparent precision and reproducibility for both Micropacks and thermocouples. Neither Micropacks nor thermocouples consistently reported longer $\mathrm{Bb}$ values, except in whole kernel corn runs in $603 \times 700$ can size where Micropacks reported longer $\mathrm{Bb}$ values. This may in part be due to the stainless steel mass of the "extenders."

\section{Implications for Further Research}

More research needs to be conducted comparing Micropacks to thermocouples in larger can sizes using various food systems. The differences between the $401 \times 411$ and $603 \times 700$ can sizes cannot be adequately explained. The "extenders" used in the $603 \times 700$ can size could be affecting the early stages of the heat penetration tests by acting as a stir bar which would help heat up the product faster. 
However, the longer $\mathrm{Bb}$ values indicate that possibly the air space in the hollow "extenders" could be acting as insulation which would slow down the heating of the product. Also, the fact that the containers with Micropacks had less product in them than did the containers with thermocouples may have had some effect on the heating parameters.

Spore count reduction studies and inoculated pack studies need to be conducted to verify if the lethality values, indicated by Fo values of the Micropacks, can be reproduced microbiologically. 


\section{References}

Anonymous (1972). Avicel RC microcrystalline cellulose in canned foods. Bulletin RC-31, Philadelphia: FMC Corp.

Anonymous (1977). Carrageenan. (Marine Colloids Monograph No. 1). Chicago: FMC Corp.

Anonymous (1978). O. F. Ecklund custom thermocouples information sheet. (Available from Custom Thermocouples, P. O. Box 279, Cape Coral, FL. 33910).

Ball C. O. (1923). Thermal process time for canned food. Bulletin National Research Council. 7, Part1, No. 37.

Ball Corporation Electronic Systems Division Industrial Instruments. (1987). Operators manual for Datatrace Temp TM (version 1.02). Westminster, CO: Author.

Ball, C. O. (1928). Mathematical solution of problems on thermal processing of canned food. University of California Published in Public Health 1, No. 2(15), 245.

Ball, C. O., \& Olson, F. C. (1957). Sterilization in food technology. New York: McGraw Hill.

Bigelow, W. D., Bohart, G. S., Richardson, A. C., \& Ball C. O. (1920). Heat penetration in processing canned foods. Bulletin No. 16- $\mathrm{L}$. Research Laboratory National Canners Association, Washington, D.C.

Bitting, (1912). U.S. Department of Agriculture. Bureau of Chemical Bulletin 151.

Cross, R. C. \& Lesley, D. R. (1985). Self-contained microcircuit probe acquires and records food-process temperature data. Food Technology, 39(12), 36-41. 
Ecklund, O. F. (1949). Apparatus for the measurement of the rate of heat penetration in canned foods. Food Technology, 3, 231- 233.

Fagerson, I. S. \& Esselen, W. B., Jr. (1950). Heat transfer in commercial glass containers during thermal processing. Food Technology, 4(10), 411.

Fagerson, I. S., Esselen, W. B., Jr., \& Licciardello,P. (1951). Heat transfer in commercial glass containers during thermal processing. II. Distribution in foods heating by convection. Food Technology. $5(6), 261$.

Gillespy, T. G. (1951). Estimation of sterilizing values of processes as applied to canned foods. I. Packs heating by conduction. Journal of Food Science, $2,107$.

Hardt, P. K., Adams, H.W., \& Henderson, J. M. (1980). Simulation of the thermal properties of cream style corn. Journal of Food Science, 45(4), 840-843.

Hicks, E. W. (1951). On the evaluation of canning process. Food Technology, 5, 134-141.

Jackson, J. M. \& Olson, F. C. (1940). Thermal processing of canned foods in tin containers. IV. Studies of the mechanisms of heat transfer within the container. Food Research, 5, 409-421.

Lesley, D. (1986). [Comparison of datatrace micropacks to O. F. Ecklund thermocouples for acquisition of heat penetration data in bentonite solutions]. Unpublished raw data.

Lesley, D. (1987, a). [Comparison of datatrace micropack tracers to O. F. Ecklund thermocouples for the acquisition of heat penetration data in canned food products]. Unpublished raw data.

Lesley, D. (1987, b). Evaluation of a temperature sensing device for heat penetration data acquisition in food products. Paper presented at the Institute of Food Technologists, Las Vegas, NV. 
McConnell (1952). Effect of a drop in a retort temperature upon the lethality of processes for convection heating products. Food Technology, $6(2), 76$.

National Canners Association Research Labs. (1968). Laboratory manual for food canners and processors, vol. 1. Westport, CT: Avi.

Okada, M. (1940). Natural convection in can-shaped space, referred to the laws of similitude. Japanese Society Scientific Fisheries Bulletin. 9, 64 .

Olson, F. C. \& Stevens, H. P. (1939). Thermal processing of canned foods in tin containers II. Nomograms for graphic calculation of thermal process for non-acid canned foods exhibiting straight-line simi-logarithmic heating curves. Food Research, 4(1).

Oyster, C. K., Hanten, W. P., \& Llorens, L. A. (1987). Introduction to research: A guide for the health science professional. Philadelphia: J. B. Lippincott.

Patashnik (1953). A simplified procedure for thermal process evaluation. Food Technology 7, 1-6.

Shultz, O. T. \& Olson, F. C. (1938). Thermal processing of canned foods in tin containers. I. Variation of heating rate with can size for products heating by convection. Food Research, 3, 647.

Stumbo, C. R. (1948). Bacteriological considerations relating to process evaluation. Food Technology, 2, 115.

Stumbo, C. R. (1949). Further considerations relating to evaluation of thermal processes for foods. Food Technology.3. 126-131.

Stumbo, C. R. (1953). New procedures for evaluating thermal processes for foods in cylindrical containers. Food Technology, 7 , 309-315. 
Stumbo, C. R. (1973). Thermobacteriology in food processing. (2nd ed.) New York: Academic Press.

Underferth, J. (1987). [Datatrace ${ }^{\mathrm{TM}}$ temperature measurement system]. Unpublished raw data. 
Appendix A: Ë̈AMPLE COMPUTER PLOT OF DATA

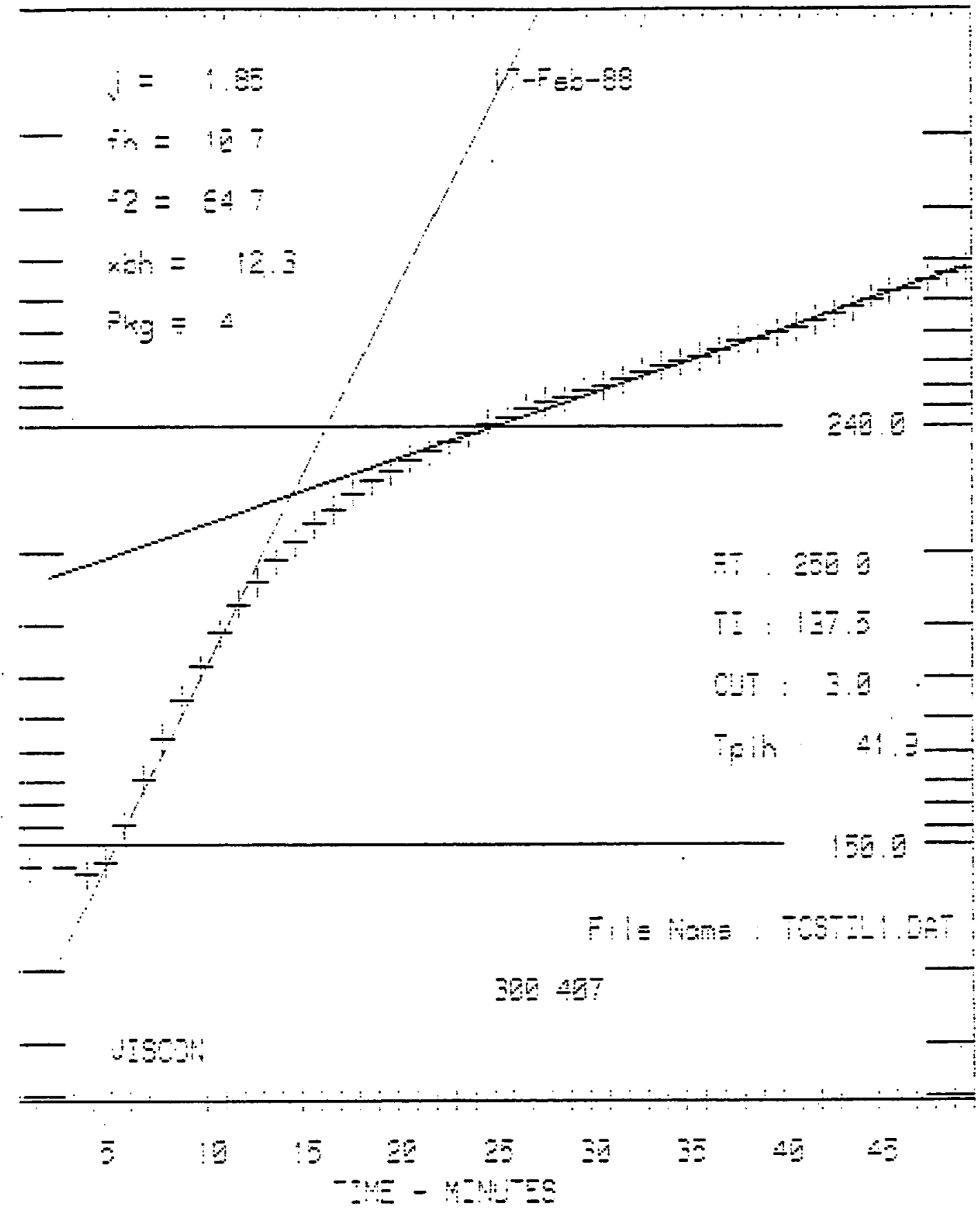




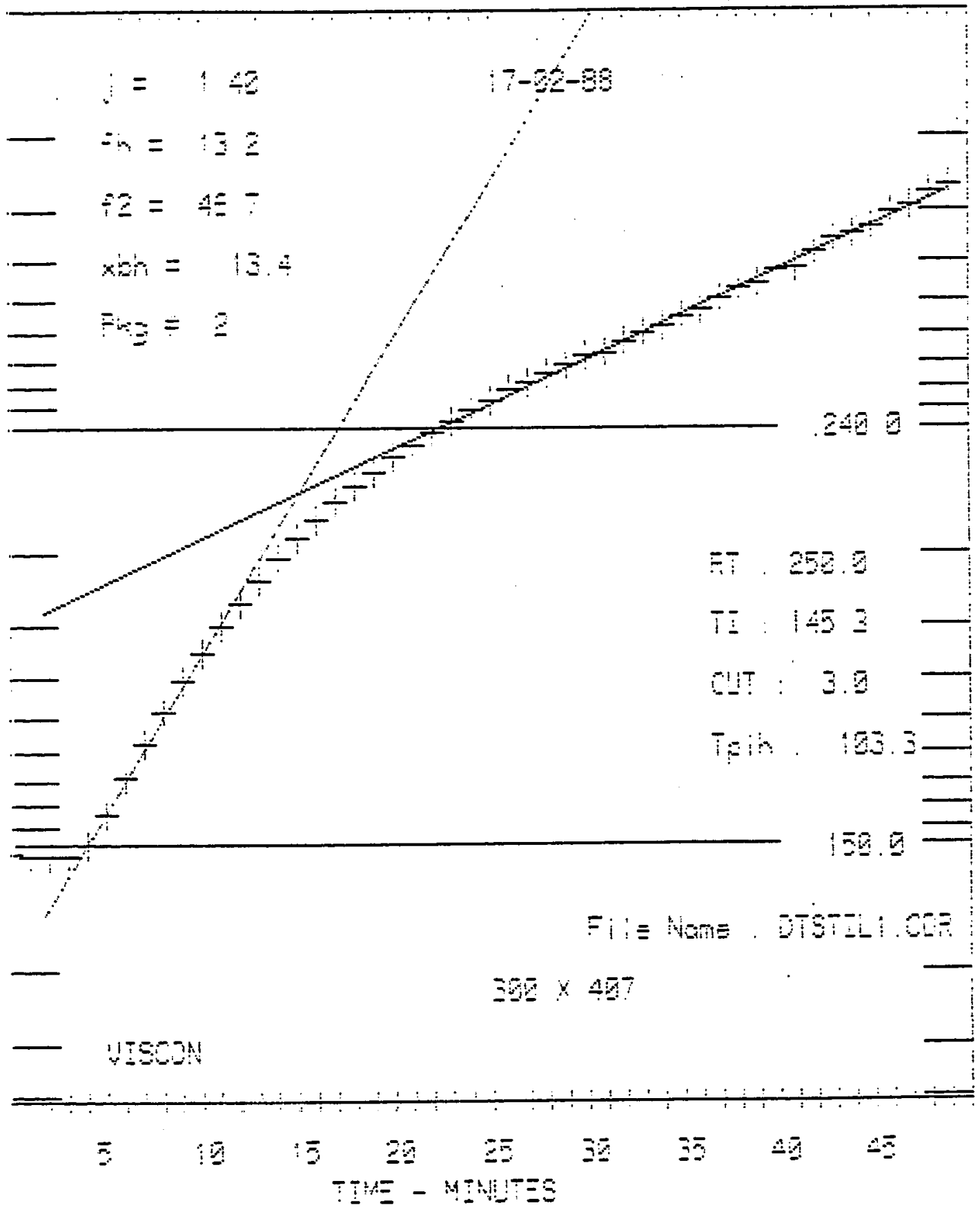




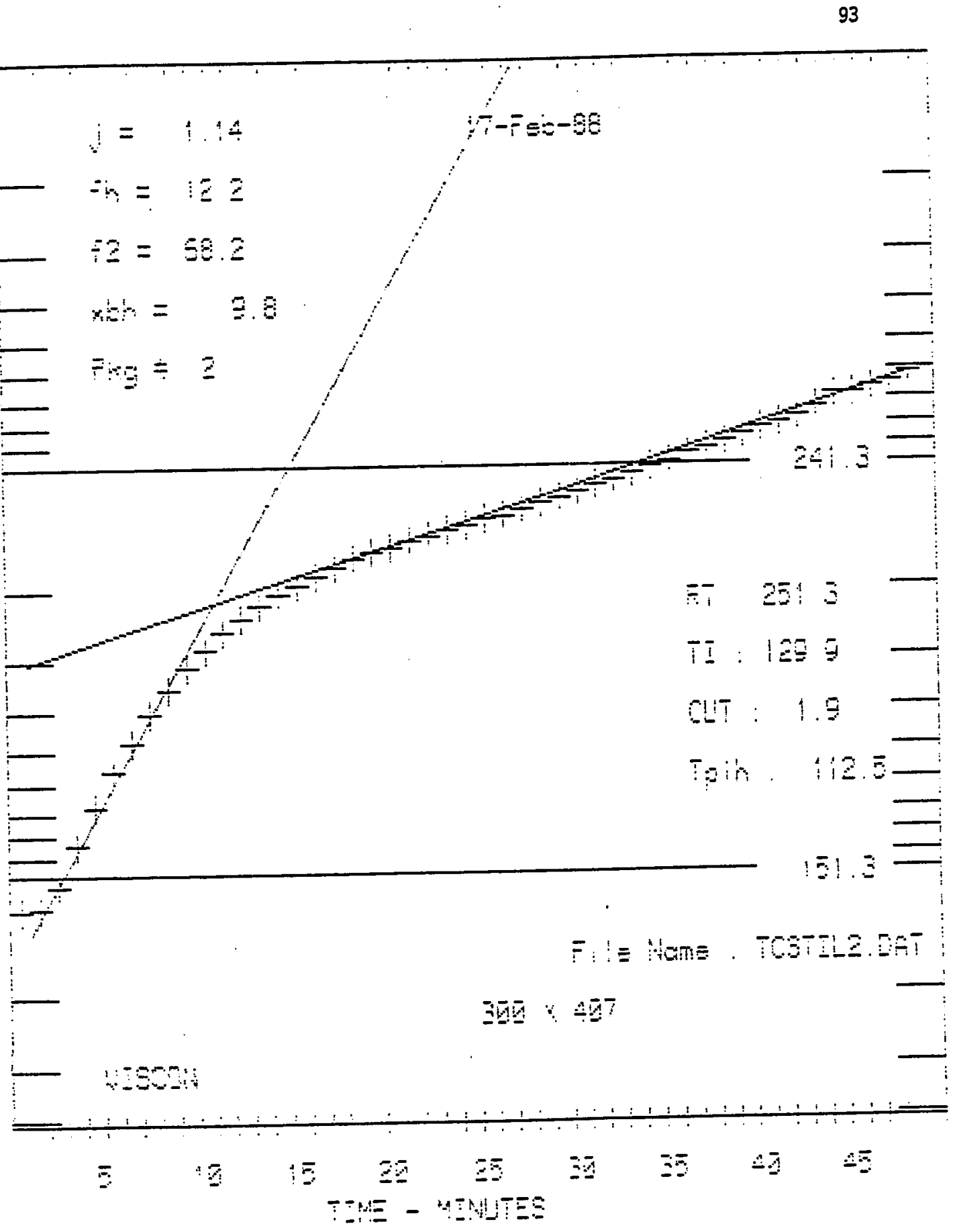




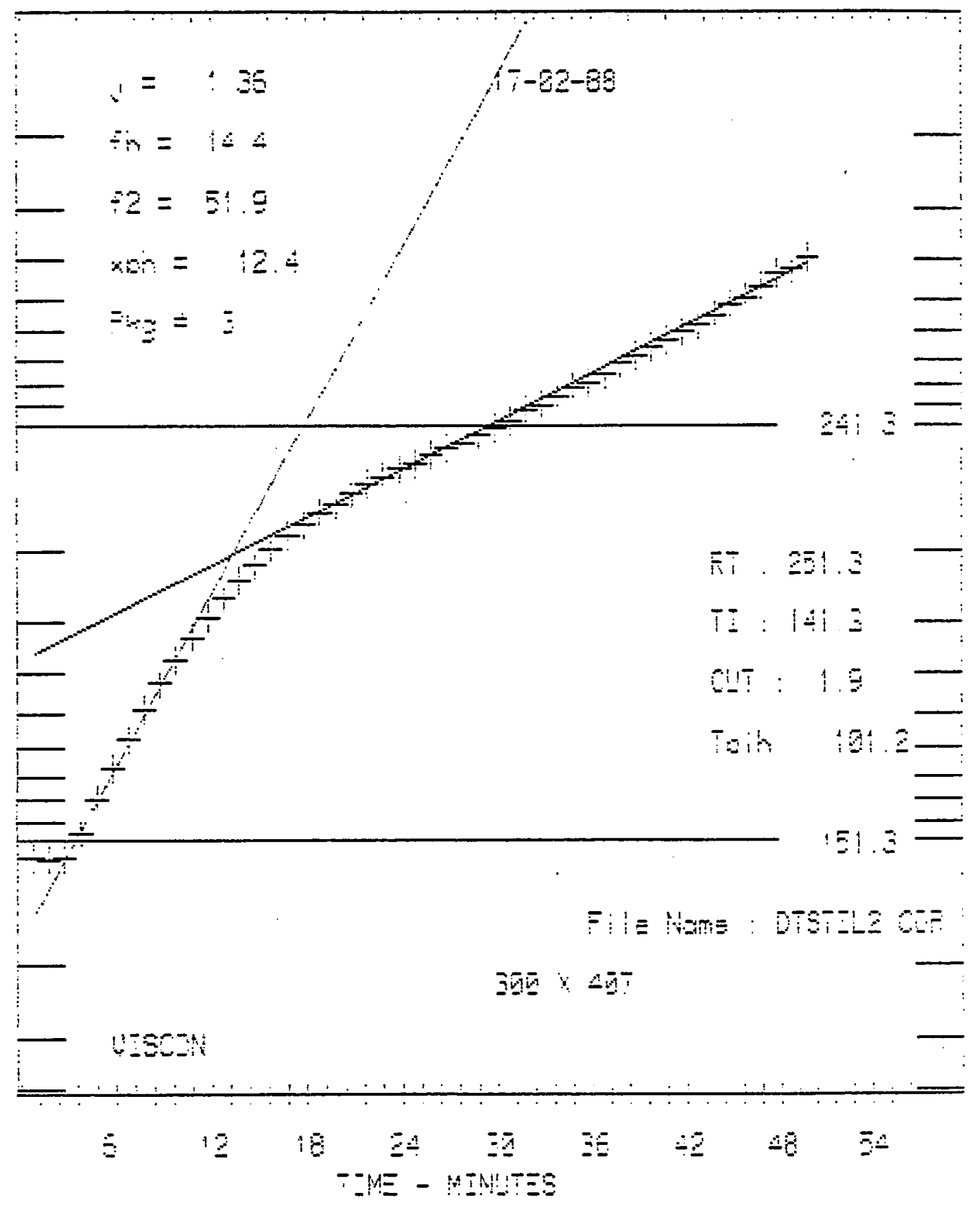




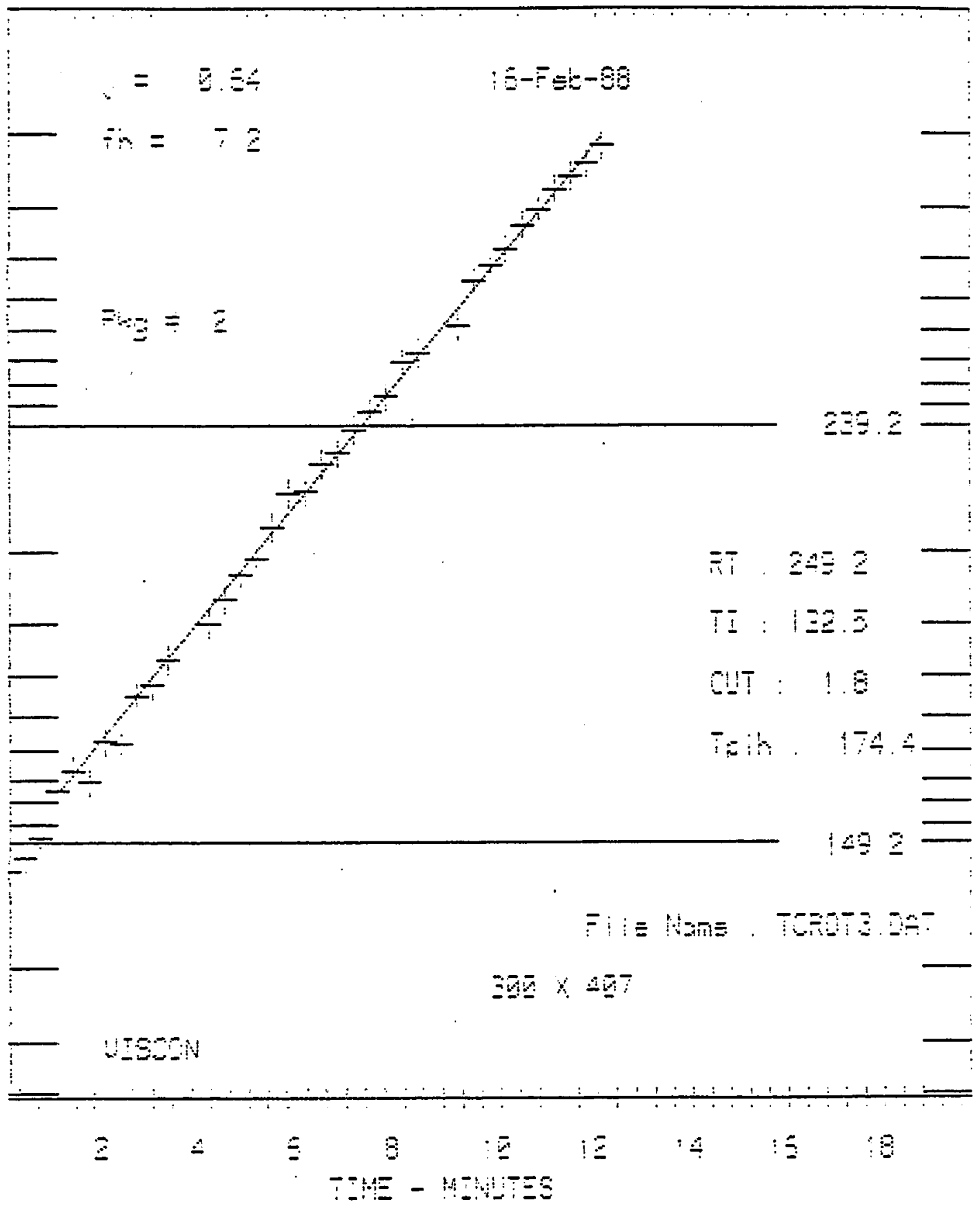




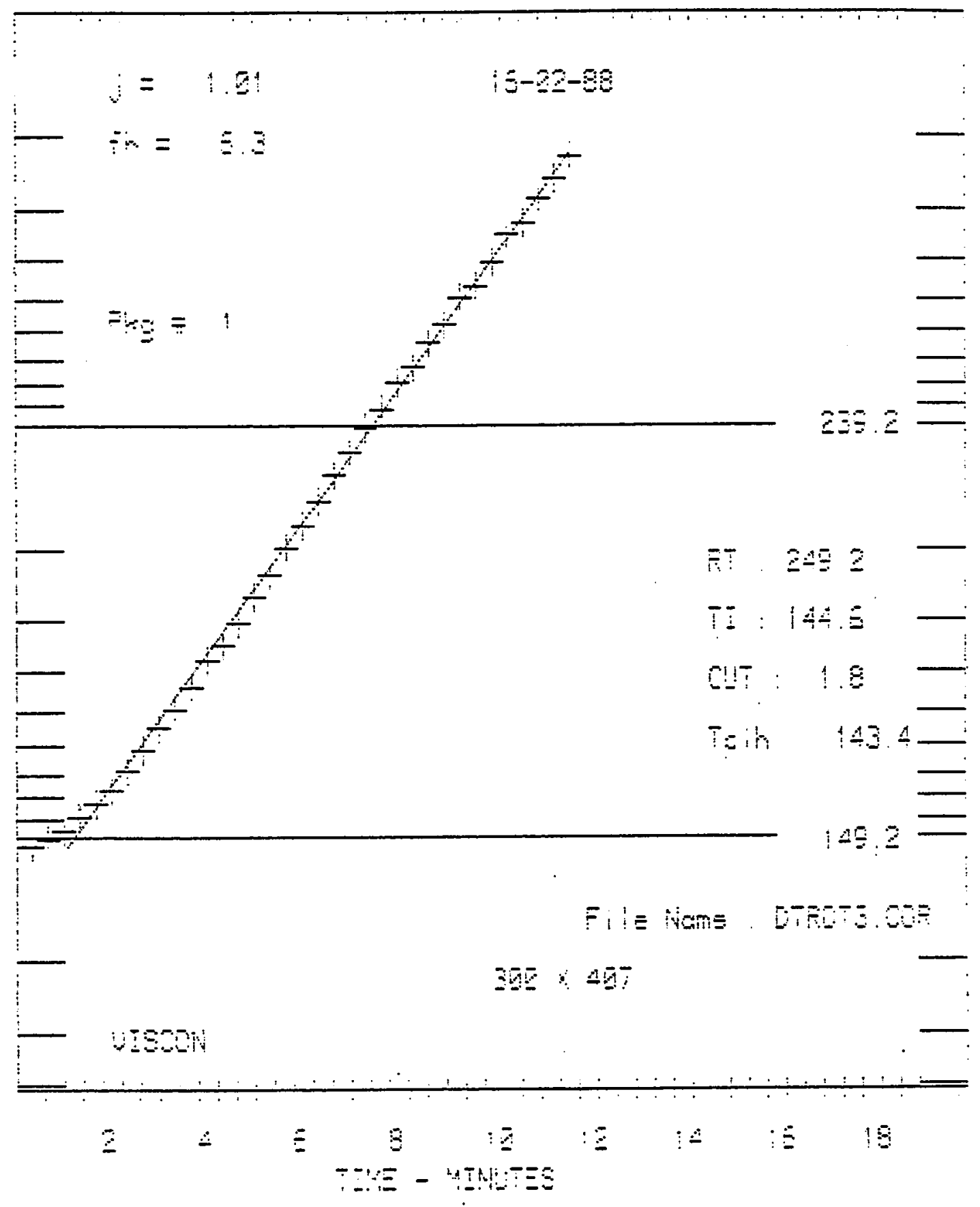




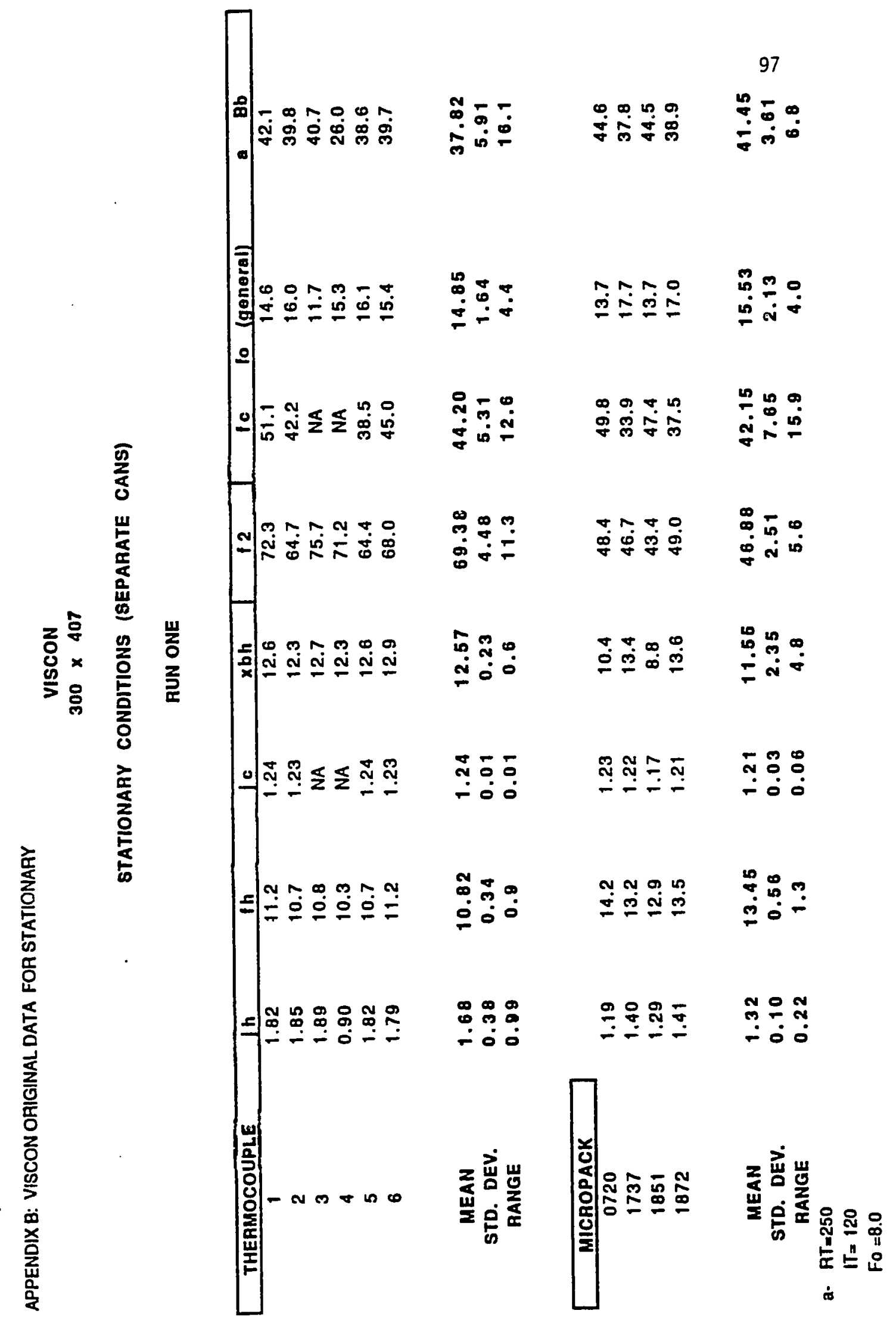




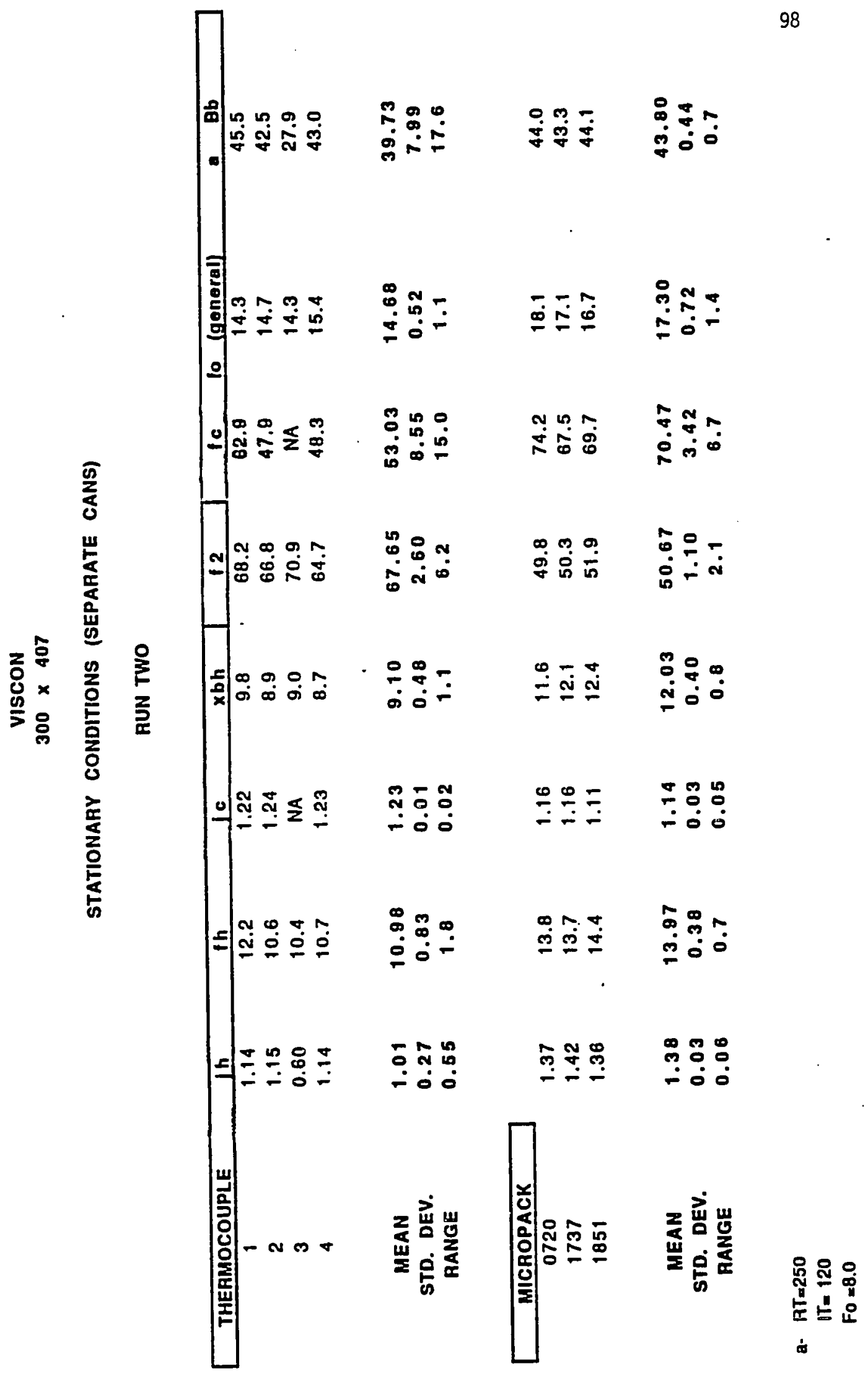




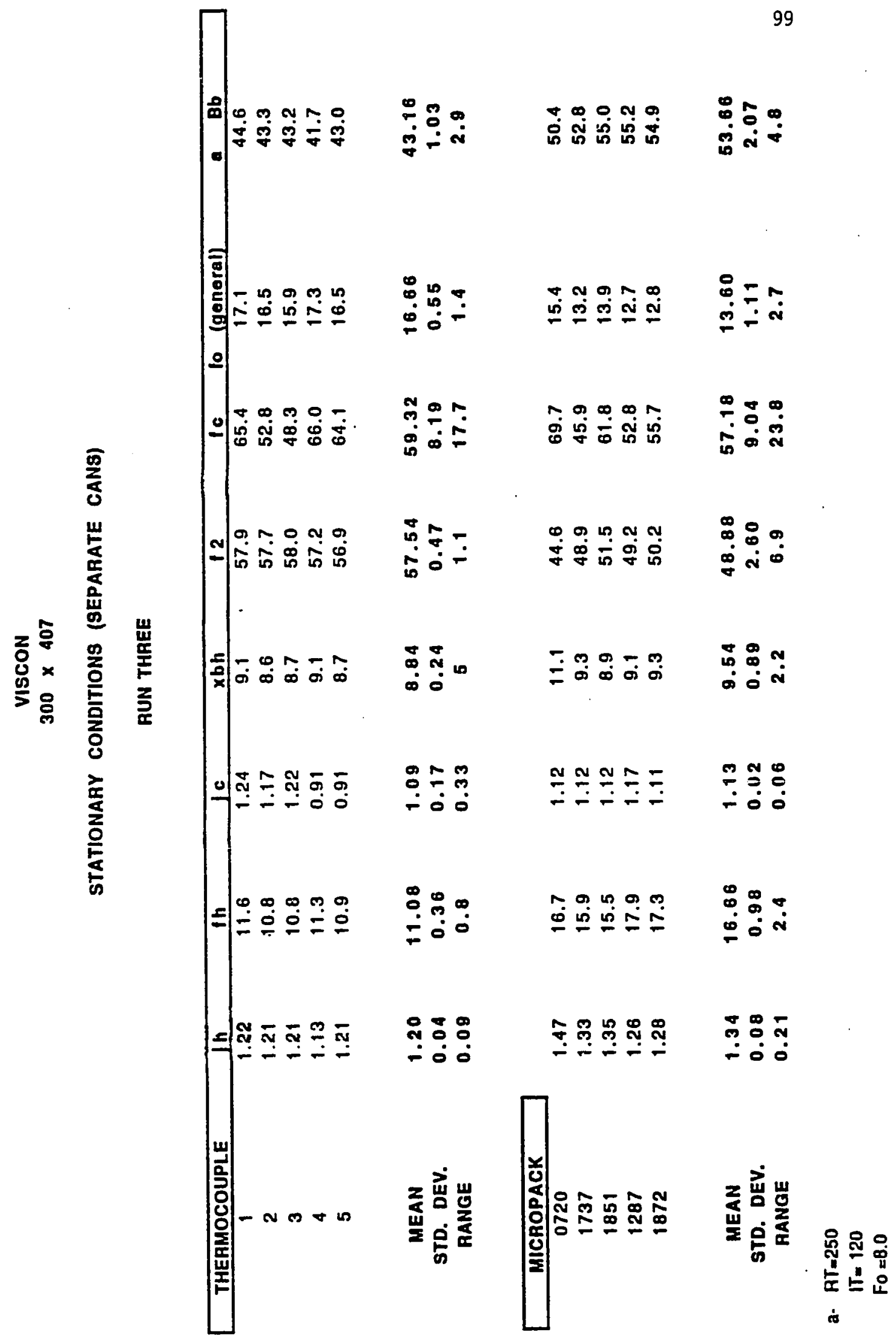




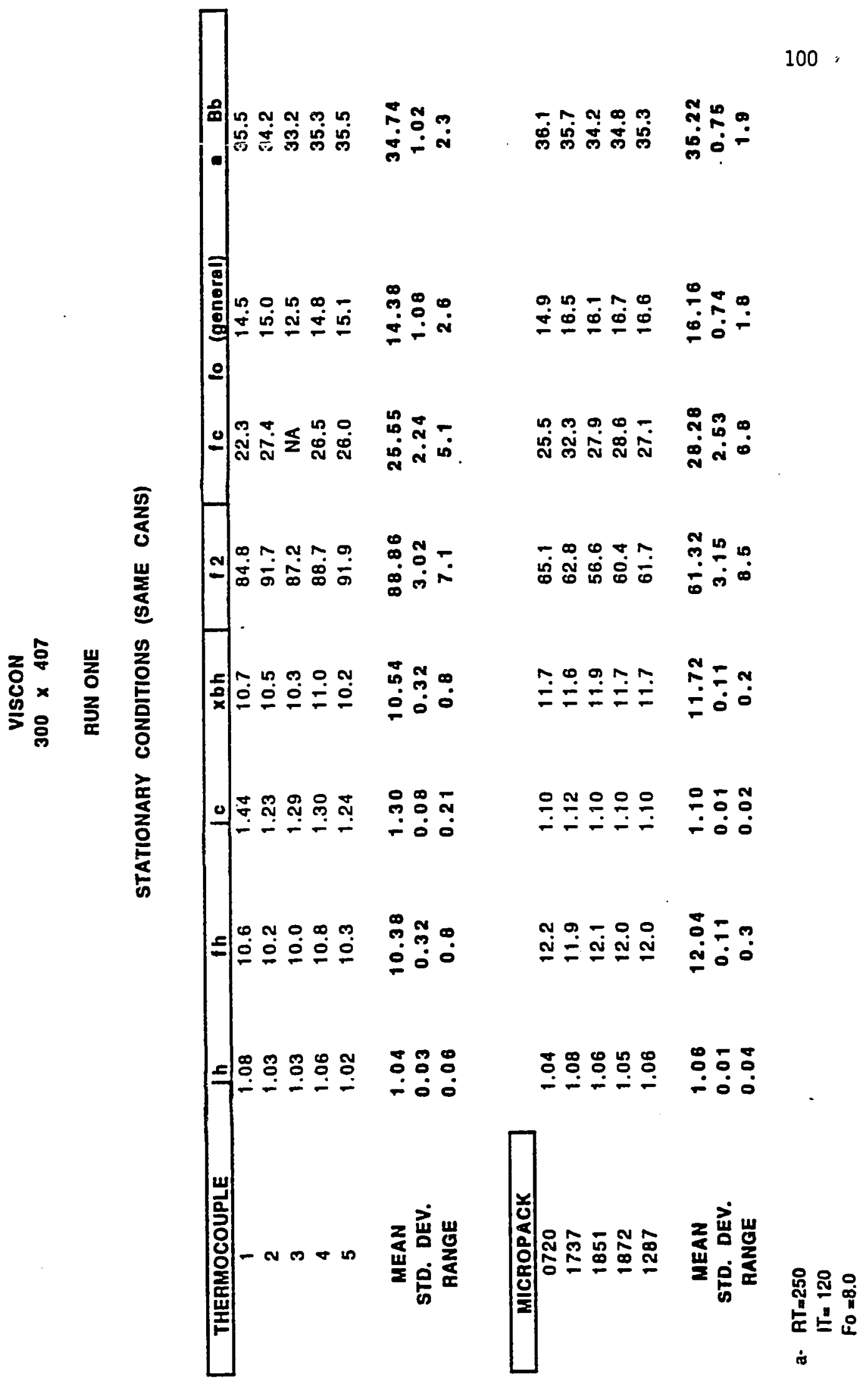




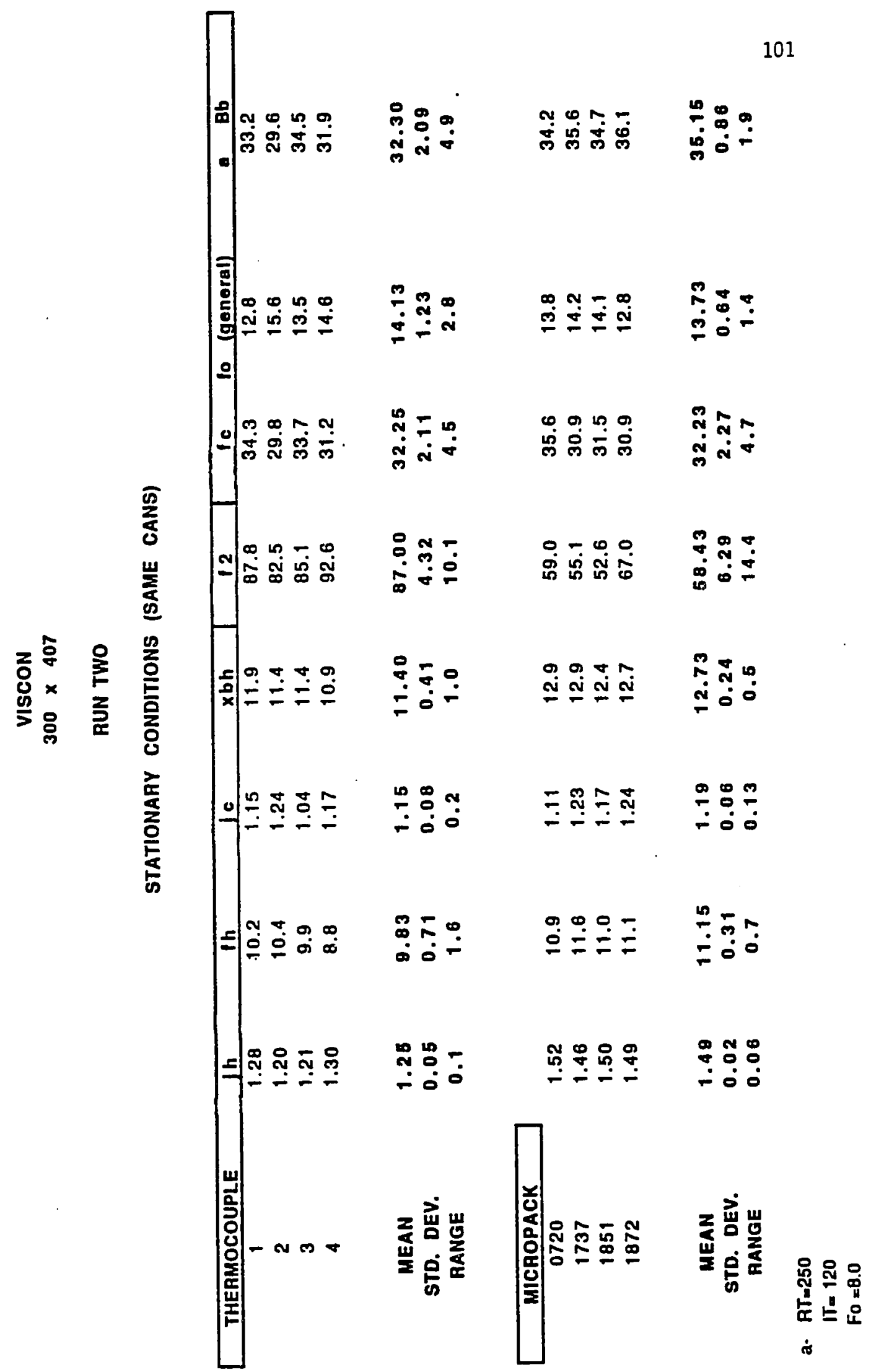




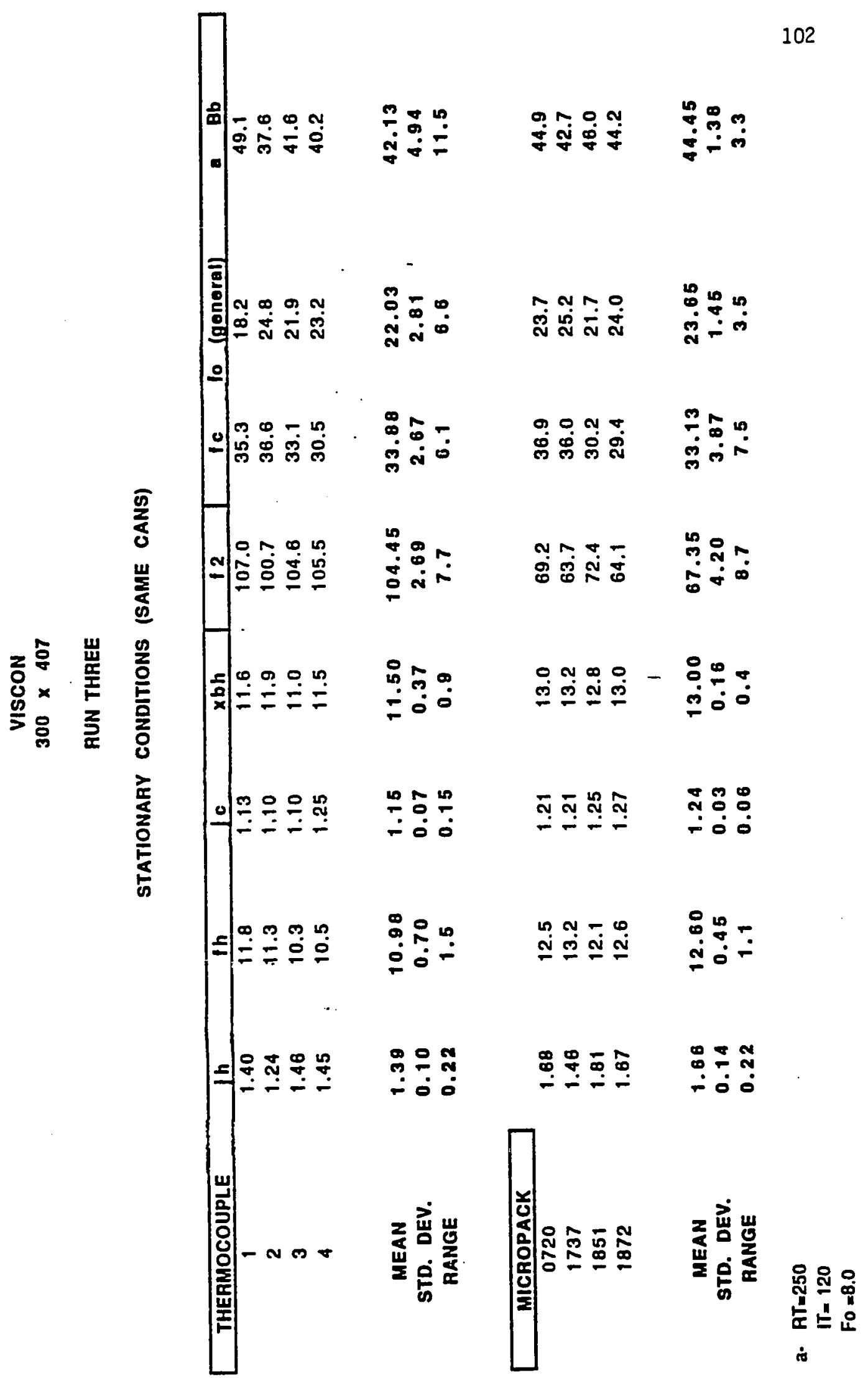




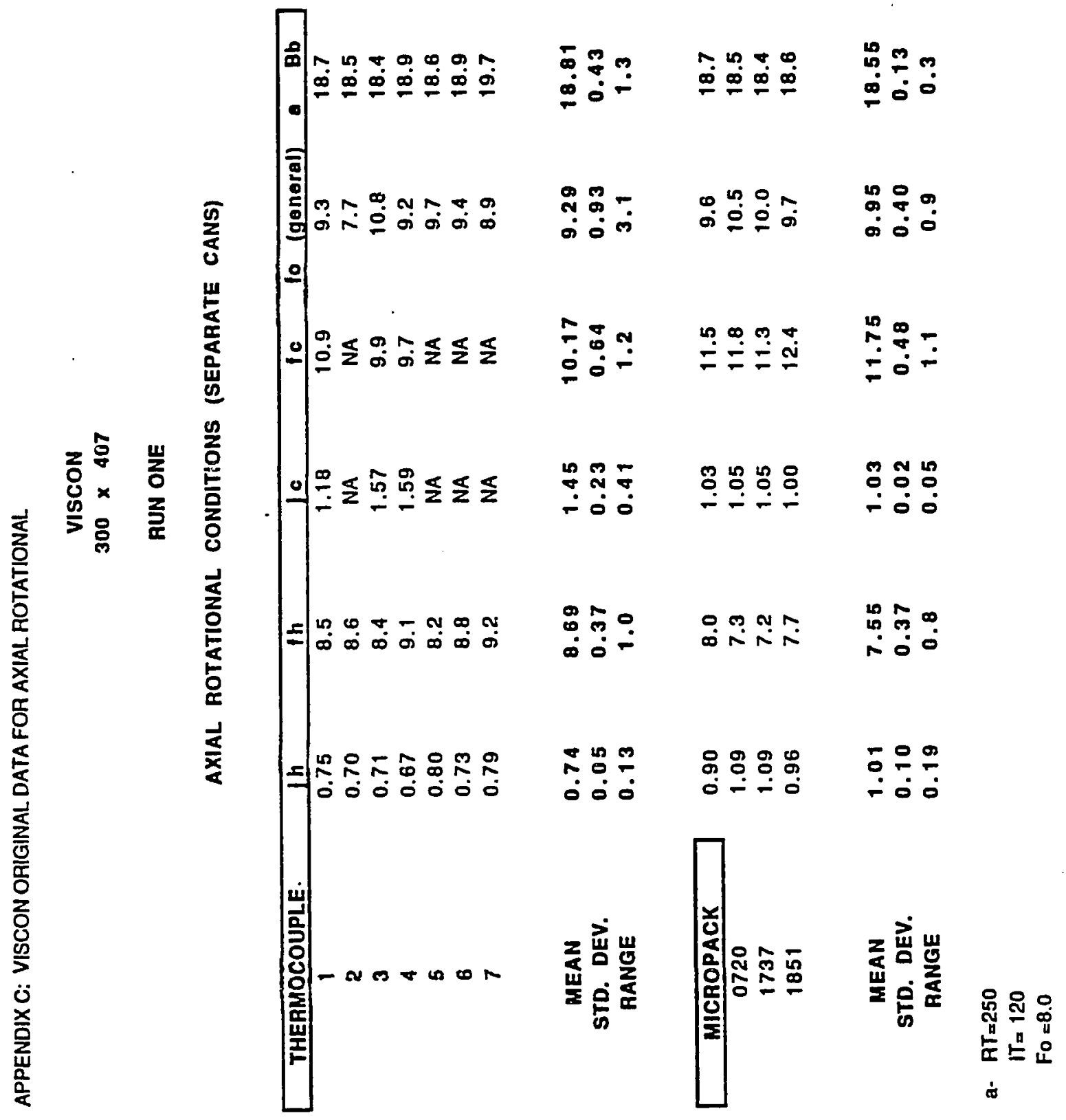




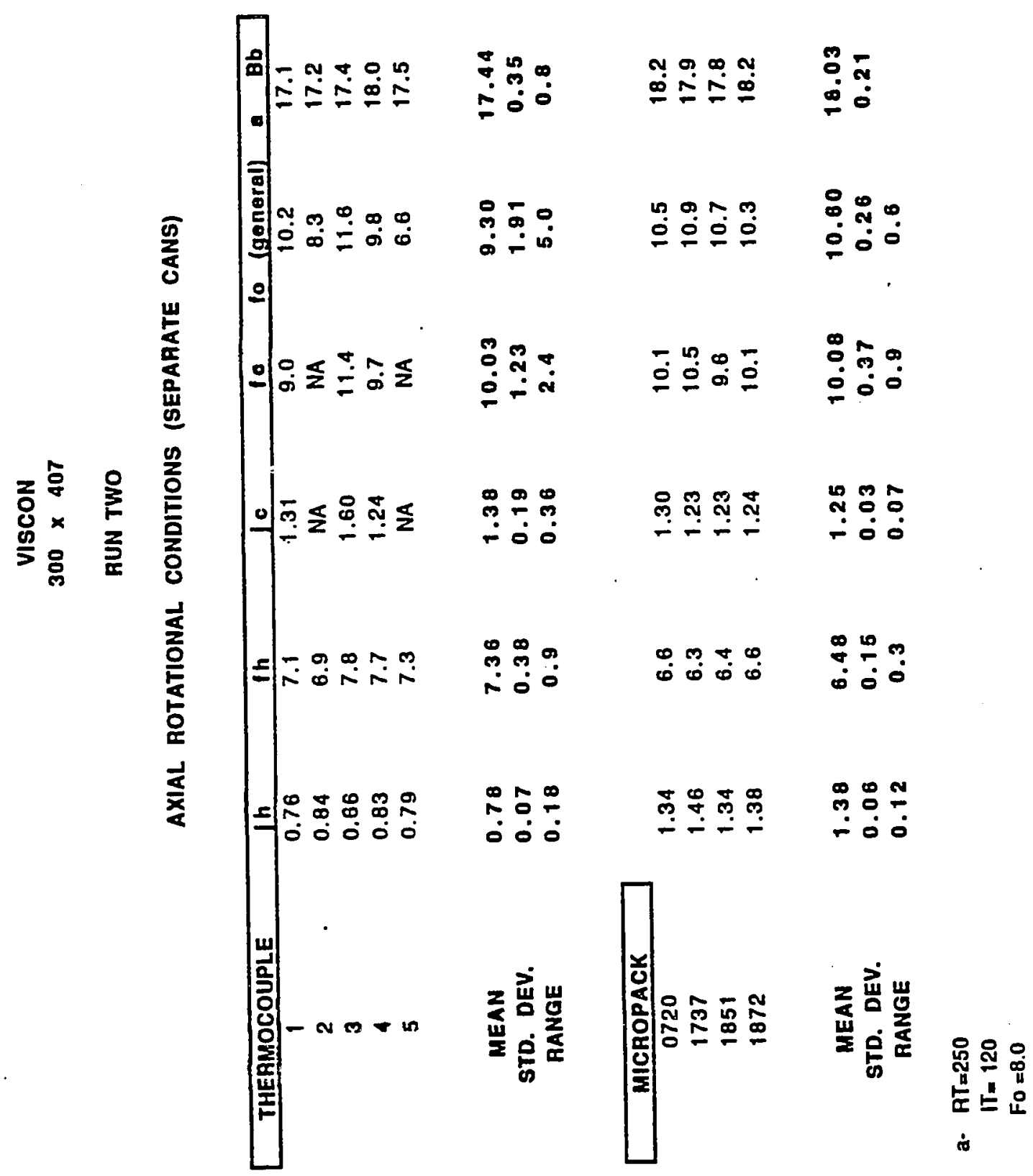




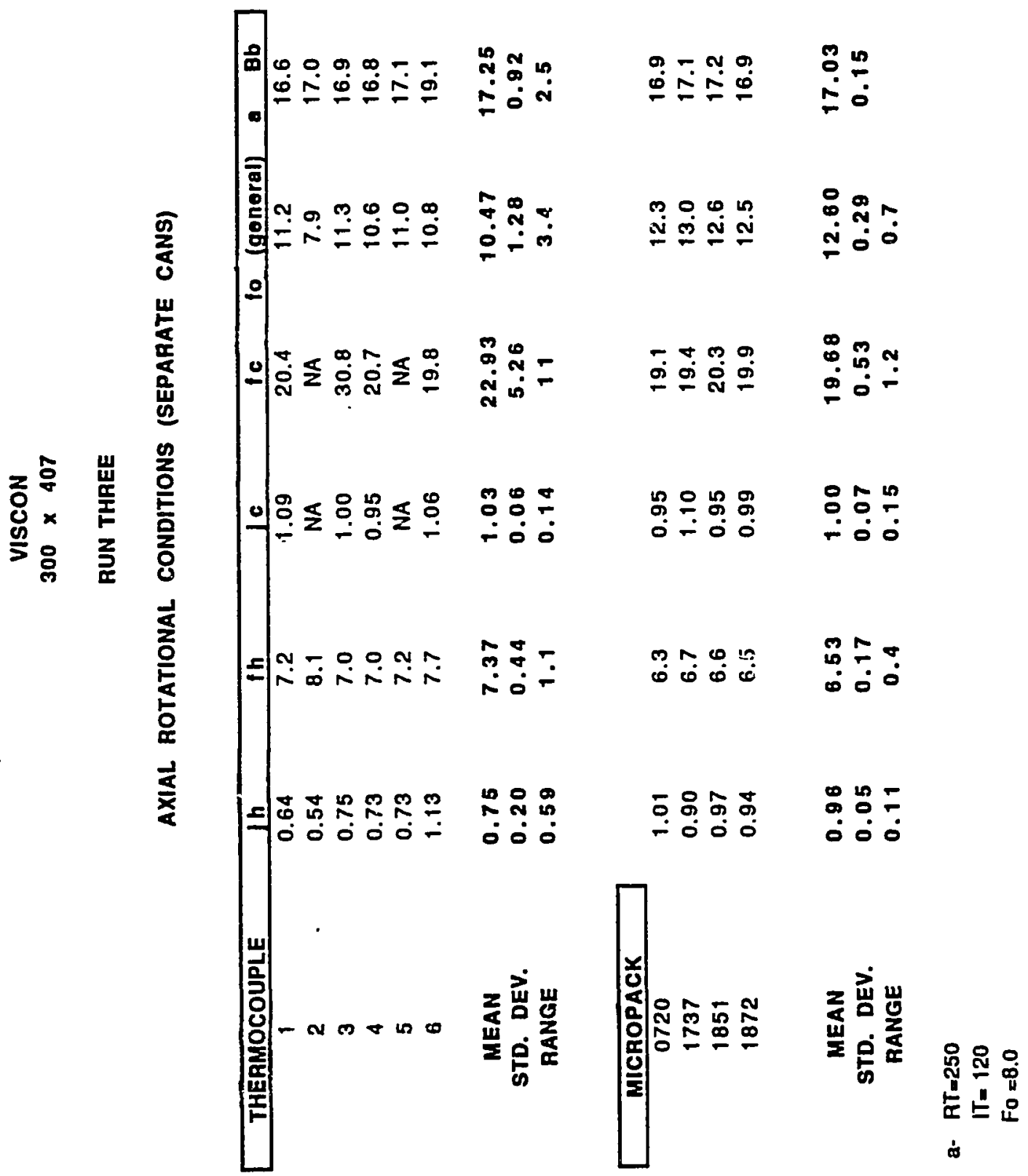




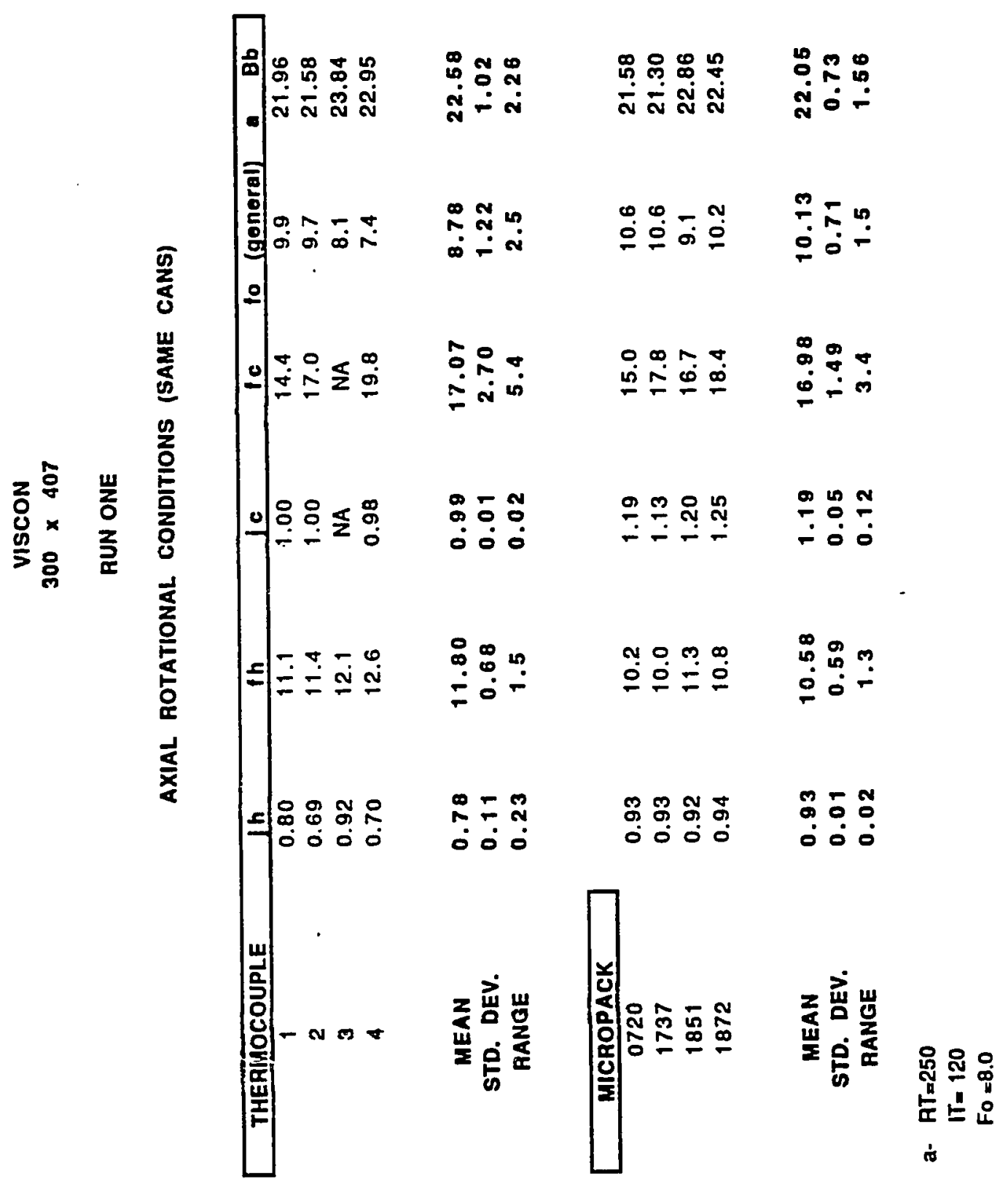




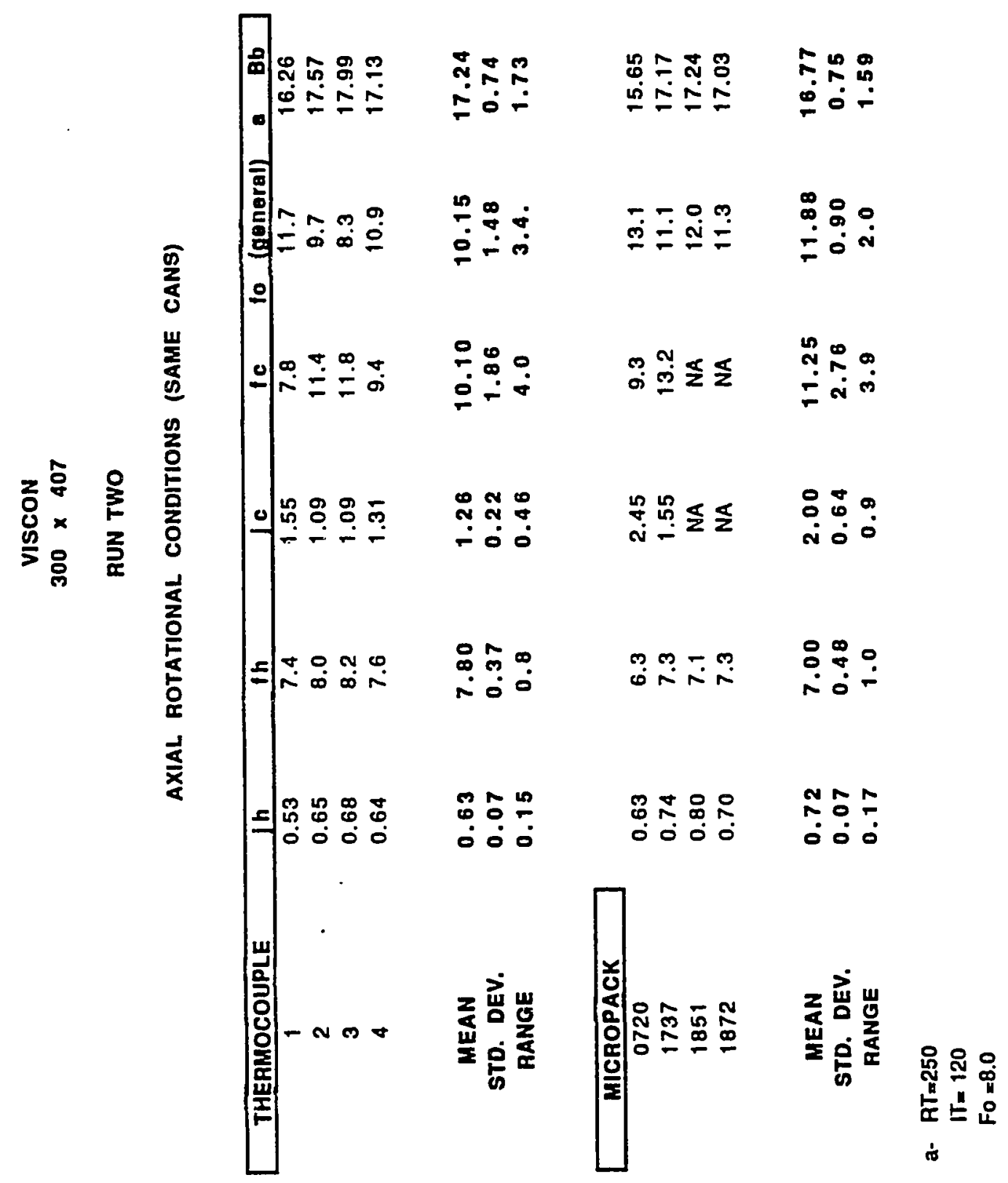




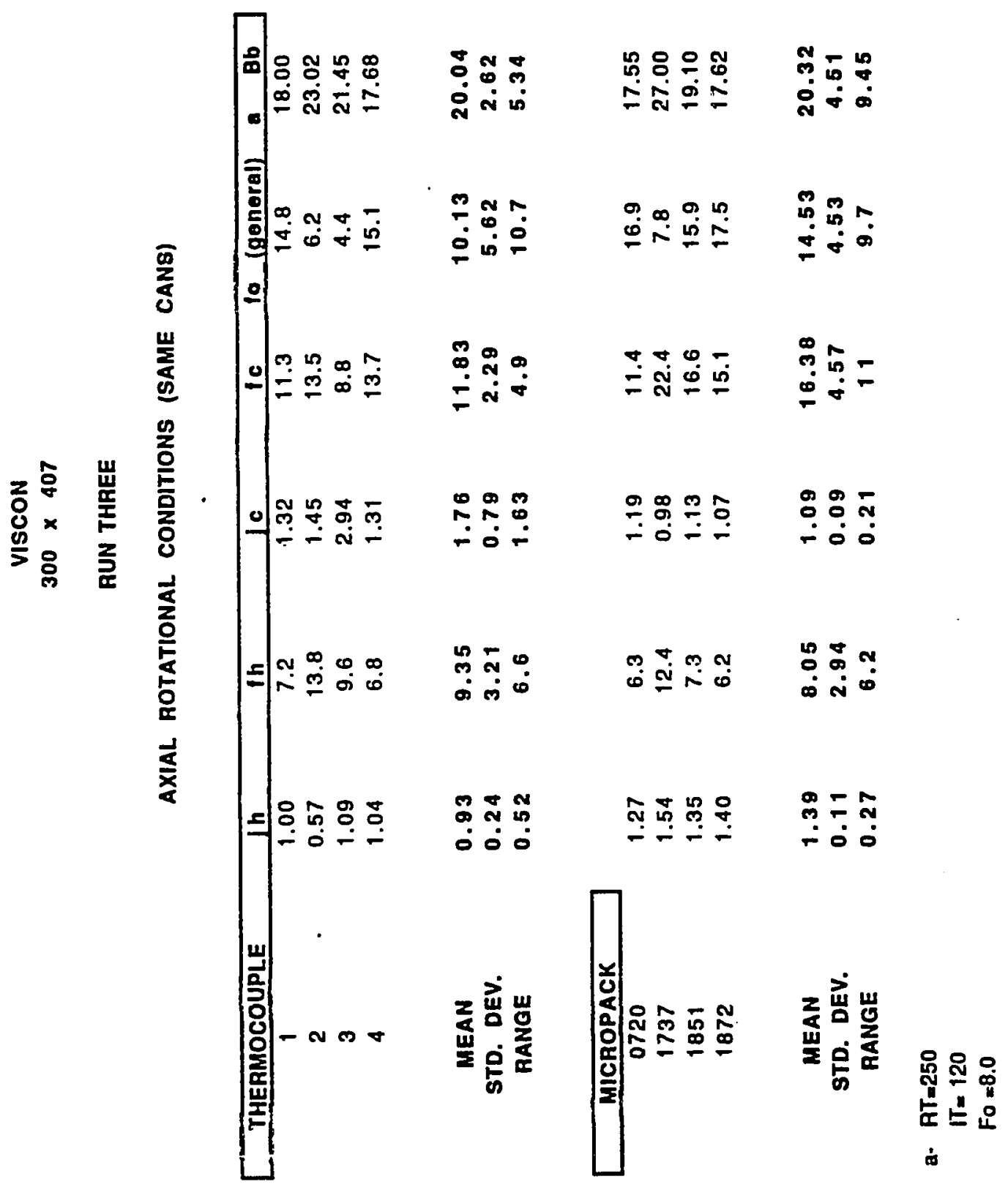




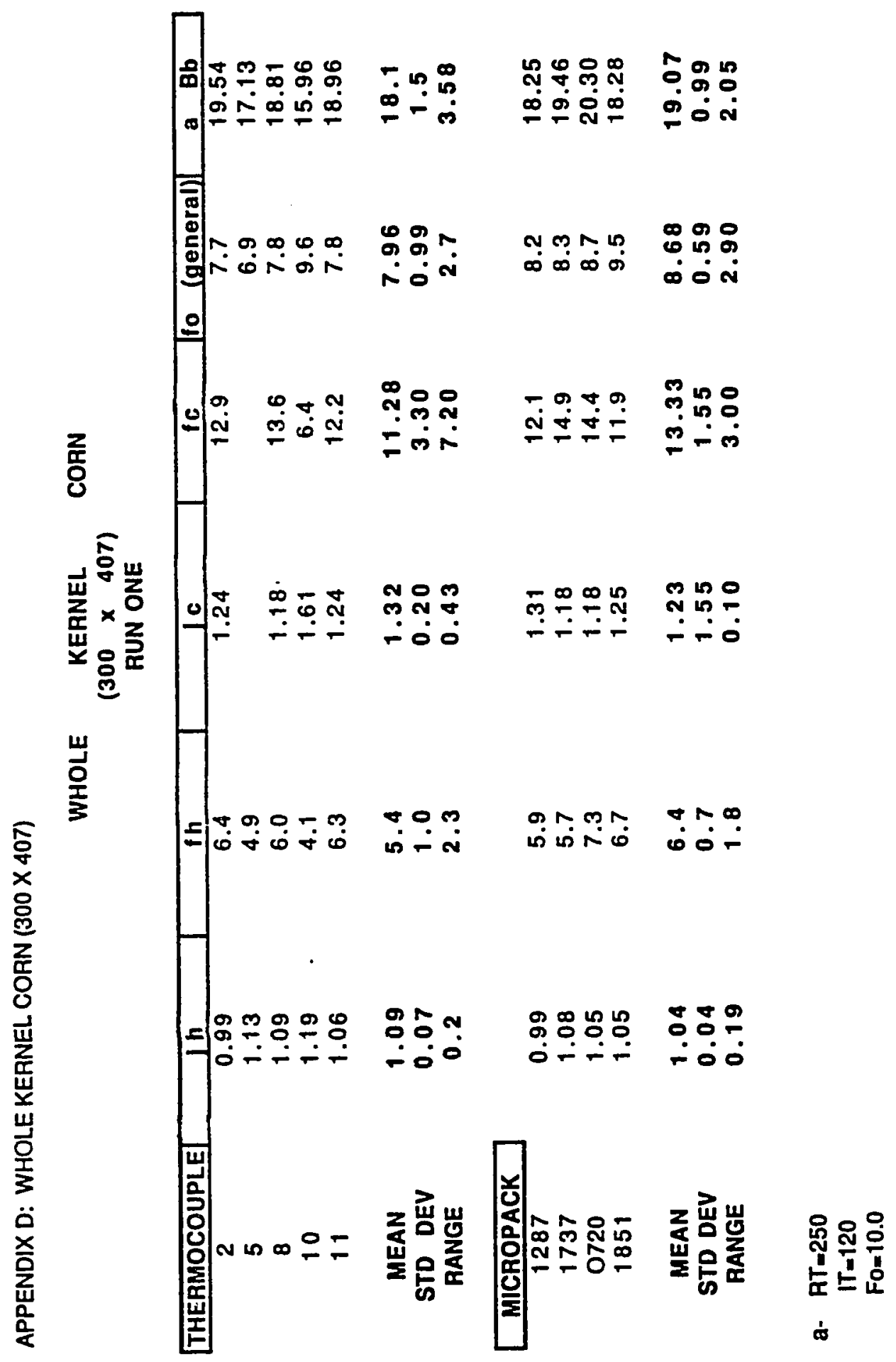




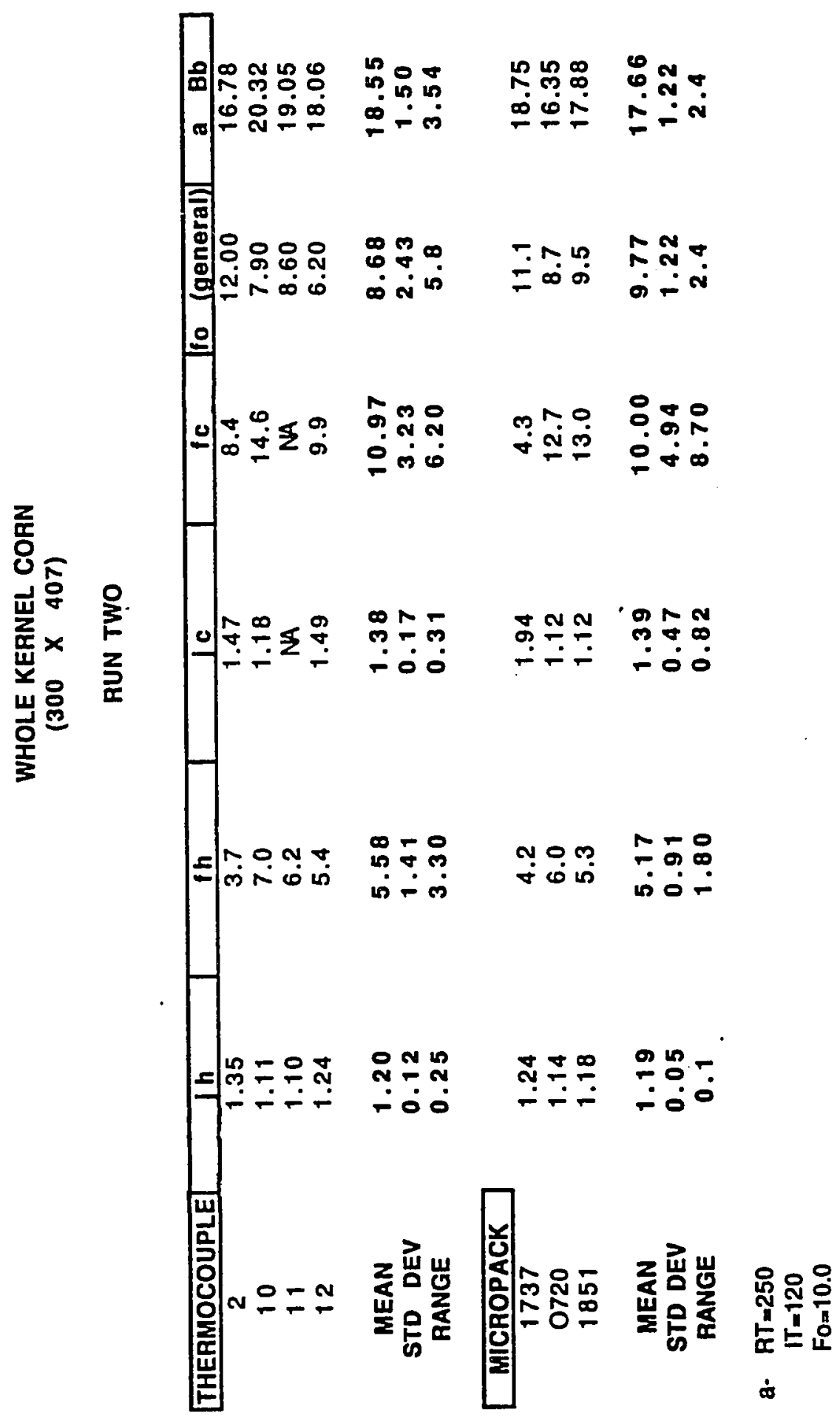




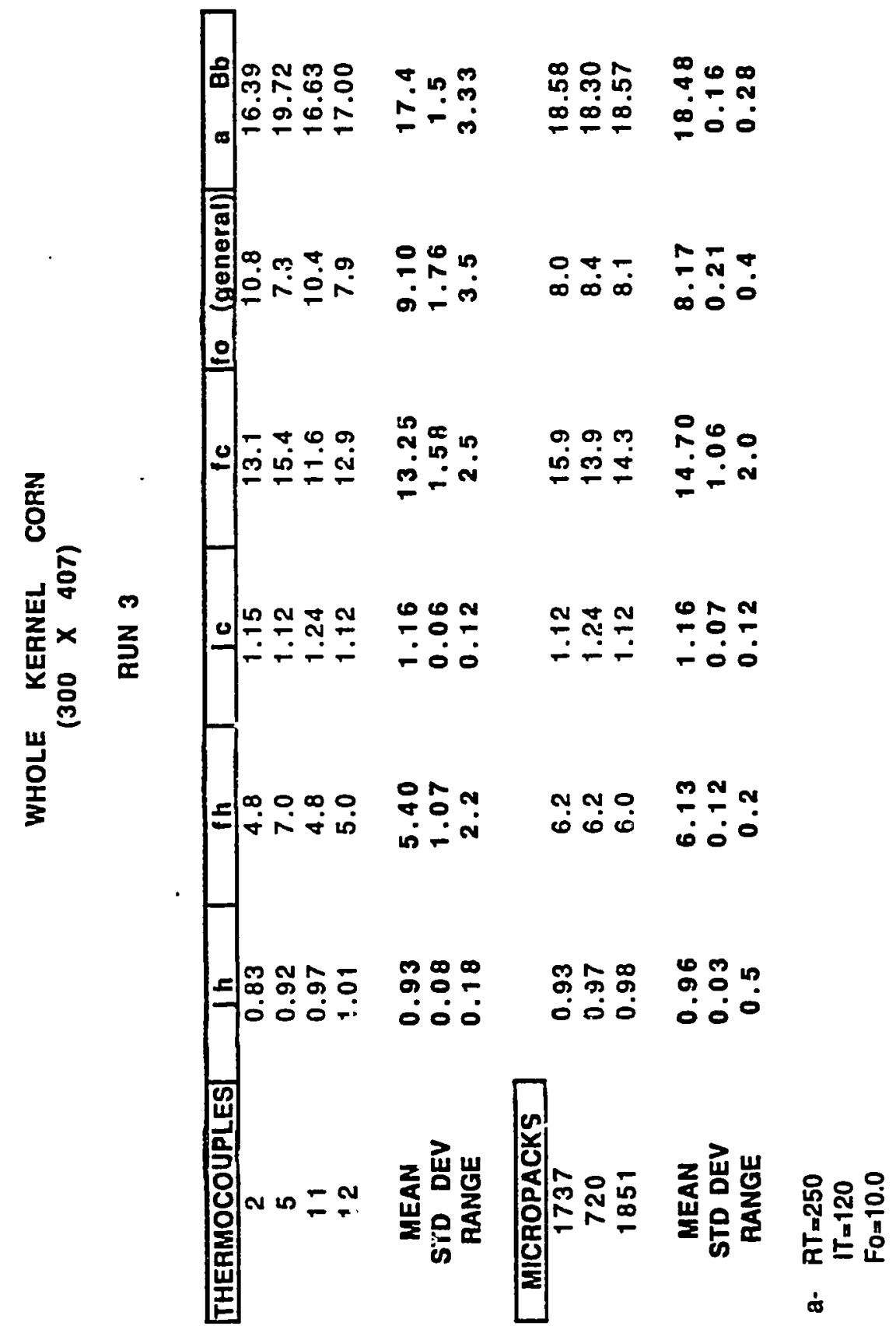




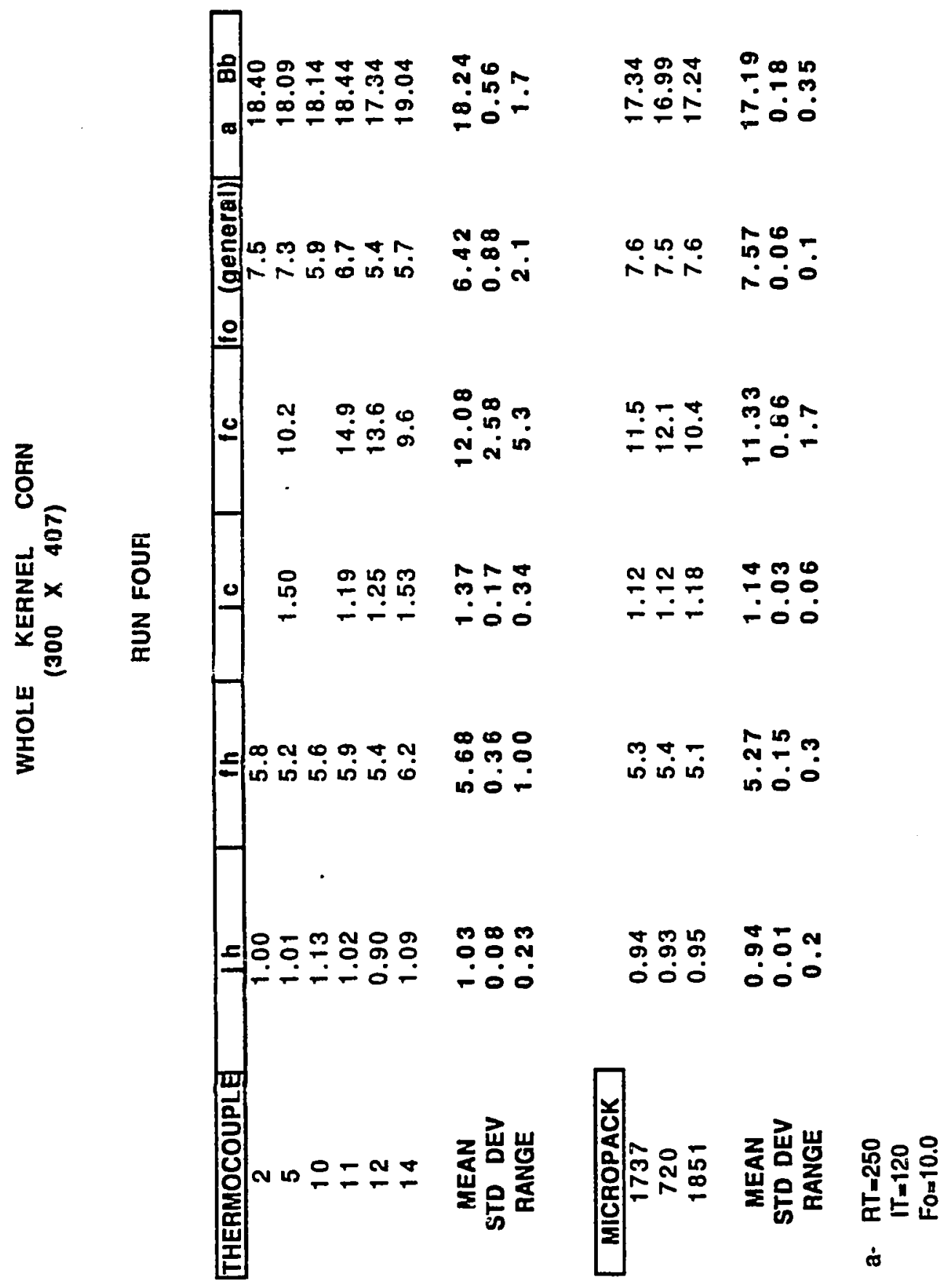




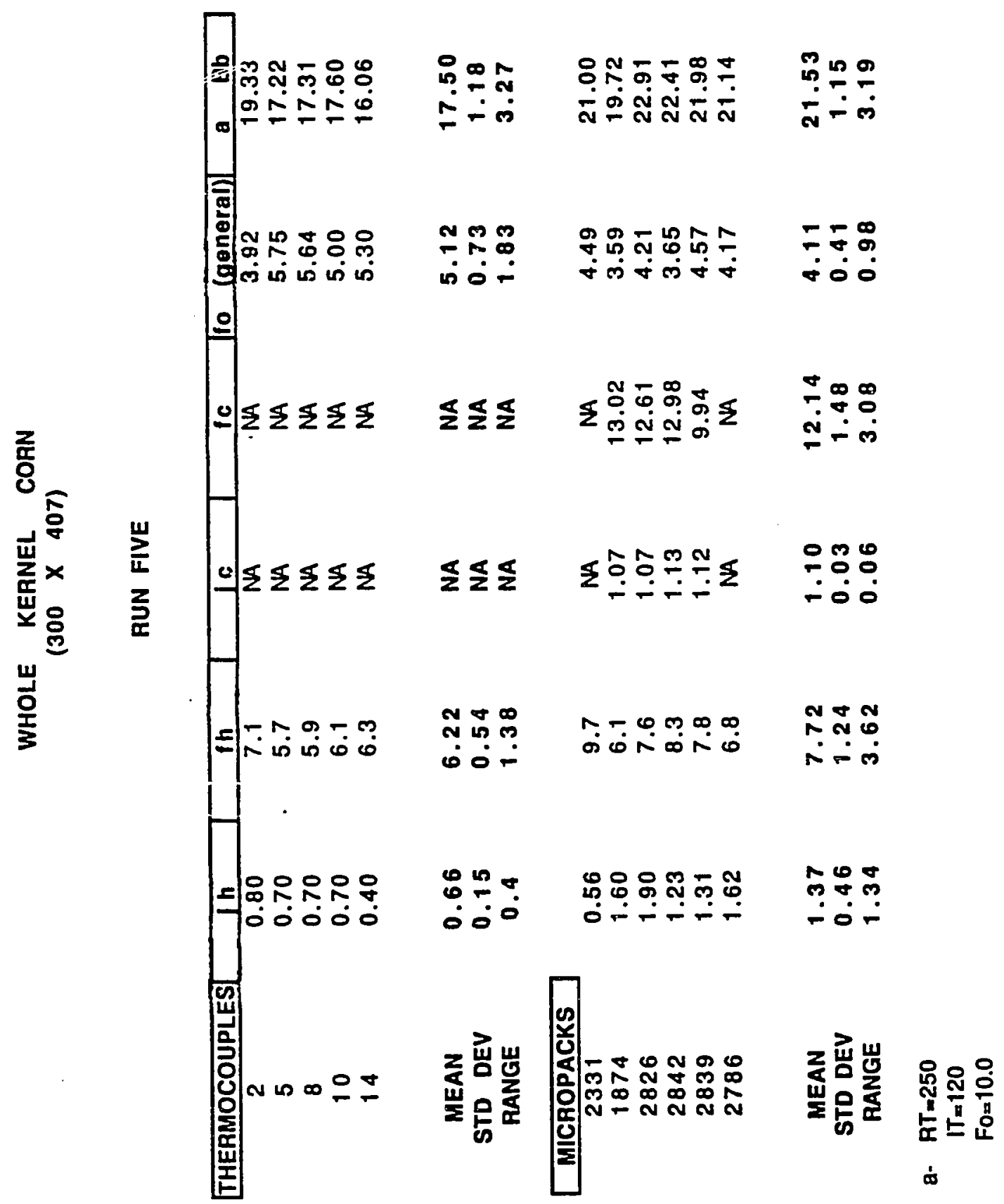




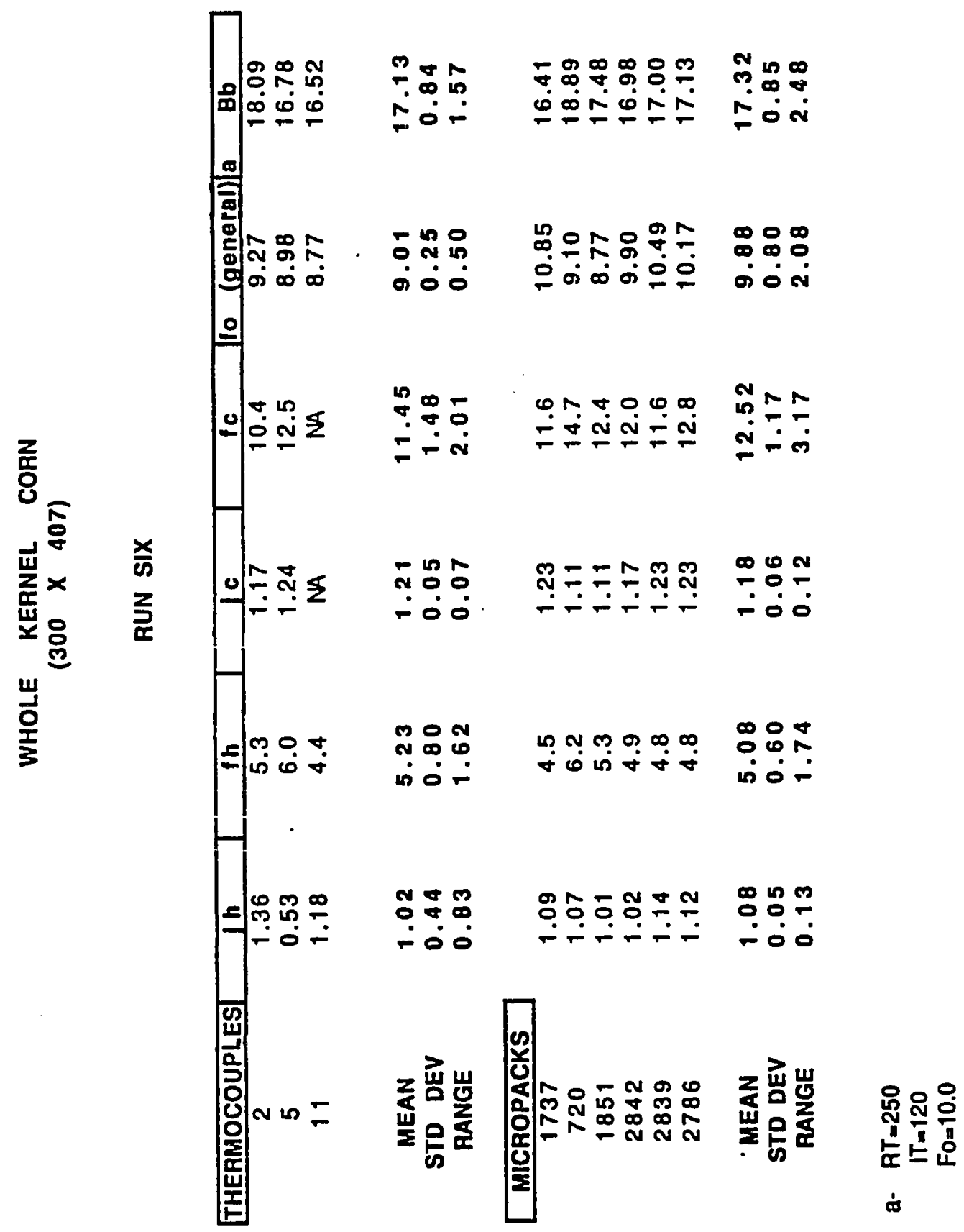




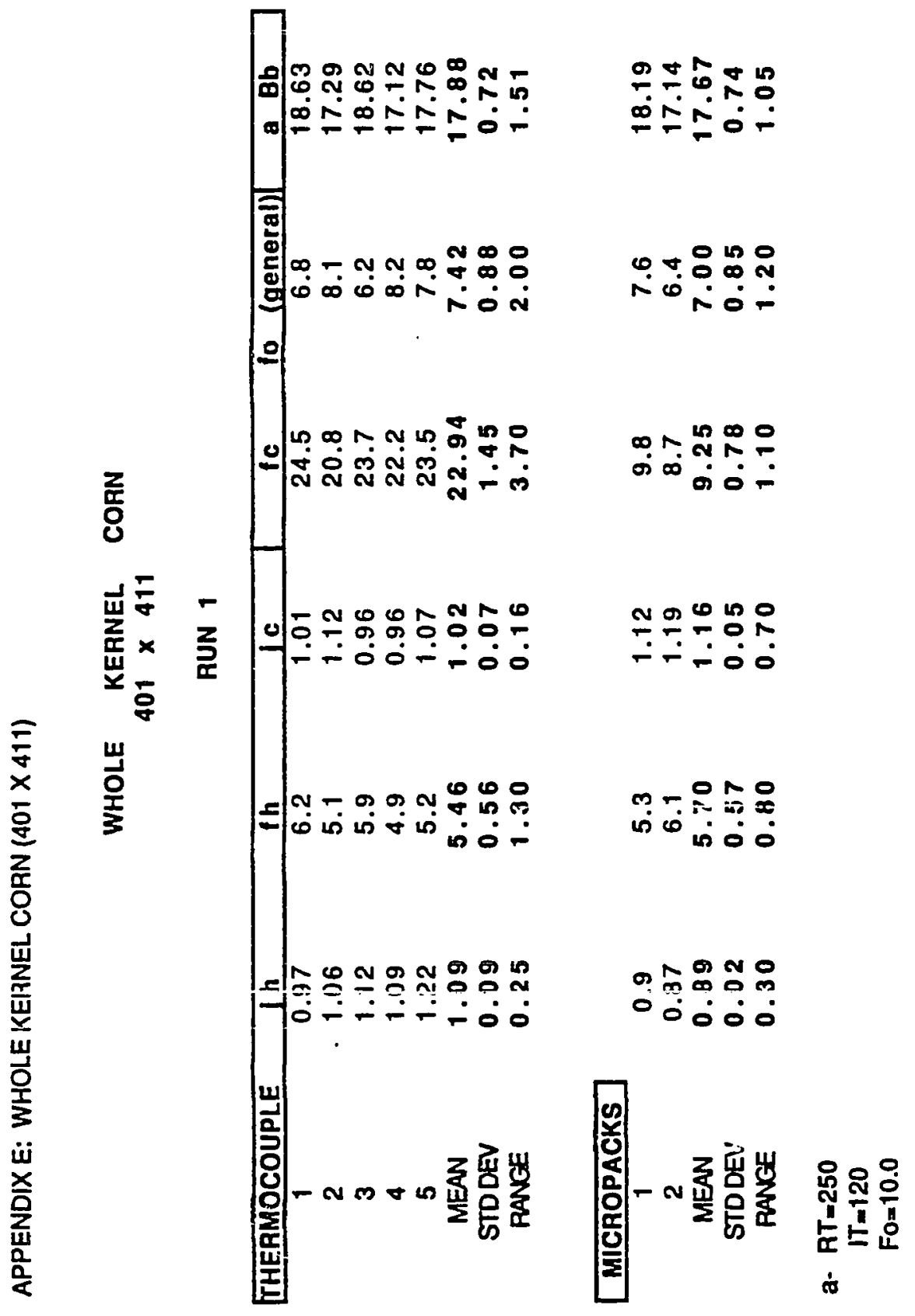




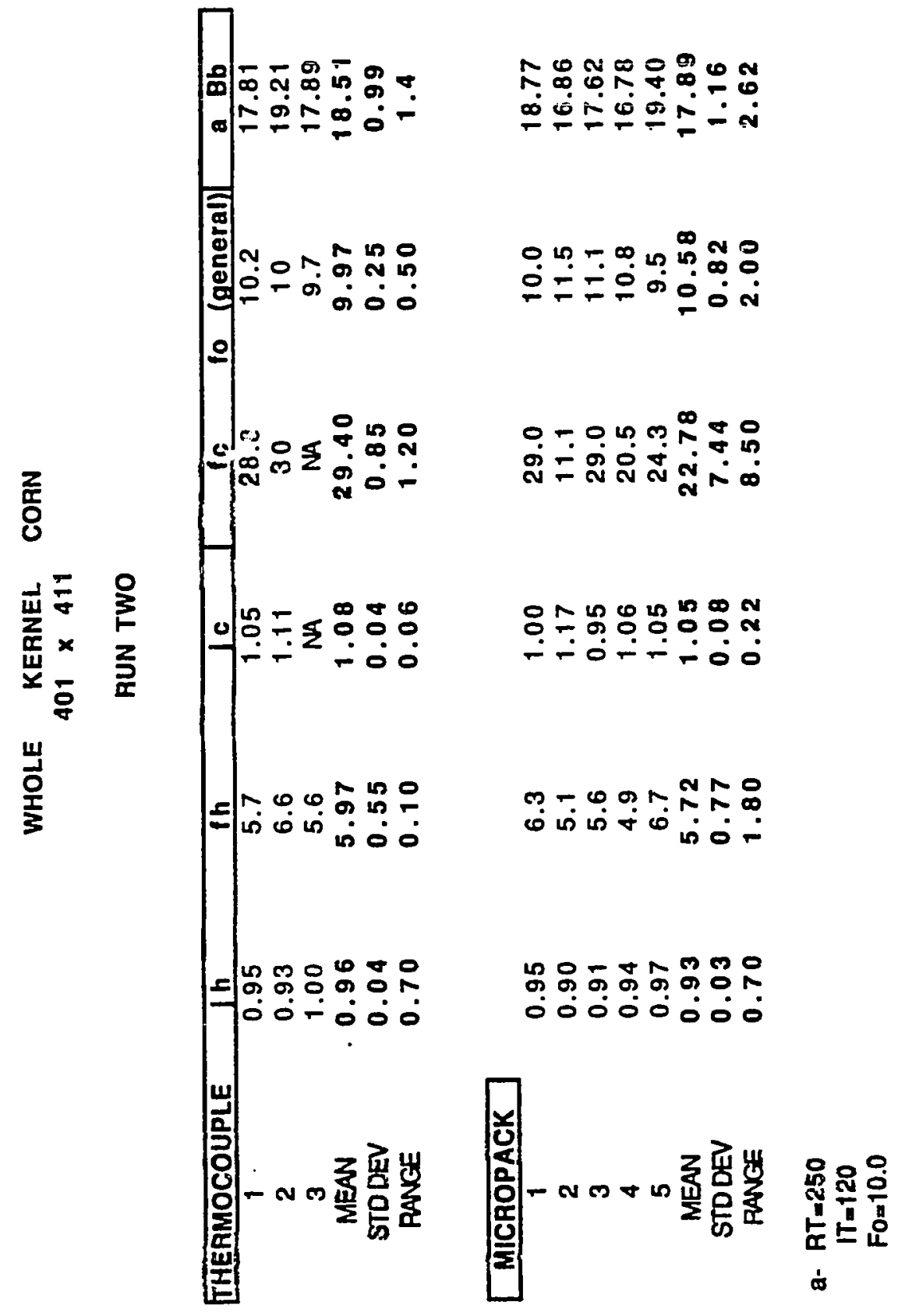




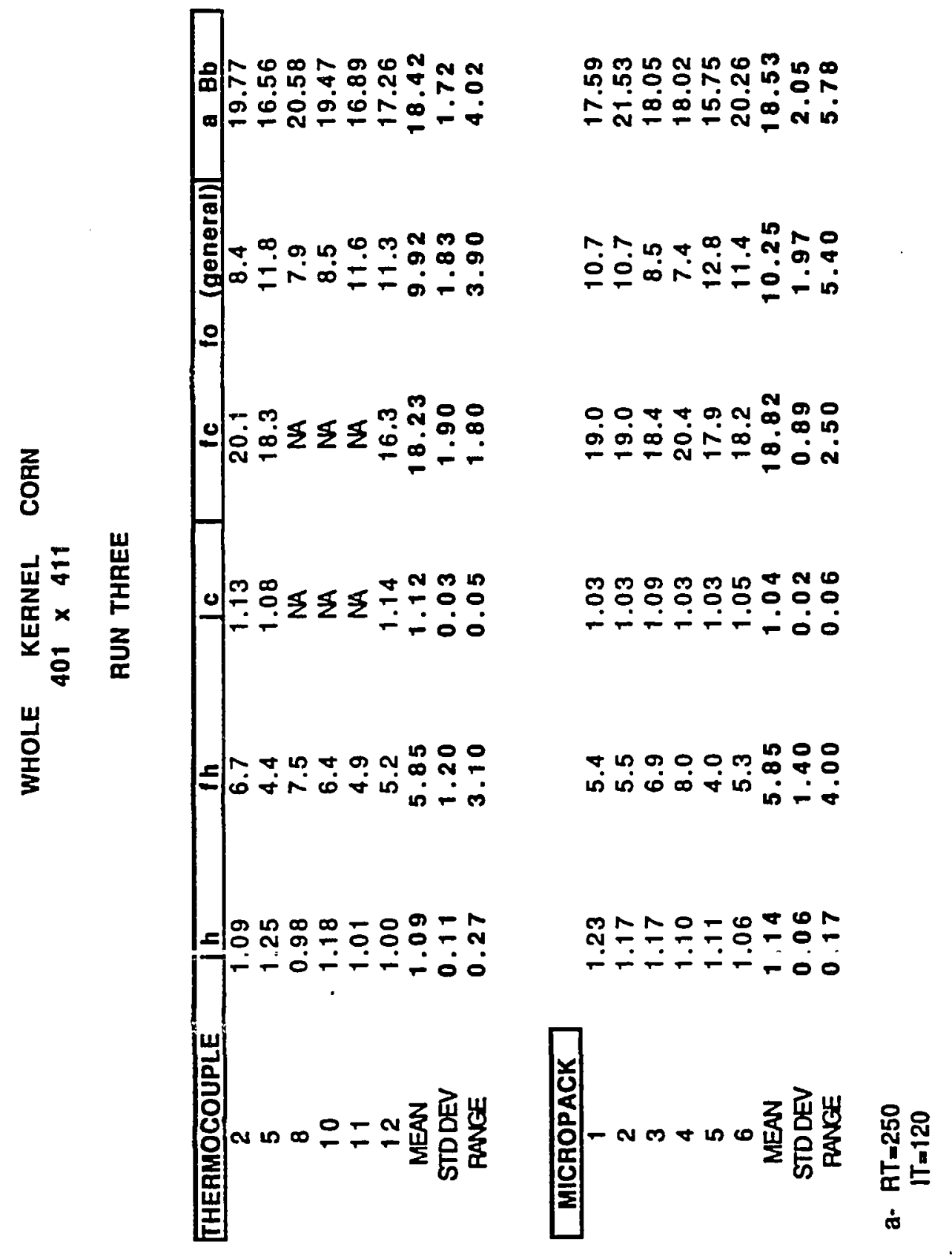




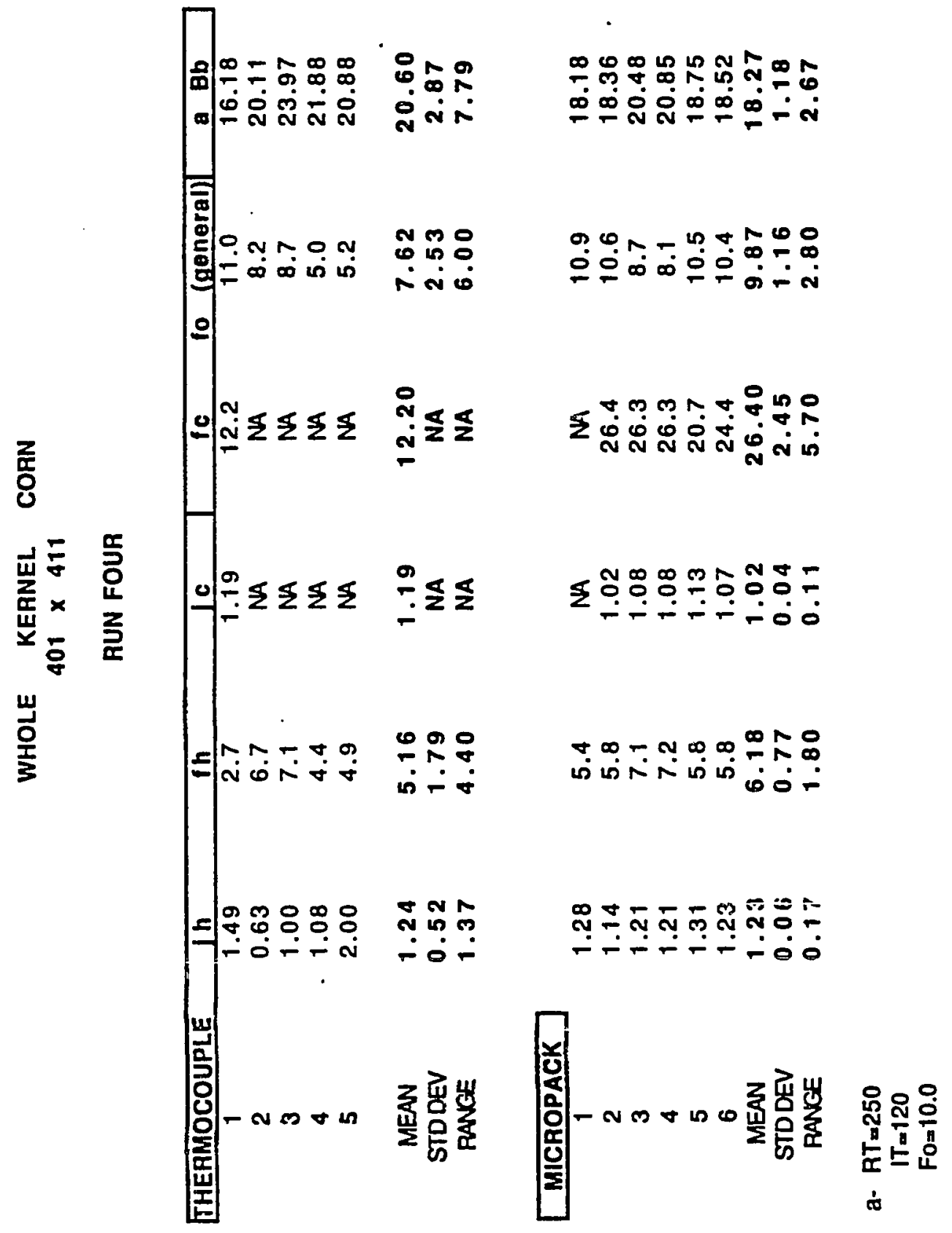




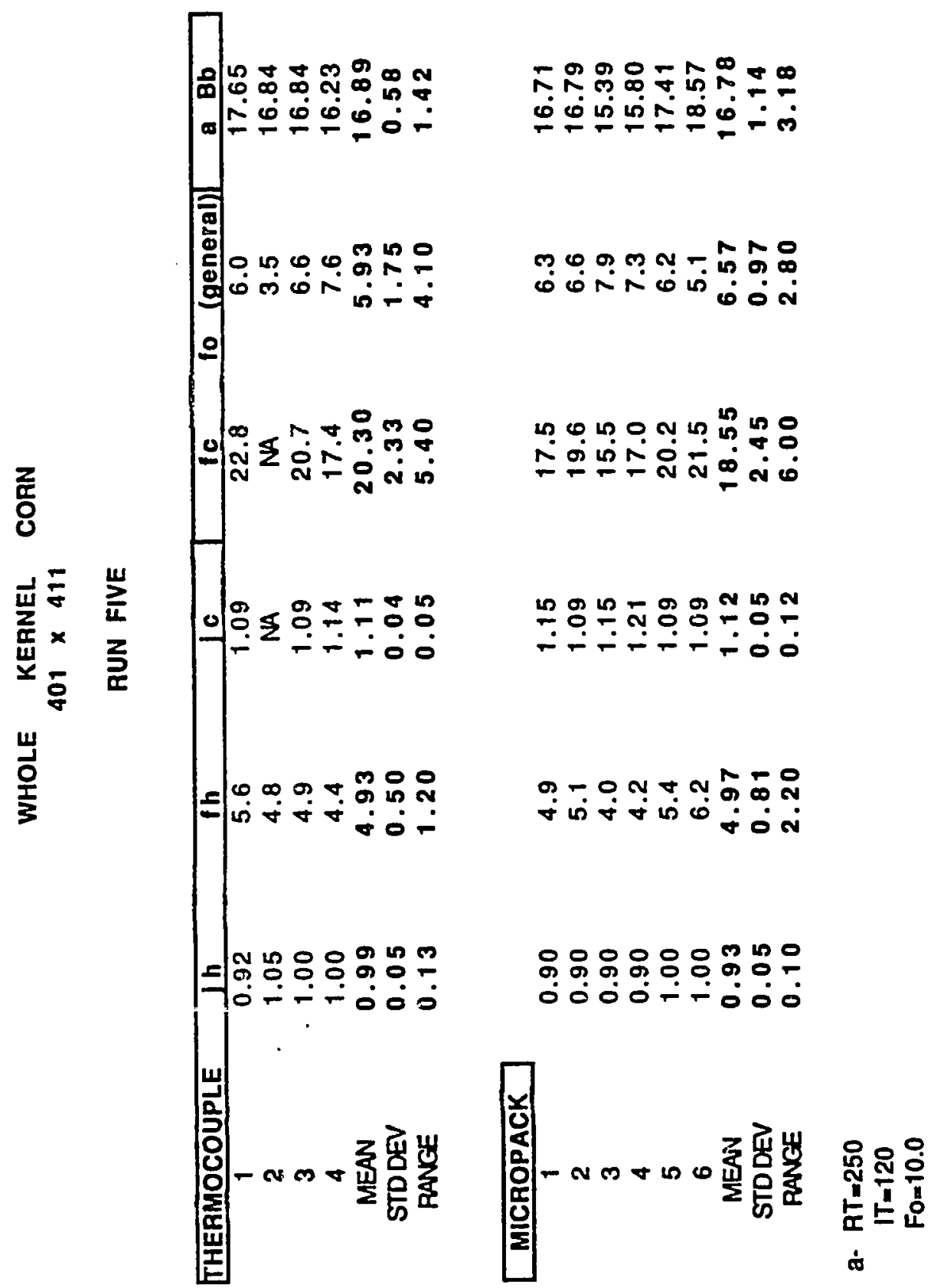




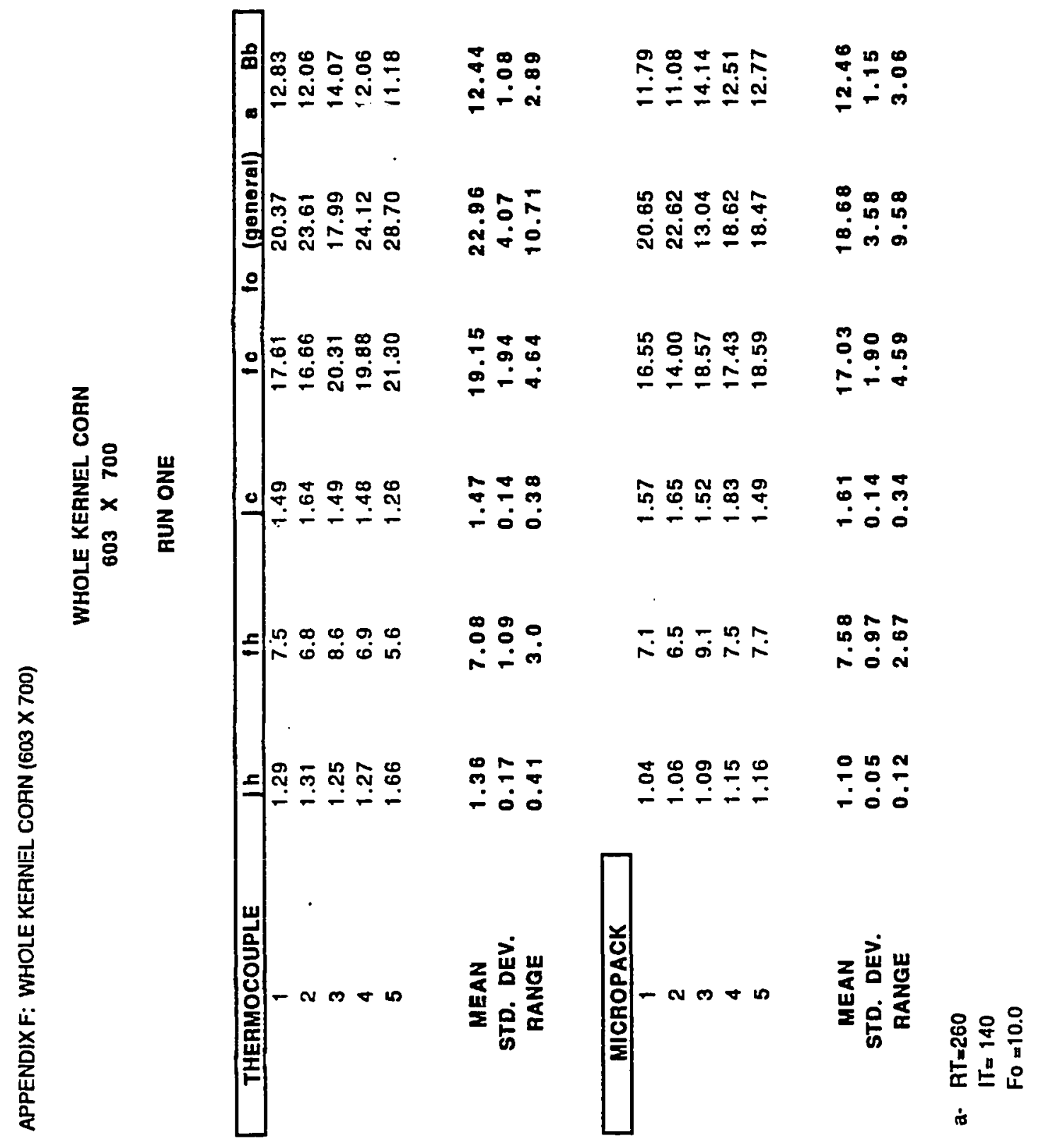




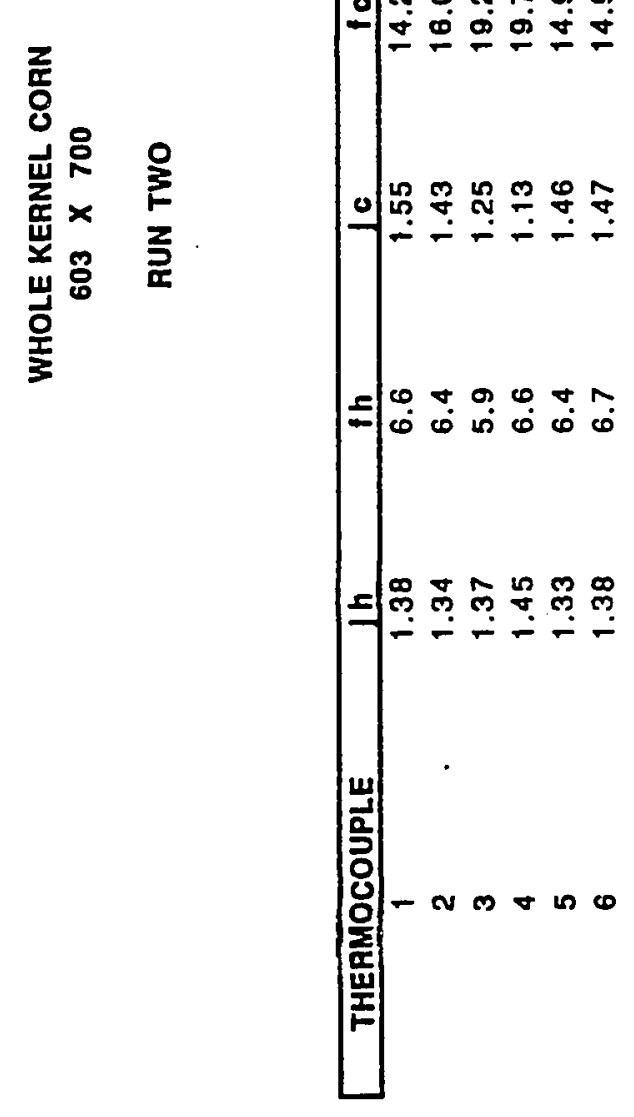

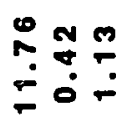

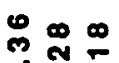

힝요 옹 -

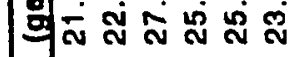
의

-

$\infty$

$\because 00$

\begin{tabular}{l}
$\infty$ \\
\hdashline \\
0 \\
0
\end{tabular}

\begin{tabular}{l}
$\infty$ \\
\hdashline 0 \\
$\because 0$ \\
\hdashline 0
\end{tabular}

z岁岕

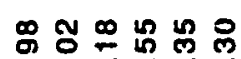

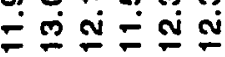

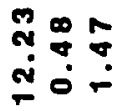

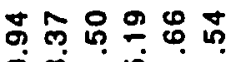

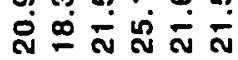

$\infty$

$\because \check{\circ}$

N

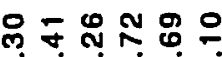

ำ

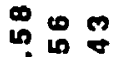

ஜீ-

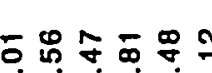

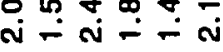

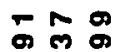

$\because \because 0$

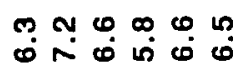

옹ํํ

i: -

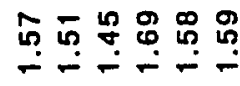

$\sim \infty$

$\because 00$

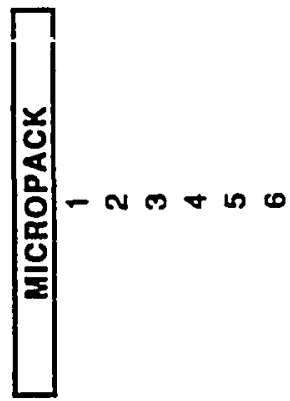

咅岁

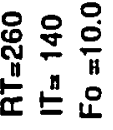

क 


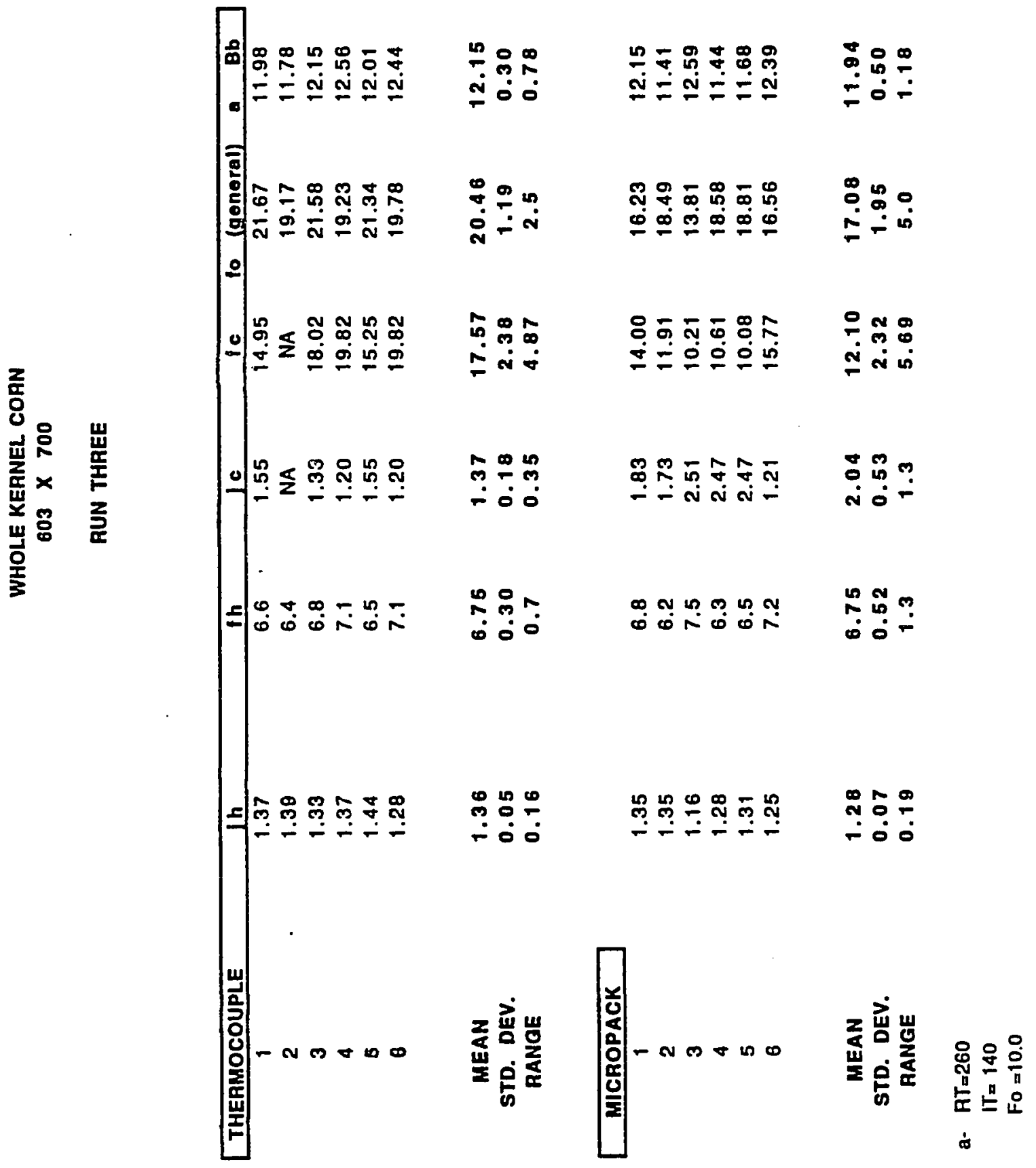




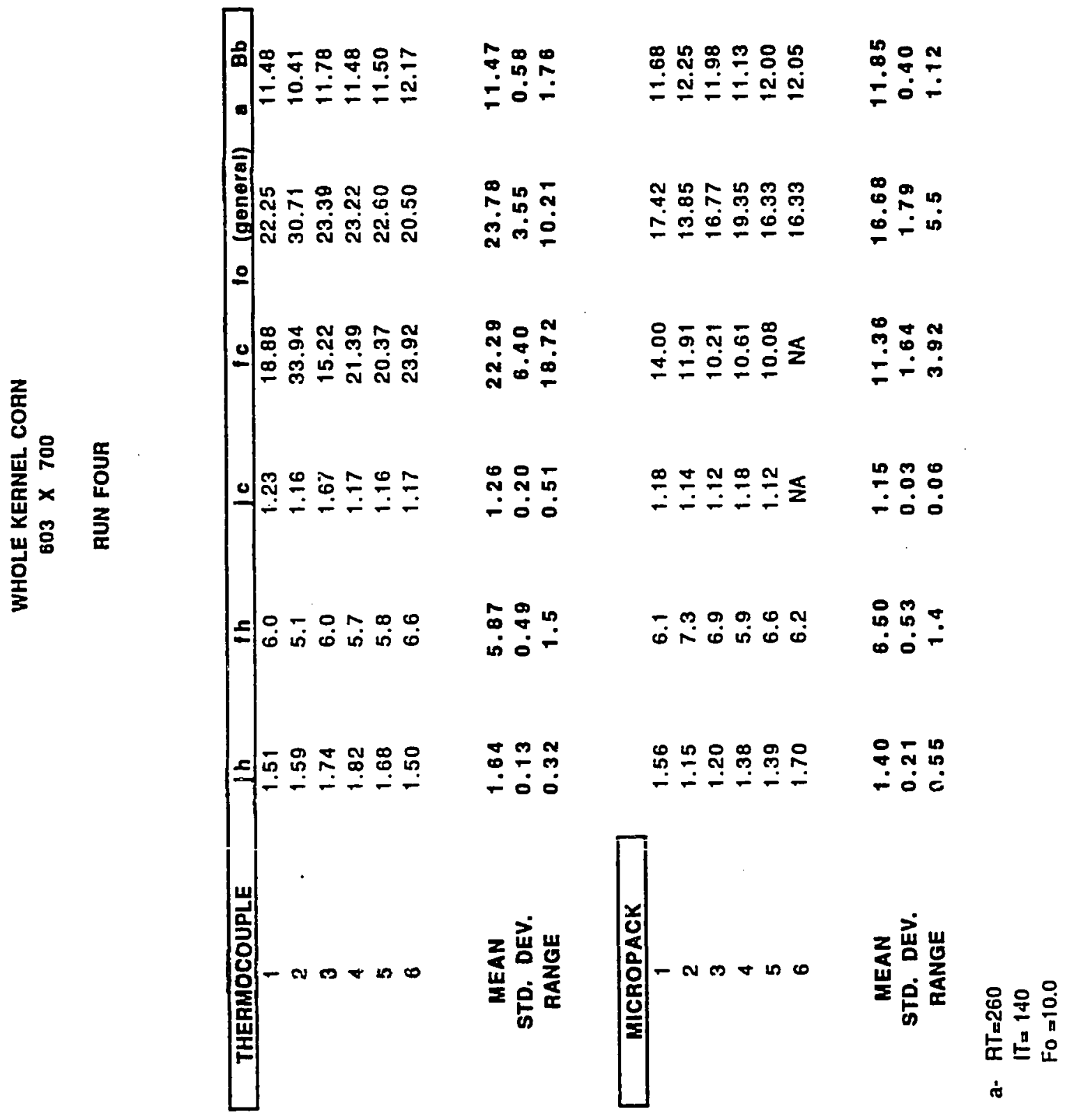




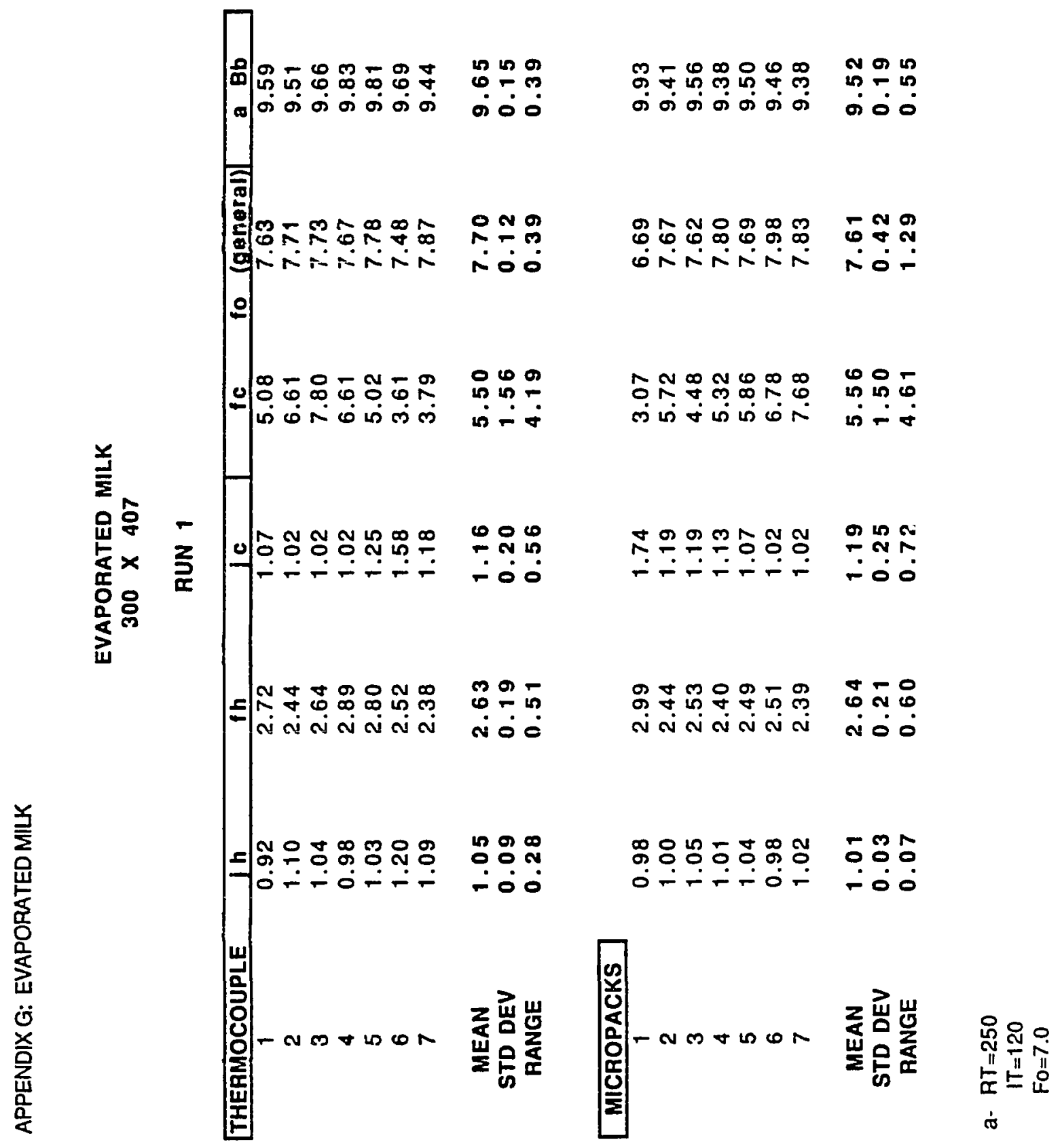




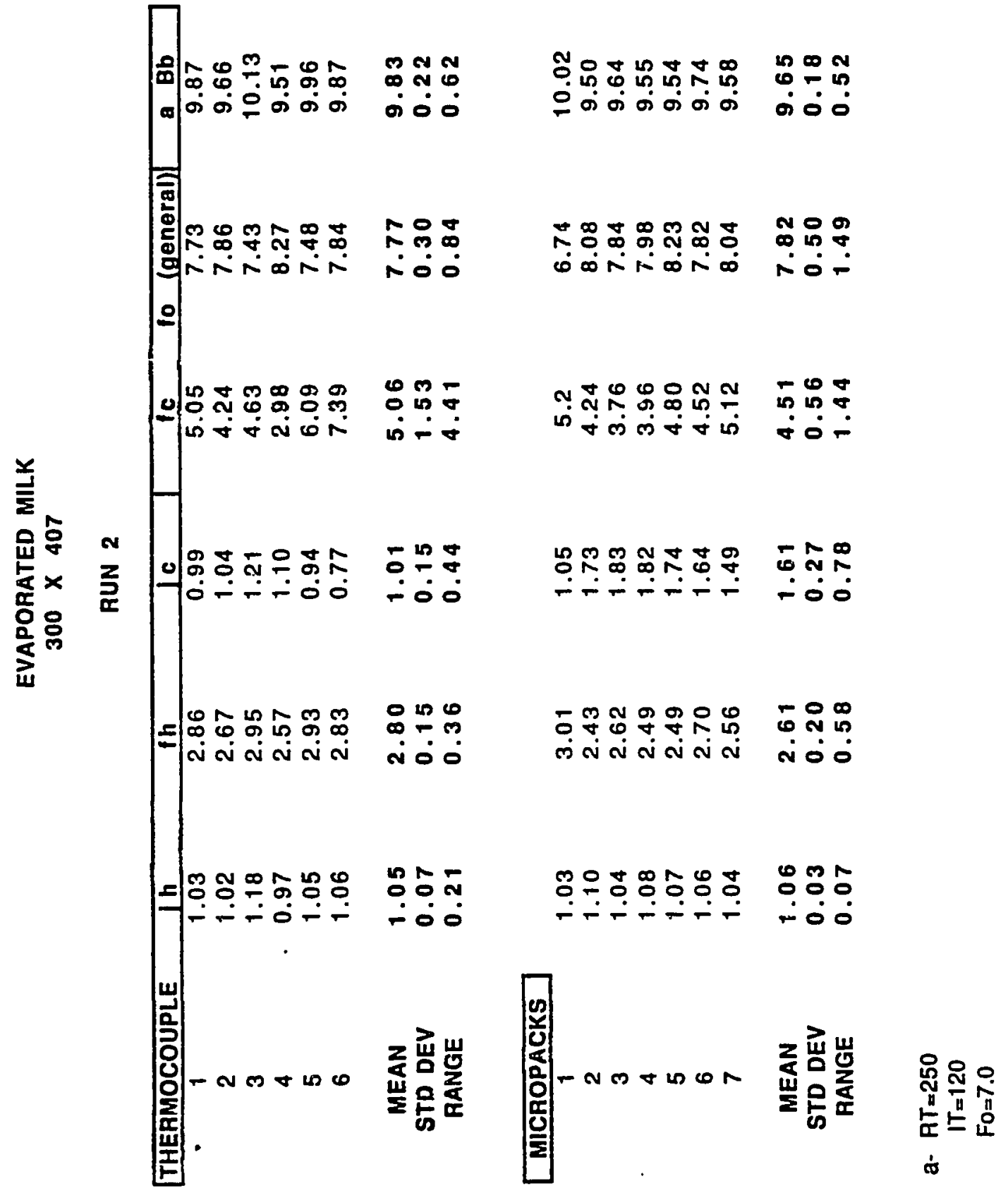




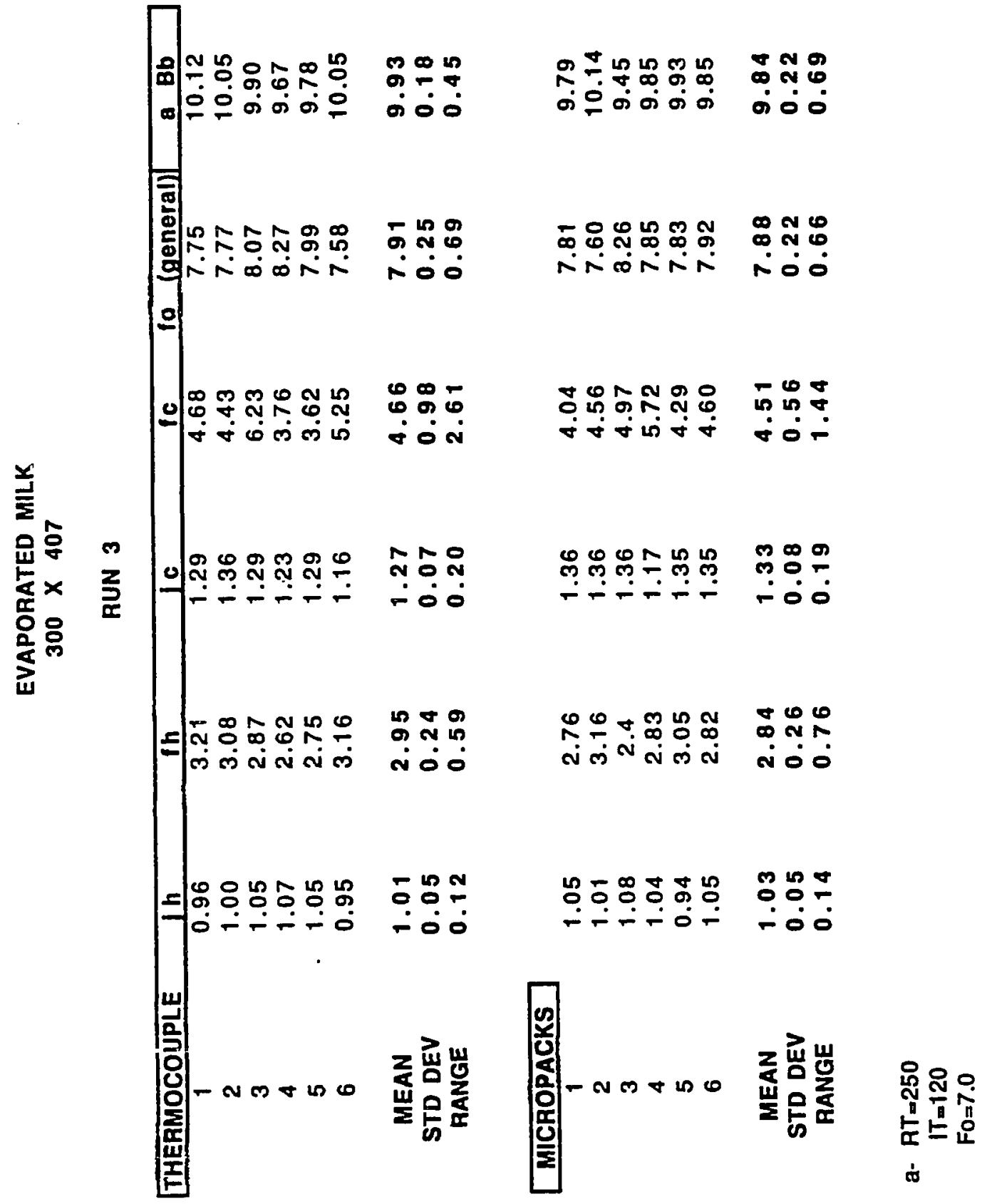

